\title{
WestVirginiaUniversity
}

THE RESEARCH REPOSITORY @ WVU

Graduate Theses, Dissertations, and Problem Reports

2016

\section{The role of miRNAs in niche regulation of ALL phenotype}

Blake Stephen Moses

Follow this and additional works at: https://researchrepository.wvu.edu/etd

\section{Recommended Citation}

Moses, Blake Stephen, "The role of miRNAs in niche regulation of ALL phenotype" (2016). Graduate Theses, Dissertations, and Problem Reports. 6270.

https://researchrepository.wvu.edu/etd/6270

This Dissertation is protected by copyright and/or related rights. It has been brought to you by the The Research Repository @ WVU with permission from the rights-holder(s). You are free to use this Dissertation in any way that is permitted by the copyright and related rights legislation that applies to your use. For other uses you must obtain permission from the rights-holder(s) directly, unless additional rights are indicated by a Creative Commons license in the record and/ or on the work itself. This Dissertation has been accepted for inclusion in WVU Graduate Theses, Dissertations, and Problem Reports collection by an authorized administrator of The Research Repository @ WVU.

For more information, please contact researchrepository@mail.wvu.edu. 


\title{
The role of miRNAs in niche regulation of ALL phenotype
}

\author{
Blake Stephen Moses
}

Dissertation submitted to the School of Medicine at West Virginia University in partial fulfillment of the requirements for the degree of

Doctor of Philosophy

$\ln$

Cancer Cell Biology

J. Michael Ruppert, M.D./Ph.D., Chair

William Petros, Pharm. D.

Linda Vona-Davis, Ph.D.

Karen H. Martin, Ph.D.

Ivan Martinez, Ph.D.

Laura F. Gibson, Ph.D., mentor

Cancer Cell Biology Program

Morgantown, West Virginia

2016

Key Words: acute lymphoblastic leukemia, chemotherapy resistance, quiescence, bone marrow stromal cells, osteoblasts, microenvironment, miRNA, miR-221/222, p27

Copyright 2016 Blake S Moses 


\section{Abstract \\ The role of miRNAs in niche regulation of ALL phenotype Blake S Moses}

While modern acute lymphoblastic leukemia $(A L L)$ treatment regimens have dramatically improved the survival of ALL patients, disease relapse still occurs in approximately $20 \%$ of cases. ALL relapse is, in part, due to the inability of traditional chemotherapeutic agents to efficiently target quiescent, non-dividing tumor cells. The number of viable remaining leukemia cells in patients after initial treatment, termed minimal residual disease (MRD), is directly correlated with likelihood of disease relapse. This reflects the proliferative potential of these refractory cells, consistent with the ability of their healthy hematopoietic progenitor pro- and preB cell counterparts. Developing novel therapies to combat refractory disease is essential in the continued battle of eradicating this cancer based on the aggressive nature of relapsed ALL that is much more challenging to effectively treat than disease at initial diagnosis. Many features of malignant immature B-lineage cells, as noted above, are shared with normal B cell progenitors, including their ability to respond to diverse signals from the bone marrow microenvironment that culminate on regulation of cell cycle progression and survival. Bone marrow derived cues from supportive stromal and osteoblast cells influence many elements of both steady state hematopoiesis and hematopoietic tumor cell phenotype through modulation of pro- and pre-B cell gene expression profiles.

Developing a system that models interactions between bone marrow niche cells and leukemia is essential in supporting discovery of mediators of bone marrow protection of ALL. Although in vivo animal modeling can be superior to standard cell culture, disadvantages exist 
including expense, time expenditure, and the inability to perform efficient high-throughput experimentation. In Chapters II and III, we describe an in vitro co-culture model in which both ALL cell lines and primary patient samples uniquely interact with bone marrow derived stromal cells (BMSC) or human osteoblasts (HOB). ALL cells in this model form distinct subpopulations, including one subset that buries beneath the adherent bone marrow niche cell monolayer, termed "phase dim" (PD) ALL. They exhibit a unique phenotype characterized by altered metabolism, distinct protein expression profiles, increased quiescence, and pronounced chemotherapy resistance. The PD ALL cell bone marrow derived protection is specific to bone marrow niche cells, compared to adherent cells from other anatomical locations suggesting biologically relevant features have been retained in this model that is, by design, simplified to allow targeted investigation. From these observations, along with the ability to isolate this clinically relevant ALL subpopulation, studies focused on the PD subpopulation of tumor cells may more efficiently inform pre-clinical design and the investigation of MRD and relapse that arises from bone marrow supported leukemia cells compared to models that include the entire tumor population.

Utilizing the model outlined above, our laboratory focused on bone marrow niche regulated ALL miRNAs as a master regulator of phenotype that had not been previously evaluated in ALL as a potential pathway through which the marrow niche may impact on tumor cell biology. miRNAs define one regulatory class of small non-coding RNAs that have been shown to be increasingly important in diverse settings of malignancy. Global alterations in miRNA profiles were observed in ALL cells following exposure to BMSC or HOB. Two miRNAs of interest, miR-221 and miR-222, were reduced in ALL cells co-cultured with bone marrow niche cells coincident with an increase in CDKN1B (p27) protein levels. Increased p27 protein in ALL 
cells exposed to BMSC or $\mathrm{HOB}$ is consistent with accumulation of tumor cells in the Go phase of cell cycle and resistance to chemotherapy induced death described in Chapters II and III. Constitutive expression of miR-221 in ALL cells was partially able to overcome the protective nature of the bone marrow niche and render cells more susceptible to chemotherapy exposure. Traditional chemotherapy, with the addition of miR-221/222 manipulation, could be an intriguing addition to a clinician's arsenal of treatment regimens for ALL with the potential to eradicate resistant disease or potentially decrease the intensity of agents required if sensitivity of tumor cells could be improved.

The overall objective of these studies was to increase our understanding of bone marrow regulated chemotherapy resistant ALL by utilizing our well characterized in vitro co-culture model. Through this model system we identified a subset of bone marrow niche associated ALL cells that were quiescent and highly resistant to chemotherapy exposure, partially due to modulation of miR-221/222. From these studies, we hope to contribute to the design of novel treatment strategies for aggressive and resistant ALL, with an emphasis on improving the outcome of patients with disease with poor prognosis. Ideally, both a better response during initial treatment, as well as more efficacious therapy when relapse does occur can be achieved by better understanding the molecular basis of niche supported tumor cell survival. As a very common site of metastatic disease, the broader application of this work is the potential relevance to additional tumor types that find sanctuary from therapy-induced death in the same marrow niches that support normal hematopoiesis and hematopoietic disease. 


\section{Dedication and Acknowledgements}

I would like to dedicate this dissertation to anyone that has ever lost family or friends to cancer. The motivation for this work was not solely to improve the life of the patient, but anyone that has been affected by a malignancy.

First and foremost I would like to acknowledge my mentor, Laura Gibson. When I first arrived in her lab I was unsure of my focus, but Laura kept an open mind and gave me the freedom in my projects to follow my interests. I thank her for giving me the opportunity to work in her lab. She instilled confidence and inspiration in not only my research, but in my future as a scientist. Laura has taught me to see the bigger picture, to be patient, independent, and has given me all the tools to be a successful scientist. I cannot thank her enough for all of the support and guidance in and outside of science.

I wouldn't be here without the support of our lab. We have all grown so close over the past five years and my life would not be the same without Beckie, Deb, Will, lan, Patrick, and past lab members Jim and Audrey. You have all not only helped me with experiments, you have helped me through this, sometimes crazy and frantic, life. Deb, I will always cherish our joking around and WVU gossip. Will, you have become a great lab mate, landlord, and friend. I could not have made it through these years without you. lan, although we haven't spent as much time together, you have become a really good friend. From the "tude" room, to the junk food, to lan blaring his music so the entire health science center can hear, I will truly cherish and miss each and every one of you.

Throughout my time here at WVU, I have worked with some great people. One person has always been by my side, supporting me, helping me with every aspect of science, but more importantly, my life. Beckie, I honestly do not know where I would be without your brilliant mind and sweet heart. I owe you so much and I am extremely fortunate that you are in my life. Thank you from the bottom of my heart for not only making me a better scientist, but making me a better person.

Lastly, I would like thank my family: Mom, Dad, Theresa, Brooks, Rachel (and Xavier). Without your constant support and love, it would have been impossible to be where I am today. Theresa, you have been like a mother to me and influenced my life in so many positive ways. I am a better man because of it. Brooks and Rachel (and Xavier), I hope you realize how important you are to me. From opening your lives when I visit home, to always being there and giving me encouragement when I need it most. Mom and Dad, I am so grateful for you supporting all my decisions, and never letting me give up on myself. Although you tell me how proud you are of me, I am the one who is proud to call you my parents. My passion, drive, intelligence, determination, strength, and morals are installed in me from you. I would not be the person I am today without both of you. Everything I am is because of my family and a portion of this dissertation belongs to you. 


\section{Table of Contents}

The role of miRNAs in niche regulation of ALL phenotype

Abstract ii

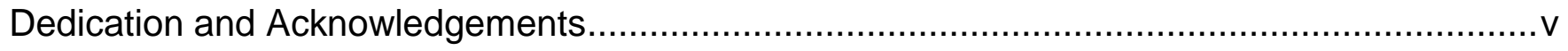

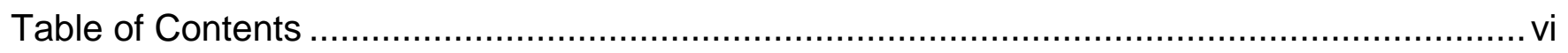

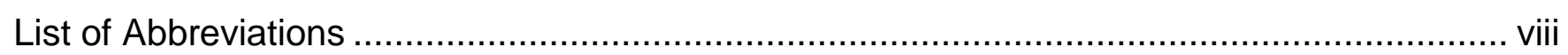

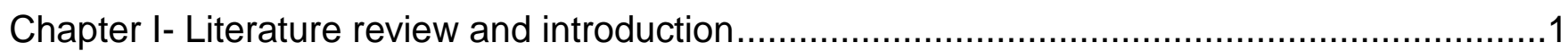

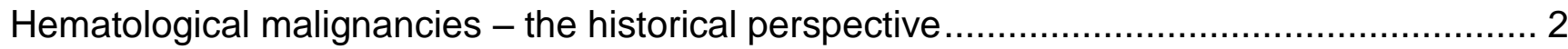

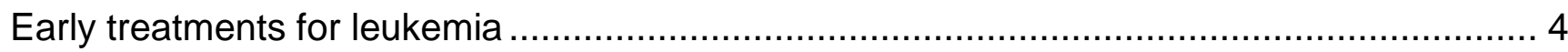

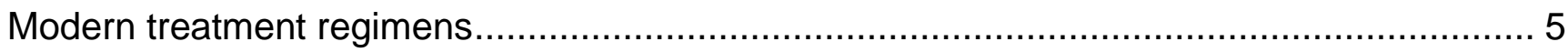

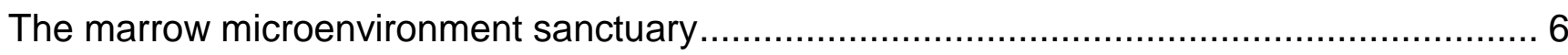

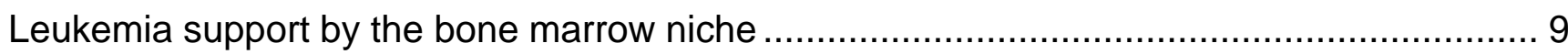

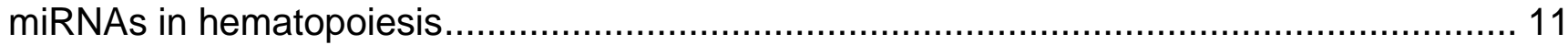

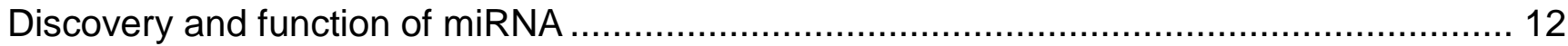

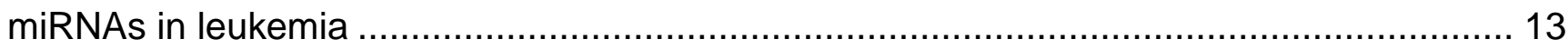

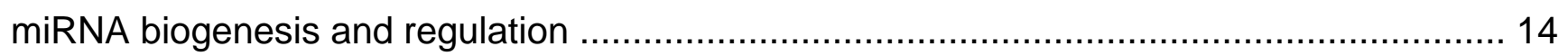

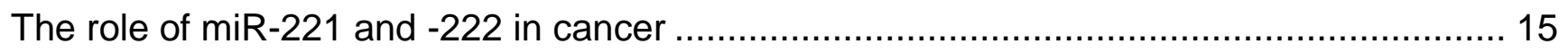

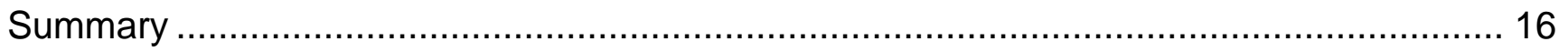

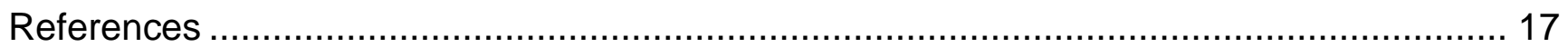

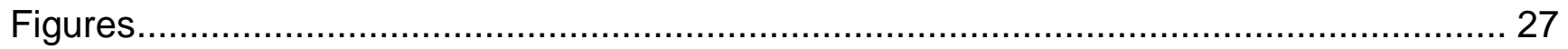

Chapter II- Modeling chemotherapy resistant leukemia in vitro ............................................30

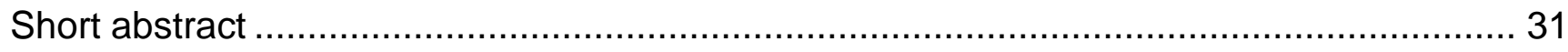

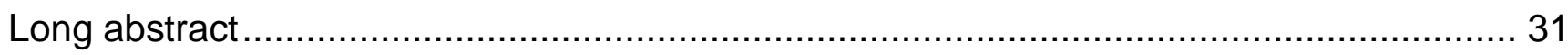

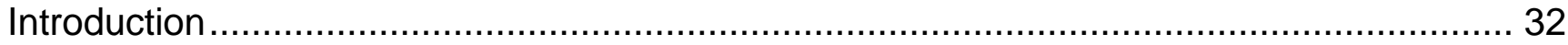

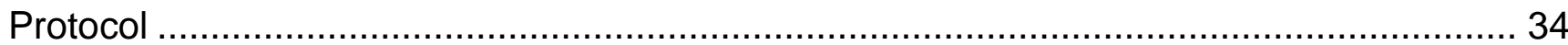

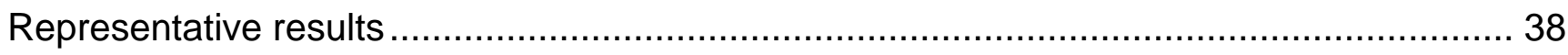

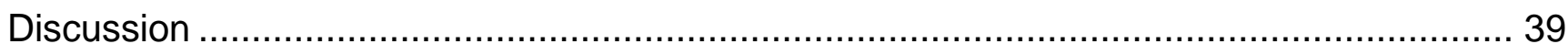

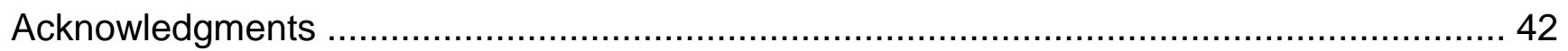

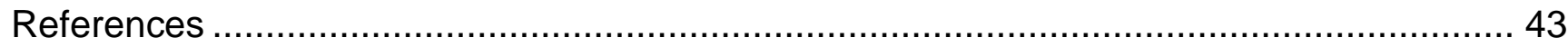

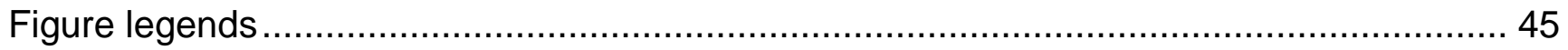

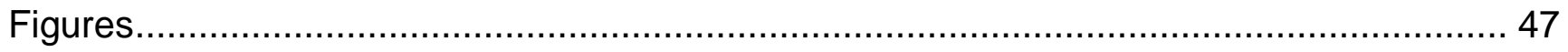


Chapter III- Bone marrow microenvironment modulation of acute lymphoblastic leukemia

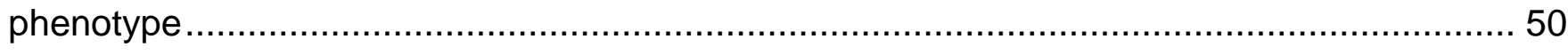

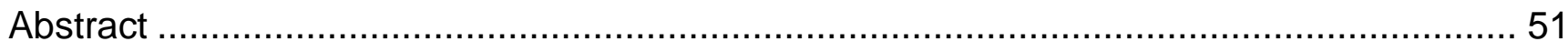

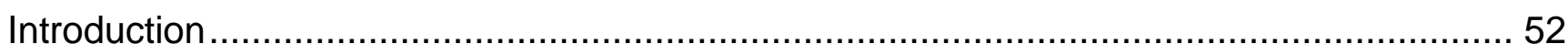

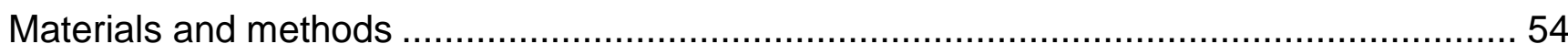

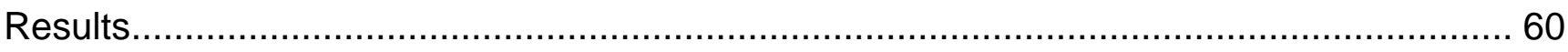

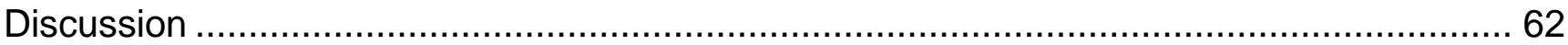

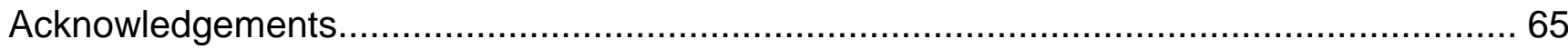

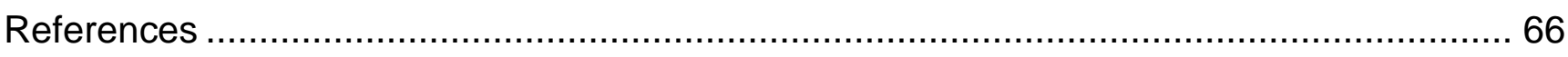

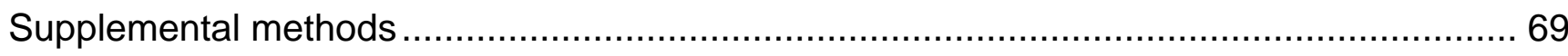

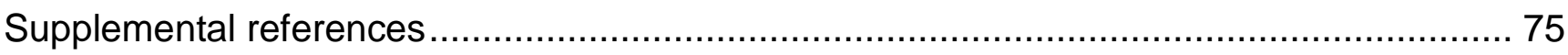

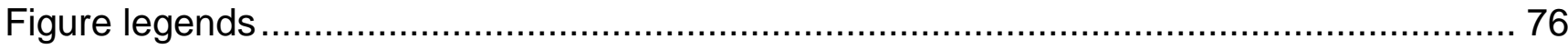

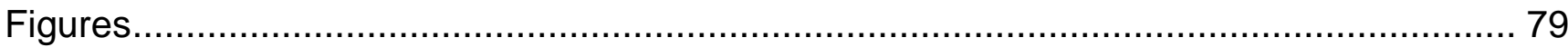

Chapter IV- Microenvironment regulation of miR-221/222 in acute lymphoblastic leukemia ....85

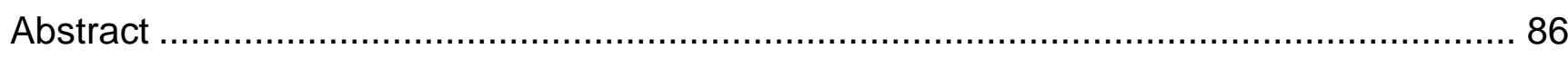

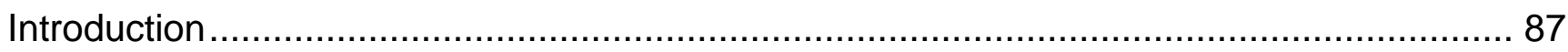

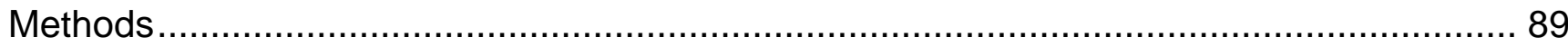

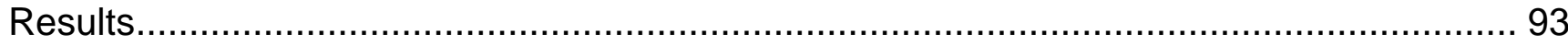

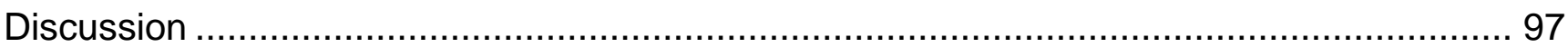

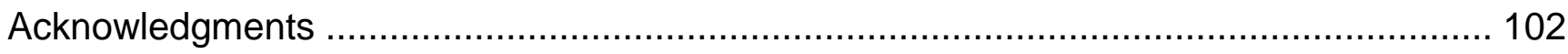

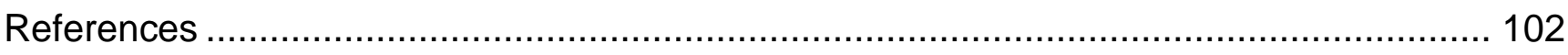

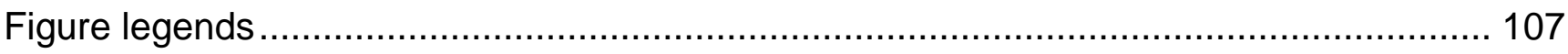

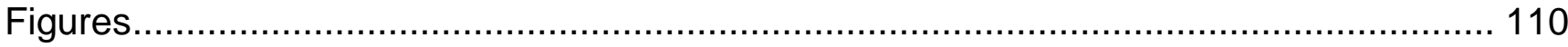

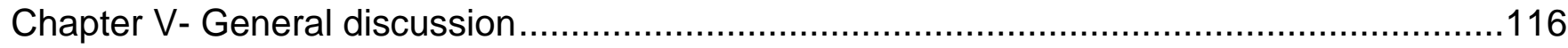

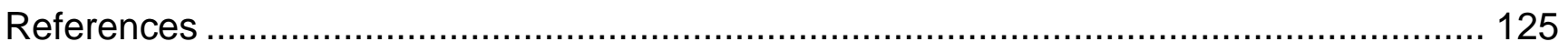




\section{List of Abbreviations}

293T

3T3

Ago

ALL

AML

Ara-C

BCA

Bcl-2

BMM

BMSC

C. elegans

CAR

CDKN1B; p27

CML

CNS

CXCL-12

DGCR8

DNA

DNS

ECAR

FBS

FoxO

G10
Human embryonic fibroblasts

3T3 mouse embryonic fibroblasts

Argonaute

Acute lymphoblastic leukemia

Acute myelogenous leukemia

Cytarabine

Bicinchoninic acid

B-cell lymphoma 2

Bone marrow microenvironment

Bone marrow stromal cell

Caenorhabditis elegans

Cxcl-12-abundant reticular cells

Cyclin-dependent kinase inhibitor 1B

Chronic myeloid leukemia

Central nervous system

C-X-C motif chemokine-12

DiGeorge syndrome critical region 8

Deoxyribonucleic acid

Data not shown

Extracellular acidification rate

Fetal bovine serum

Forkhead box

Gel type 10 cross-linked dextran 


\begin{tabular}{|c|c|}
\hline $\mathrm{H} / \mathrm{PY}$ & Hoechst33342/Pyronin Y \\
\hline $\mathrm{HOB} ; \mathrm{OB}$ & Human osteoblast \\
\hline HSC & Hematopoietic stem cell \\
\hline HSPC & Hematopoietic stem and progenitor cell \\
\hline HT & HT-1080 human fibrosarcoma \\
\hline LAESI & Laser ablation electrospray ionization \\
\hline M; MA & Media alone or media control \\
\hline MEF & Mouse embryonic fibroblasts \\
\hline miRNA; miR & microRNA \\
\hline MRD & Minimal residual disease \\
\hline MSC & Mesenchymal stem cell \\
\hline MTX & Methotrexate \\
\hline ncRNA & Noncoding RNA \\
\hline NSG & NOD-SCID gamma mice \\
\hline nt & Nucleotides \\
\hline OCR & Oxygen consumption rate \\
\hline OncomiRs & Oncogenic microRNA \\
\hline $\mathrm{P} 1, \mathrm{P} 2$ & Patient sample 1, 2 \\
\hline PB & Phase bright ALL cells \\
\hline PBS & Phosphate buffered saline \\
\hline PD & Phase dim ALL cells \\
\hline PFA & Paraformaldehyde \\
\hline $\mathrm{Ph}-, \mathrm{Ph}+$ & Philadelphia chromosome negative, positive \\
\hline pHLIP & pH low insertion peptide \\
\hline
\end{tabular}




$\begin{array}{ll}\text { PI } & \text { Propidium iodide } \\ \text { PI3K } & \text { Phosphoinositide 3-kinase } \\ \text { Pre-miRNA } & \text { Precursor microRNA } \\ \text { Pri-miRNA } & \text { Primary microRNA } \\ \text { qRT-PCR } & \text { Quantitative real-time polymerase chain reaction } \\ \text { RISC } & \text { RNA-induced silencing complex } \\ \text { RNA } & \text { Ribonucleic acid } \\ \text { RNAi } & \text { RNA interference } \\ \text { RNase } & \text { Ribonuclease } \\ \text { S } & \text { Suspended ALL cells } \\ \text { SCF } & \text { Stem cell factor } \\ \text { SCP } & \text { Sheep choroid plexus } \\ \text { SEM } & \text { Standard error of the mean } \\ \text { STAT } & \text { Signal transducer and activator of transcription } \\ \text { TBS } & \text { Tris buffered saline } \\ \text { TGF- } \beta & \text { Transforming growth factor- } \beta \\ \text { UTR } & \text { Untranslated region } \\ \text { VCAM-1 } & \text { Vascular cell adhesion protein 1 } \\ \text { VCR } & \text { Vincristine } \\ \text { VE-cadherin } & \text { Vascular endothelial cadherin } \\ \text { VEGF } & \text { VLA-4 }\end{array}$




\section{Chapter I}

Literature review and introduction 


\section{Hematological malignancies - the historical perspective}

Cancers arising from the blood are collectively termed hematological malignancies. This varied class of cancers include numerous forms of lymphoma, leukemia, and myeloma. Less than 200 years have passed since Thomas Hodgkin documented the first case in medical literature of a hematological malignancy ${ }^{1}$. Later, the disease of the lymph and spleen was characterized and named by Samuel Wilks, designating it as "Hodgkin disease"2. Utilizing immunophenotyping and cytogenetics, it is now understood that hematological malignancies

include diverse diseases with some of the causes of these cancers still not well understood. They affect all ages and have little, if any, hereditary pattern, although many have characteristic genetic rearrangements that contribute to phenotype and are predictive of outcome. To understand the uniqueness and struggles that have been faced in attempts to cure various hematological malignancies, it is important to appreciate the history of them.

As mentioned above, the first recorded case of a hematological malignancy pertained to lymphoma, but leukemias were collectively considered a blood disease recognized between the $4^{\text {th }}$ and $5^{\text {th }}$ century $\mathrm{BC}^{3}$. In the early nineteenth century, physicians recognized that pus and inflammation were associated with blood, but the explanation of how or why the blood was altered in color was not yet understood. Before the identification of leukemia, changes in the color of blood was interpreted as an infection ${ }^{4}$. The nineteenth century was considered the golden age for leukemia discovery and began when Alfred Donnè pioneered the microscope for observing blood cells in the 1820 's. Having the ability to visualize blood microscopically lead to the first diagnosis of leukemia made by John Hughes Bennett in $1845^{5}$. He described alterations in size and shape of the blood cells unlike anything observed from infected patients who 
produced pus and inflammation. Twenty-three years later a pathological anatomy professor, Ernest Neumann, linked the source of blood development to the bone marrow. Distinctions were made in 1877 amongst various blood cells by a stain developed by Paul Ehrlich which subsequently aided in the specific classifications of leukemia ${ }^{3,6}$. Work done by these scientists led to the generation of four subtype classifications of leukemia that include; chronic lymphocytic leukemia (CLL), chronic myeloid leukemia (CML), acute lymphoblastic leukemia (ALL), and acute myeloid leukemia (AML). These remain general classifications today. Although great strides were made in understanding blood diseases in a general way, the complexity and molecular based uniqueness that comprises these subtypes of leukemia were still unknown for several years which hindered treatment progress.

When Watson and Crick discovered the molecular structure of DNA in 1953, the true complexity and potential causes of cancer began to be better understood ${ }^{7}$ From their work, scientists had the ability to detect abnormalities in cancer patients' chromosomes. It wasn't until 1960 that chromosome abnormalities in leukemia were shown to be significant by pathologist Peter Nowell ${ }^{8}$. He and his colleague David Hungerford discovered that patients with CML had an abnormally small chromosome in their white blood cells. This abnormality would later be called the Philadelphia chromosome $(\mathrm{Ph})$ and changes in protein expression downstream of this rearrangement, specifically constitutive Abl kinase activity, was later demonstrated to contribute to initiation of $\mathrm{CML}^{9,10}$ with the same rearrangement later described in some ALL as well. This observation represents just one of the genetic rearrangements that have been described in hematopoietic malignancies, with the bulk of disease lacking such characteristics. Before these scientific breakthroughs were made that provided insight into the diversity of disease and the 
molecular underpinnings of some subtypes, treatment of leukemia was somewhat "generic" in nature.

\section{Early treatments for leukemia}

Early therapeutic agents for the treatment of leukemia were limited in their long term efficacy. Arsenic was first used by Lissauer in 1865 to treat leukemia and was the first agent to have some beneficial effects for patients ${ }^{11}$. Although arsenic was shown to reduce the number of white blood cells in a leukemic patient, it also reduced red blood cells and the benefits from the agent were short term. Blood transfusions ${ }^{12}$ and X-ray radiation ${ }^{13}$ were used to treat the disease as well. Like arsenic, the therapies had only short-term or no effect on leukemic patients survival. It wasn't until 1941, during World War II, that great strides were made with leukemia treatment. The introduction and experimentation of nitrogen mustards and the influence they had on neoplasms changed the way hematological and other malignancies were managed ${ }^{3,14}$. Nitrogen mustards function by inducing an apoptotic response through alkylation of DNA molecules ${ }^{15,16}$ American and British groups ${ }^{14,17}$ both performed clinical trials using nitrogen mustard derivative methyl-bis-( $\beta$-chloroethyl) and collectively saw notable improvements in subsets of patients. Since this treatment strategy only benefited a small number of patients (majority of which were lymphomas) further chemotherapy exploration needed to occur.

In 1946 the first antimetabolite agent, a folic acid antagonist, was synthesized by the Lederle laboratory along with the first effective clinical trials reported ${ }^{18}$. The success of the trials due to the drug's effective mechanism of inhibiting DNA synthesis lead researchers to further study this class of chemotherapy. Using folic acid antagonists, Sidney Farber of Harvard Medical School began the first clinical trials with children that had acute leukemias ${ }^{19}$. The study was 
shown to be beneficial to the majority of the infant and adolescent patients. The trial was the first time a treatment was shown to obtain a temporary remission in acute leukemia patients. After the notable success of the folic acid antagonists, chemical structures were improved upon which ultimately lead to the modern day chemotherapy agent methotrexate.

\section{Modern treatment regimens}

Modern treatments of leukemia involve a highly scheduled regime that assists in targeting tumor cells through a variety of cellular pathways. Standard treatments for acute leukemia consist of three general phases; however, it should be noted that specific characteristics at diagnosis will influence the therapeutic approach as well as institutional variation due to physician preference and experience. As noted, while the specific chemotherapies used depend to some degree on the clinician's preference, but the different classes of drugs used are relatively standard. The first phase of treatment is the induction phase which utilizes a combination of drugs, including antimicrotubular agent vincristine, topoisomerase inhibitor doxorubicin, alkylating agent cyclophosphamide, metabolic enzyme L-asparaginase, and glucocorticoid prednisone over 4-6 weeks. The primary goal of this phase is to achieve a remission. After the initial induction regime, consolidation treatment is administered for 4-8 weeks using a multi-agent approach including antimetabolites methotrexate, cytarabine (Ara-C), and 6-mercaptopurine along with the other agents mentioned in the induction phase. The objective of this phase is to reduce the number of leukemic cells still present in the patient, with the multi-agent approach employed to assist in the prevention of any remaining leukemic cells from developing resistance to treatment. The last phase is maintenance therapy which consists of a combination of the same drugs used in both the induction and consolidation phases except at lower doses. This final 
phase is administered to help destroy any remaining cancer cells and can last between 2 to 3 years depending on the patient's risk level which is determined by a combination of factors including age, genetic abnormalities, and presence of minimal residual disease (MRD) ${ }^{20}$.

Although this treatment regimen described in general above is often very effective, chemotherapy resistance and relapses still occur in about $20 \%$ of patients ${ }^{21}$. Currently 54,200 new cases of leukemia occur every year in the United States with 6,200 of those cases being ALL. Leukemia causes 24,400 deaths a year with ALL contributing to 1,500 of those deaths in the United States ${ }^{22}$. Although great advances have been made in the treatment of leukemia, aggressive refractory disease and post chemotherapy treatment toxicities still exist and define significant clinical challenges. Further investigation is required to better treat disease relapse along with lowering long-term treatment toxicities in patients. This can only be achieved by understanding the molecular underpinnings of this disease to identify points of potential vulnerability that can be targeted. The bone marrow microenvironment is believed to be one site that plays an important role in the chemotherapy resistance and eventual relapse of leukemia ${ }^{23}$ and while various other sites are also reported for initial relapse, including the testes and central nervous system ${ }^{24}$, the bone marrow is the most frequent ${ }^{23}$. Our laboratory focuses on bridging the gap between disease relapse and the mechanisms by which the marrow microenvironment influences this in ALL.

\section{The marrow microenvironment sanctuary}

The bone marrow niche consists of osteolineage cells, osteoclasts, sinusoidal endothelial cells, mesenchymal stromal cells, sympathetic neurons, adipocytes, and extracellular matrix. These factors provide support to hematopoietic stem and progenitor cell (HSPC) through the 
regulation of self-renewal, proliferation, differentiation, localization and quiescence (Figure 1) ${ }^{25-}$ 27. It is the site where the vast numbers and various types of blood cells are generated on a daily basis and where response to stressors, including injury and repair processes, are meticulously orchestrated. A significant body of literature exists to support the assertion that the bone marrow includes functionally distinct niches that support the different physiological circumstances hematopoietic cells may endure in addition to steady state "normal" hematopoiesis.

The location within the marrow that is closest to the trabecular bone is termed the endosteal niche. Osteolineage cells, which include osteoblasts, have been shown in the endosteum by Xie et al. $^{28}$ and others ${ }^{29,30}$ to secrete molecules including CXCL-12 and osteopontin that support migration, or homing, of HSPCs to the marrow. Hematopoietic derived osteoclasts have been shown within this niche to support bone marrow homeostasis by counterbalancing signaling administered by osteolineage cells ${ }^{31}$. Other cell types involved in the endosteal niche include mesenchymal cells and endothelial cells. Although it is somewhat unclear how the endosteal niche is involved in hematopoiesis $26,27,30$, recent evidence by several laboratories demonstrated no acute affect in HSPC frequency ${ }^{32,33}$, proliferation or differentiation ${ }^{34}$ when the number and function of mature osteoblasts were altered. On the other hand, another group has shown when osteoblast differentiation is blocked an almost complete elimination of hematopoiesis occurred, supporting the importance of this intact niche to promote normal hematopoiesis ${ }^{35}$. Although conflicting, these results, along with live-animal imaging of the HSPC niche in the mouse calvarium ${ }^{36}$, supports the hypothesis that differentiating osteoprogenitors within the endosteum are important in constructing and maintaining the HSPC niche, but do very little after maturation to directly maintain $\mathrm{HSPCs}^{37,38}$. On the contrary, evidence in mice supports that lymphoid progenitor cells are maintained and reliant on the 
endosteal niche which displays importance in the context of lymphoid leukemia ${ }^{32}$. Indirect support from osteolineage cells does appear to occur in the context of calcium flux. Since calcium is vital to normal HSPC function, the regulation of free calcium by osteolineage cells is a very important contribution ${ }^{39}$.

Most recent evidence suggests that the main location for HSPC support is the perivascular niche $e^{26,40}$. As the name implies, this niche location is heavily influenced by blood vesicles. Since the endothelial layers of the dorsal aorta and umbilical arteries have been proposed to be the origins of HSCs, their heavy association with the vasculature within the bone marrow is not unforeseen ${ }^{41,42}$. HSCs in this niche are surrounded by sinusoids or other vessels along with numerous tissue types involved in their maintenance and differentiation including mesenchymal stromal, osteolineage progenitors, endothelial, and sympathetic nervous tissue ${ }^{27}$. Signals including stem cell factor, CXCL-12, Notch ligands, and TGF- $\beta$ are released by these supportive cells to home and regulate surrounding $\mathrm{HSCs}^{43}$. Together, cytokines and growth factors released by the surrounding bone marrow stroma regulate key transcription factors and other lineage specific proteins within hematopoietic cells that initiate differentiation events or maintain stem/progenitor cell self-renewal. FoxO transcription factors are an example of a family of genes that are temporally expressed due to external signaling cues to hematopoietic cells that control cell proliferation, survival, and self-renewal| ${ }^{44}$. The microenvironment control over hematopoietic differentiation has been observed when a number of different cytokines and growth factors stimulate the expression of STAT transcription factors ${ }^{45}$. The precise control of transcription factor activity, including FoxO and STAT proteins, by the bone marrow stroma is vital because modulations in both have been shown to contribute to myeloid and lymphoid malignancies ${ }^{46,47}$. Collectively, the bone marrow niche is critical for the establishment, 
maintenance, and proper differentiation of hematopoietic cells and disruption of any of the baseline functions can facilitate malignant transformation of hematopoietic progenitor cells ${ }^{48}$.

\section{Leukemia support by the bone marrow niche}

Due to the protective, growth stimulating environment created within the bone marrow, it is one of the most common sites for tumor metastasis ${ }^{49}$. In contrast to other tumor types that often metastasize to the marrow, leukemia typically initiates, progresses, and often relapses in this site as noted previously. Given the remarkable similarity between healthy and malignant immature hematopoietic cells is it not surprising that these tumors thrive in this anatomical setting. Hematopoietic malignancies take full advantage of bone marrow niche signaling by sharing similar surface cytokine and chemokine receptors as well as adhesion molecule expression profiles ${ }^{50}$. Since the normal immature B-lineage hematopoietic and malignant cells are similar, the malignant cells are well positioned to respond to similar cues which can induce quiescent and protected phenotypes ${ }^{51,52}$. Cues received by leukemia cells after commandeering the HSPC niche allow the cells to evade stressors such as chemotherapy treatment, leading to treatment resistance and reestablishment of disease following completion of therapy.

Our lab and several others have provided evidence for B cell leukemia robustly responding to the bone marrow niche, leading to an increase in survival and preservation of a stem-like phenotype ${ }^{53-63}$. Early work investigated how leukemic cells in physical contact with stroma, specifically the interaction between tumor cell VLA-4 and stromal cell VCAM-1, lead to an increase in chemotherapy protection through PI3K activated pathways and anti-apoptotic Bcl-

2 expression ${ }^{53,55}$. Later, it was demonstrated that the survival advantage of leukemic cell Akt activation due to stromal interaction after chemotherapy exposure ${ }^{56}$ was required for optimal 
microenvironment derived protection of tumor cells during cytotoxic stress. Alterations were also observed in cleaved Caspase-3 pro-apoptotic pathway ${ }^{54}$ and in VEGF induced activation of Bcl2 when leukemic cells had access to bone marrow derived stromal cells ${ }^{57,58}$. In addition, the preservation of stem-like characteristics through the primitive hematopoietic adhesion molecule VE-cadherin, often considered a classic endothelial cell marker, was observed on leukemia cells in contact with stromal cells, indicating a unique position of the leukemia cells to respond to selfrenewal and/or proliferative cues derived from the bone marrow niche ${ }^{60,61}$. Recently, we have described cell cycle alterations, along with metabolite variation in leukemia cells co-cultured with stromal cells and osteoblasts, leading to a quiescent, chemotherapy resistant sub-population of ALL cells (Chapter II and III) ${ }^{64,65}$. Furthermore, we observed different leukemic sub-populations forming when influenced by the bone marrow derived cells. Following individual isolation, a distinct survival advantage was seen in one population, those physically buried beneath marrow derived adherent layers, when compared to tumor cells either freely floating in the media or loosely adherent to the top of stroma or osteoblasts. This anatomical and phenotypic heterogeneity, observed even in vitro, suggests complexity of disease even though leukemia is often considered a clonal disease ${ }^{66}$. The bone marrow microenvironment can have an immense impact on tumor cell phenotype and is clearly dynamic as described in Chapter III where these populations of tumor are described in more detail.

Leukemia-stromal cell interaction is not considered unidirectional, but rather an interchange of signaling. Evidence of leukemic cells remodeling the bone marrow niche to produce a more favorable environment that supports their specific behavior has been shown by Kim et al. ${ }^{67}$ and Krause et al. ${ }^{25}$ along with several others ${ }^{68,69}$. These alterations were shown to benefit leukemia cell survival, self-renewal, and anchorage to the bone marrow. Altering the 
bone marrow niche has devastating effects on normal HSPC pools which often leads to hematopoietic cell exhaustion and reduction of normal blood cell development. Counter to the involvement the leukemic cells have on the bone marrow niche, the marrow niche can influence hematopoietic transformation. For example, Raaijmakers et al. observed that in vivo deletion of Dicer1 from osteoprogenitor cells induced myelodysplasia and AML in mice ${ }^{34}$. Together, these observations demonstrate the extensive cross-talk that occurs between leukemia and the bone marrow niche.

\section{miRNAs in hematopoiesis}

As mentioned above, signaling from the microenvironment is essential for normal hematopoiesis to occur via the modulation of hematopoietic gene expression. Extensive research has been described focused on the alterations of noncoding RNA (ncRNA) expression in these cells as well ${ }^{70,71}$. Several studies have demonstrated the temporal importance of ncRNA, specifically microRNA (miRNA) expression on self-renewal and differentiation of hematopoietic cells ${ }^{72-75}$. Similar to coding genes during hematopoiesis, miRNA transcription is tightly regulated during differentiation events (Figure 2$)^{76}$. The importance of miRNAs in hematopoiesis has been clearly shown when miRNA regulator proteins including DGCR8 ${ }^{77}$, Dicer ${ }^{78}$, and $\mathrm{Ago2}^{79}$ were conditionally knocked out of HSCs in mice causing severe hematopoietic defects. Disruption of miRNA expression at key points has been shown to cause abnormal differentiation and behavior. For example, miRNA 155 (miR-155) knockout in mice affected T-cell differentiation, germinal B cell response, and immunological response to bacterial infections ${ }^{80}$. Zhou B, et al. and Chen CZ, et al. observed a blunting in lymphoid differentiation when miR-150 and miR-181 expression, respectively, were altered at different lymphoid stages 
further supporting the reliance hematopoiesis has on miRNAs ${ }^{81,82}$. The increasing number of miRNAs that have been shown to influence hematopoiesis indicates the importance of this mechanism in HSPC regulation, highlighting the need for future investigations in this field as we attempt to better understand the dysregulated hematopoiesis that results in leukemic disease.

\section{Discovery and function of miRNA}

The first miRNA, lin-4, was discovered in the nematode $C$. elagans in 1993 by Victor Ambros and colleagues ${ }^{83}$. Ambros discovered that lin-4 negatively affected the protein levels of lin-14 and lin-28, and these two proteins inhibit the expression of larva differentiation protein lin$29^{84}$. They concluded that there was a hierarchical mode of control with lin-4 at the top of the hierarchy. Because of the partisan levels of control, lin-4, which was unique in that it didn't code for a protein, and lin-14 were sequenced by Ambros and Ruvkun, respectively. When Ambros' group sequenced lin-4, they discovered two copies of its mRNA, both having less nucleotides than any other gene that had been sequenced to date. Once the two laboratories compared the sequences between lin-4 and lin-14, they recognized that the two copies of lin-4 had complementary sequences to several regions of the $3^{\prime}$ untranslated region (UTR) of lin-1483. After performing reporter assays using the binding sites of lin-14 from wild type or mutated lin-4

C. elegans, it was confirmed there was direct binding of lin-4 mRNA (later referred to miRNA) to lin-14 mRNA causing a repression in mRNA translation ${ }^{85}$. The biological significance of miRNAs was not appreciated until 2000, when Reinhart et al. first discovered let-7. Unlike lin-4, let-7 is shown to be highly conserved and expressed across species, including humans ${ }^{86}$.

Since the first discovery in 1993, nearly 2600 miRNAs have been validated in humans. miRNAs regulate gene function by binding to target mRNAs predominantly within their $3^{\prime} U T R^{87}$. 
Mature miRNAs are 19-23 nucleotides in length and contain a seed sequence located between nucleotides 2-8 of the 5 ' end. The seed sequence facilitates the specific target binding through consecutive Watson-Crick base pairing ${ }^{88}$. A single miRNA has the potential to target hundreds of different mRNAs leading to vast phenotypic alterations by minimal miRNA expression variation ${ }^{89}$. This observation positions miRNAs as influential regulators of diverse events, making their regulation in tumor cell biology a critical, and rapidly growing, area of interest. miRNA genes can share promoter regions with other genes or have their own promoter regions specific only to their gene or gene cluster. They are located within introns of coding genes (intragenic) or can be located in DNA regions between coding genes (intergenic) which used to be thought of as "junk" DNA. Transcription of miRNAs is similar to protein coding genes in that the majority are transcribed by RNA polymerase II, then 5' capped and 3' polyadenylated ${ }^{90}$. In animals, miRNAs function by near-precise complementary binding to target gene mRNA facilitated by RNAinduced silencing complex (RISC) machinery. Once bound, miRNA either silence target mRNAs through translation repression, mRNA deadenylation, or rarely cleavage of mRNA ${ }^{91}$. miRNAmRNA binding specificity is generally reliant on the seed sequence complementary, and it has been shown that mutation of just one of the nucleotides within the mRNA target region can inhibit efficient miRNA binding and silencing ${ }^{92}$. This observation further supports the highly precise mechanism of miRNA regulation.

\section{miRNAs in leukemia}

Implications that miRNAs may be involved in cancer began to arise following the identification of a genome-wide correlation between genomic localization of miRNA genes and cancer associated genomic regions as described by Calin et al. ${ }^{93}$. The first discovered miRNA 
in disease was by Carlo Croce and colleagues who investigated a chromosome deletion event that occurred in the majority of CLL patients. The deleted locus did not appear to have an annotated gene present, but the event had an inverse correlation to Bcl-2 expression. Later the group discovered that the locus contained miR-15 and miR-16, and that they were both master regulators of $\mathrm{Bcl}-2$ in the context of $\mathrm{CLL}^{94}$. When the locus containing the two miRNAs was knocked out of HSCs in healthy mice, greater than $42 \%$ of mice had abnormal B cell proliferation which eventually led to the presentation of leukemia ${ }^{95}$. The magnitude of miRNA alterations in leukemia was not brought to light until miRNA genome-wide expression studies were conducted which described the expression pattern differences in normal patients relative to acute leukemia patients' bone marrow ${ }^{96,97}$. From these initial observations there have been numerous studies outlining the involvement of miRNAs in leukemia. As shown in Figure 2, miRNAs are vital to the delicate balance of differentiation and self-renewal in hematopoiesis. If their expression is dysregulated, maintained at inappropriately high levels or down regulated in response to external stimuli, such as bone marrow niche elaborated signals, disease has been shown to arise ${ }^{98,99}$.

\section{miRNA biogenesis and regulation}

After transcription, the majority of miRNAs go through several processing steps in order to become mature, functional miRNA. The initial transcript, designated the primary transcript (pri-) is large, consisting of potentially several thousand base pairs in length with secondary stem-loop structures ${ }^{100}$. An RNase III enzyme Drosha, along with RNA binding protein DGCR8 and other accessory proteins, form the microprocessor complex within the nucleus and specifically cleave the pri-miRNA at the base of the secondary stem-loop structures ${ }^{77}$. The miRNA is then in its shorter precursor (pre-) form and exported out of the nucleus through 
exportin molecules ${ }^{101}$. In the cytoplasm, the pre-miRNA is cleaved once more by Dicer with assistance from double stranded binding protein, TRBP, to form the passenger and guide strand miRNA duplex ${ }^{102}$. The miRNA duplex is separated and the guide strand binds to one of the four Argonaute proteins along other core proteins that bind to form the miRNA RISC complex (miRISC) $)^{103,104}$. The details related to all the steps mentioned above are not fully understood, and specific aspects of regulation of loading of the miRNA duplex and separation of passenger and guide miRNA strands are still controversial. Several chaperone and accessory proteins are involved in the this process ${ }^{105,106}$; In addition, there are four Argonaute family members, each able to be modified and phosphorylated to create numerous complex combinations that appear to be not only species specific, but cell type specific as well ${ }^{103}$. Adding to the complexity of miRNA biogenesis, several modifications can be made to not only the biogenesis proteins, but to miRNAs directly (Figure 3$)^{107}$. Relevant to our model, alterations that occur due to hypoxia, TGF- $\beta$, and other signaling pathways influenced by the bone marrow niche cells have the potential to vastly change the landscape of global miRNA biogenesis within leukemia cells ${ }^{108-}$ 111.

\section{The role of miR-221 and -222 in cancer}

Protein coding genes that facilitate cancer initiation and progression are designated as oncogenes. Conversely, genes that are responsible for controlling abnormal cell proliferation and survival are described as tumor suppressor genes. miRNAs can be classified under either of these two umbrellas as well. In both cases, coding and noncoding genes may fall under either class and is context specific. In the instance of miR-221 and -222 (miR-221/222) they are traditionally observed as oncogenic miRNA (oncomiRs) ${ }^{112-114}$. The two miRNAs are located in a 
stable locus on the $\mathrm{X}$ chromosome and are transcribed from the same primary transcript therefore are regulated by the same promoter. They share identical seed sequences which makes their targets nearly indistinguishable ${ }^{115}$. The observed difference in mRNA target specificity arises from disparities in complementary base pairing outside of the seed sequence ${ }^{116}$. The two miRNAs are oncomiRs because they positively regulate cell proliferation and are traditionally upregulated in tumor cells compared to matching normal tissue ${ }^{114,117,118}$. The most thoroughly annotated miR-221/222 target gene is cell cycle regulator CDKN1B (p27) ${ }^{119-122}$. p27 inhibits cell cycle progression at the $G_{0}$ to $S$ phase transition by binding to and regulating the activity of cyclin-dependent kinases ${ }^{123}$. In various normal and cancerous tissues, including leukemia, p27 is highly regulated and considered the master regulator of cellular quiescence $114,119,121,123-128$. In our model, we observe downregulation of miR-221/222 in leukemia cells co-cultured with bone marrow stromal cells and osteoblasts (Chapter IV). As a consequence, an increase in p27 protein level and a reduction in cell cycle progression are seen, leading to chemotherapy resistance. Forced expression of miR-221/222 sensitizes bone marrow niche regulated leukemia cells to chemotherapy exposure and is a potential technique to therapeutically target chemotherapy resistant leukemia.

\section{Summary}

In summary, the bone marrow microenvironment is a complex system of cell types that regulate the development of hematopoietic cells. Different sub-locations within the bone marrow have been shown to have very different roles in blood cell development within this unique anatomical site. As a consequence, solid and hematological malignancies can exploit the nurturing, protective niches resulting in a very difficult to treat, highly resistant diseases. Specific 
to our in vitro model, viability of ALL cells that receive quiescence inducing signals from the marrow niche are virtually unaffected by traditional cytotoxic chemotherapy agents (Chapter II and III). Novel strategies need to be established in order to disrupt the bone marrow microenvironment interactions with leukemia. Disrupting these interactions can lead to sensitization of leukemic cells to chemotherapy treatment. Achieving this can provide benefits to patient care in two ways. First, through the establishment of sustained remission with eradication of disease. A secondary benefit is derived from diminishing the adverse effects of chemotherapy treatment by lowering the dose or duration of exposure to cytotoxic agents. The latter has the greatest chance in improving the quality of life in pediatric patients by decreasing the incidence of chemotherapy induced long term cognition deficiencies as well as blunting the likelihood of secondary malignancies documented to sometimes occur following sustained treatment. Overall, the findings presented in this dissertation outline the potential of niche regulated miR-221/222 to influence chemotherapy resistance in ALL cells through the use of a novel co-culture system. We hope this work will collectively provide a broader appreciation for the role the bone marrow microenvironment in regulation of leukemic disease and its response to treatment.

\section{References}

1. Hodgkin, T. On some Morbid Appearances of the Absorbent Glands and Spleen. MedicoChir. Trans. 17, 68-114 (1832).

2. Wilks, S. Historical notes on Bright's disease, Addison's disease, and Hodgkin's disease. Guys Hosp. Rep. 22, 259-274 (1877).

3. Piller, G. Leukaemia - a brief historical review from ancient times to 1950. Br. J. Haematol. 112, 282-292 (2001).

4. Sénac, J.-B. Traité de la structure du coeur, de son action, et de ses maladies. (Briasson, 1749). 
5. Bennett, J. H. Case 2, case of hypertrophy of the spleen and liver, in which death took place from suppuration of the blood. Edinb. Med. Surg. J. 64, 413-23 (1845).

6. Ehrlich, P. Beiträge zur Kenntniss der Anilinfärbungen und ihrer Verwendung in der mikroskopischen Technik. Arch. Für Mikrosk. Anat. 13, 263-277 (1877).

7. Watson, J. D. \& Crick, F. H. Molecular structure of nucleic acids; a structure for deoxyribose nucleic acid. Nature 171, 737-738 (1953).

8. Patlak, M. Targeting leukemia: from bench to bedside. FASEB J. Off. Publ. Fed. Am. Soc. Exp. Biol. 16, 273 (2002).

9. Nowell, P. C. \& Hungerford, D. A. Chromosome studies on normal and leukemic human leukocytes. J. Natl. Cancer Inst. 25, 85-109 (1960).

10. Nowell, P. C. \& Hungerford, D. A. Chromosome studies in human leukemia. II. Chronic granulocytic leukemia. J. Natl. Cancer Inst. 27, 1013-1035 (1961).

11. Lissauer. Zwei Falle von Leukamie. Berl. Klin. Wochenschr. 2, 403-4 (1865).

12. Tiagi, G. K. \& Agrawal, M. K. Leukaemoid reaction after blood transfusion. Indian Med. Gaz. 81, 184 (1946).

13. Kampen, K. R. The discovery and early understanding of leukemia. Leuk. Res. 36, 6-13 (2012).

14. Gilman, A. \& Philips, F. S. The biological actions and therapeutic applications of the Bchloroethyl amines and sulfides. Science 103, 409-415 (1946).

15. Roberts, J. J. \& Warwick, G. P. STUDIES OF THE MODE OF ACTION OF TUMOURGROWTH-INHIBITING ALKYLATING AGENTS. IV. IN-VITRO REACTIONS OF 2CHLOROETHYLARYLAMINES. Biochem. Pharmacol. 12, 1315-1319 (1963).

16. Warwick, G. P. THE MECHANISM OF ACTION OF ALKYLATING AGENTS. Cancer Res. 23, 1315-1333 (1963).

17. Wilkinson, J. F. \& Fletcher, F. Effect of beta-chloroethylamine hydrochlorides in leukaemia, Hodgkin's disease, and polycythaemia vera; report on 18 cases. Lancet Lond. Engl. 2, 540-545 (1947).

18. Spies, T. D. Some Observations on the Therapeutic Usefulness of Synthetic L. Casei Factor (folic Acid). Ann. N. Y. Acad. Sci. 48, 313-342 (1946).

19. Farber, S. \& Diamond, L. K. Temporary remissions in acute leukemia in children produced by folic acid antagonist, 4-aminopteroyl-glutamic acid. N. Engl. J. Med. 238, 787-793 (1948). 
20. Gökbuget, N. [Current treatment of acute lymphoblastic leukemia in adults]. Internist 56, 344-353 (2015).

21. Adult Acute Lymphoblastic Leukemia Treatment. National Cancer Institute Available at: http://www.cancer.gov/types/leukemia/hp/adult-all-treatment-pdq\#section/_1. (Accessed: 6th March 2016)

22. Acute Lymphocytic Leukemia - SEER Stat Fact Sheets. Available at: http://seer.cancer.gov/statfacts/html/alyl.html. (Accessed: 13th March 2016)

23. Oriol, A. et al. Outcome after relapse of acute lymphoblastic leukemia in adult patients included in four consecutive risk-adapted trials by the PETHEMA Study Group. Haematologica 95, 589-596 (2010).

24. Trotter, T. N. \& Yang, Y. Matricellular proteins as regulators of cancer metastasis to bone. Matrix Biol. doi:10.1016/j.matbio.2016.01.006

25. Krause, D. S. et al. Differential regulation of myeloid leukemias by the bone marrow microenvironment. Nat. Med. 19, 1513-1517 (2013).

26. Scadden, D. T. Nice neighborhood: emerging concepts of the stem cell niche. Cell 157, 41-50 (2014).

27. Morrison, S. J. \& Scadden, D. T. The bone marrow niche for haematopoietic stem cells. Nature 505, 327-334 (2014).

28. Xie, Y. et al. Detection of functional haematopoietic stem cell niche using real-time imaging. Nature 457, 97-101 (2009).

29. Ding, L. \& Morrison, S. J. Haematopoietic stem cells and early lymphoid progenitors occupy distinct bone marrow niches. Nature 495, 231-235 (2013).

30. Stier, S. et al. Osteopontin is a hematopoietic stem cell niche component that negatively regulates stem cell pool size. J. Exp. Med. 201, 1781-1791 (2005).

31. Lévesque, J.-P., Helwani, F. M. \& Winkler, I. G. The endosteal 'osteoblastic' niche and its role in hematopoietic stem cell homing and mobilization. Leukemia 24, 1979-1992 (2010).

32. Zhu, J. et al. Osteoblasts support B-lymphocyte commitment and differentiation from hematopoietic stem cells. Blood 109, 3706-3712 (2007).

33. Lymperi, S. et al. Strontium can increase some osteoblasts without increasing hematopoietic stem cells. Blood 111, 1173-1181 (2008).

34. Raaijmakers, M. H. G. P. et al. Bone progenitor dysfunction induces myelodysplasia and secondary leukaemia. Nature 464, 852-857 (2010). 
35. Chen, Z. et al. Signalling thresholds and negative B-cell selection in acute lymphoblastic leukaemia. Nature 521, 357-361 (2015).

36. Lo Celso, C. et al. Live-animal tracking of individual haematopoietic stem/progenitor cells in their niche. Nature 457, 92-96 (2009).

37. Chan, C. K. F. et al. Endochondral ossification is required for haematopoietic stem-cell niche formation. Nature 457, 490-494 (2009).

38. Sacchetti, B. et al. Self-renewing osteoprogenitors in bone marrow sinusoids can organize a hematopoietic microenvironment. Cell 131, 324-336 (2007).

39. Adams, G. B. et al. Stem cell engraftment at the endosteal niche is specified by the calcium-sensing receptor. Nature 439, 599-603 (2006).

40. Méndez-Ferrer, S. et al. Mesenchymal and haematopoietic stem cells form a unique bone marrow niche. Nature 466, 829-834 (2010).

41. Medvinsky, A. \& Dzierzak, E. Definitive hematopoiesis is autonomously initiated by the AGM region. Cell 86, 897-906 (1996).

42. de Bruijn, M. F., Speck, N. A., Peeters, M. C. \& Dzierzak, E. Definitive hematopoietic stem cells first develop within the major arterial regions of the mouse embryo. EMBO J.19, 2465-2474 (2000).

43. Boulais, P. E. \& Frenette, P. S. Making sense of hematopoietic stem cell niches. Blood 125, 2621-2629 (2015).

44. Tothova, Z. \& Gilliland, D. G. FoxO Transcription Factors and Stem Cell Homeostasis: Insights from the Hematopoietic System. Cell Stem Cell 1, 140-152 (2007).

45. Dorritie, K. A., McCubrey, J. A. \& Johnson, D. E. STAT transcription factors in hematopoiesis and leukemogenesis: opportunities for therapeutic intervention. Leukemia 28, 248-257 (2014).

46. Sykes, S. M. et al. AKT/FOXO signaling enforces reversible differentiation blockade in myeloid leukemias. Cell 146, 697-708 (2011).

47. Maude, S. L. et al. Efficacy of JAK/STAT pathway inhibition in murine xenograft models of early T-cell precursor (ETP) acute lymphoblastic leukemia. Blood 125, 1759-1767 (2015).

48. Reagan, M. R. \& Rosen, C. J. Navigating the bone marrow niche: translational insights and cancer-driven dysfunction. Nat. Rev. Rheumatol. 12, 154-168 (2016).

49. Metastatic Cancer. National Cancer Institute Available at: http://www.cancer.gov/aboutcancer/what-is-cancer/metastatic-fact-sheet. (Accessed: 19th February 2016) 
50. Pui, C.-H., Relling, M. V. \& Downing, J. R. Acute lymphoblastic leukemia. N. Engl. J. Med. 350, 1535-1548 (2004).

51. Krivtsov, A. V. et al. Transformation from committed progenitor to leukaemia stem cell initiated by MLL-AF9. Nature 442, 818-822 (2006).

52. Damle, R. N. et al. B-cell chronic lymphocytic leukemia cells express a surface membrane phenotype of activated, antigen-experienced B lymphocytes. Blood 99, 4087-4093 (2002).

53. Mudry, R. E., Fortney, J. E., York, T., Hall, B. M. \& Gibson, L. F. Stromal cells regulate survival of B-lineage leukemic cells during chemotherapy. Blood 96, 1926-1932 (2000).

54. Fortney, J. E., Zhao, W., Wenger, S. L. \& Gibson, L. F. Bone marrow stromal cells regulate caspase 3 activity in leukemic cells during chemotherapy. Leuk. Res. 25, 901907 (2001).

55. Hall, B. M. et al. Stromal cells expressing elevated VCAM-1 enhance survival of B lineage tumor cells. Cancer Lett. 207, 229-239 (2004).

56. Wang, L., Fortney, J. E. \& Gibson, L. F. Stromal cell protection of B-lineage acute lymphoblastic leukemic cells during chemotherapy requires active Akt. Leuk. Res. 28, 733-742 (2004).

57. Wang, L., Chen, L., Benincosa, J., Fortney, J. \& Gibson, L. F. VEGF-induced phosphorylation of Bcl-2 influences $B$ lineage leukemic cell response to apoptotic stimuli. Leukemia 19, 344-353 (2005).

58. Wang, L., Coad, J. E., Fortney, J. M. \& Gibson, L. F. VEGF-induced survival of chronic lymphocytic leukemia is independent of Bcl-2 phosphorylation. Leukemia 19, 1486-1487 (2005).

59. Wang, L., Clutter, S., Benincosa, J., Fortney, J. \& Gibson, L. F. Activation of transforming growth factor-beta1/p38/Smad3 signaling in stromal cells requires reactive oxygen species-mediated MMP-2 activity during bone marrow damage. Stem Cells Dayt. Ohio 23, 1122-1134 (2005).

60. Wang, L., O'Leary, H., Fortney, J. \& Gibson, L. F. Ph+/VE-cadherin+ identifies a stem cell like population of acute lymphoblastic leukemia sustained by bone marrow niche cells. Blood 110, 3334-3344 (2007).

61. O'Leary, H. et al. VE-cadherin Regulates Philadelphia Chromosome Positive Acute Lymphoblastic Leukemia Sensitivity to Apoptosis. Cancer Microenviron. Off. J. Int. Cancer Microenviron. Soc. 3, 67-81 (2010).

62. Manabe, A. et al. Adhesion-dependent survival of normal and leukemic human B lymphoblasts on bone marrow stromal cells. Blood 83, 758-766 (1994). 
63. Bradstock, K., Bianchi, A., Makrynikola, V., Filshie, R. \& Gottlieb, D. Long-term survival and proliferation of precursor-B acute lymphoblastic leukemia cells on human bone marrow stroma. Leukemia 10, 813-820 (1996).

64. Moses, B. S. et al. Bone marrow microenvironment modulation of acute lymphoblastic leukemia phenotype. Exp. Hematol. 44, 50-59.e2 (2016).

65. Slone, W. L. et al. Modeling Chemotherapy Resistant Leukemia In Vitro. J. Vis. Exp. JoVE (2016). doi:10.3791/53645

66. Dow, L. W. et al. Evidence for clonal development of childhood acute lymphoblastic leukemia. Blood 66, 902-907 (1985).

67. Kim, J.-A. et al. Microenvironmental remodeling as a parameter and prognostic factor of heterogeneous leukemogenesis in acute myelogenous leukemia. Cancer Res. 75, 22222231 (2015).

68. Schepers, K. et al. Myeloproliferative neoplasia remodels the endosteal bone marrow niche into a self-reinforcing leukemic niche. Cell Stem Cell 13, 285-299 (2013).

69. Poulton, I. J., McGregor, N. E., Pompolo, S., Walker, E. C. \& Sims, N. A. Contrasting roles of leukemia inhibitory factor in murine bone development and remodeling involve regionspecific changes in vascularization. J. Bone Miner. Res. 27, 586-595 (2012).

70. Satpathy, A. T. \& Chang, H. Y. Long noncoding RNA in hematopoiesis and immunity. Immunity 42, 792-804 (2015).

71. Paralkar, V. R. \& Weiss, M. J. Long noncoding RNAs in biology and hematopoiesis. Blood 121, 4842-4846 (2013).

72. Kotani, A., Harnprasopwat, R., Toyoshima, T., Kawamata, T. \& Tojo, A. miRNAs in normal and malignant B cells. Int. J. Hematol. 92, 255-261 (2010).

73. Jima, D. D. et al. Deep sequencing of the small RNA transcriptome of normal and malignant human B cells identifies hundreds of novel microRNAs. Blood 116, e118-e127 (2010).

74. Chen, C.-Z., Li, L., Lodish, H. F. \& Bartel, D. P. MicroRNAs Modulate Hematopoietic Lineage Differentiation. Science 303, 83-86 (2004).

75. Kluiver, J., Kroesen, B.-J., Poppema, S. \& van den Berg, A. The role of microRNAs in normal hematopoiesis and hematopoietic malignancies. Leukemia 20, 1931-1936 (2006).

76. Baltimore, D., Boldin, M. P., O'Connell, R. M., Rao, D. S. \& Taganov, K. D. MicroRNAs: new regulators of immune cell development and function. Nat. Immunol. 9, 839-845 (2008). 
77. Wang, Y., Medvid, R., Melton, C., Jaenisch, R. \& Blelloch, R. DGCR8 is essential for microRNA biogenesis and silencing of embryonic stem cell self-renewal. Nat. Genet. 39, 380-385 (2007).

78. Cobb, B. S. et al. T cell lineage choice and differentiation in the absence of the RNase III enzyme Dicer. J. Exp. Med. 201, 1367-1373 (2005).

79. O'Carroll, D. et al. A Slicer-independent role for Argonaute 2 in hematopoiesis and the microRNA pathway. Genes Dev. 21, 1999-2004 (2007).

80. Thai, T.-H. et al. Regulation of the Germinal Center Response by MicroRNA-155. Science 316, 604-608 (2007).

81. Zhou, B., Wang, S., Mayr, C., Bartel, D. P. \& Lodish, H. F. miR-150, a microRNA expressed in mature $B$ and $T$ cells, blocks early $B$ cell development when expressed prematurely. Proc. Natl. Acad. Sci. U. S. A. 104, 7080-7085 (2007).

82. Chen, C.-Z., Li, L., Lodish, H. F. \& Bartel, D. P. MicroRNAs modulate hematopoietic lineage differentiation. Science 303, 83-86 (2004).

83. Lee, R. C., Feinbaum, R. L. \& Ambros, V. The C. elegans heterochronic gene lin-4 encodes small RNAs with antisense complementarity to lin-14. Cell 75, 843-854 (1993).

84. Ambros, V. A hierarchy of regulatory genes controls a larva-to-adult developmental switch in C. elegans. Cell 57, 49-57 (1989).

85. Wightman, B., Ha, I. \& Ruvkun, G. Posttranscriptional regulation of the heterochronic gene lin-14 by lin-4 mediates temporal pattern formation in C. elegans. Cell 75, 855-862 (1993).

86. Reinhart, B. J. et al. The 21-nucleotide let-7 RNA regulates developmental timing in Caenorhabditis elegans. Nature 403, 901-906 (2000).

87. Hobert, O. Gene Regulation by Transcription Factors and MicroRNAs. Science 319, 1785-1786 (2008).

88. Ambros, V. The functions of animal microRNAs. Nature 431, 350-355 (2004).

89. Li, J. \& Zhang, Z. miRNA regulatory variation in human evolution. Trends Genet. 29, 116124 (2013).

90. Ohler, U., Yekta, S., Lim, L. P., Bartel, D. P. \& Burge, C. B. Patterns of flanking sequence conservation and a characteristic upstream motif for microRNA gene identification. RNA N. Y. N 10, 1309-1322 (2004).

91. Winter, J., Jung, S., Keller, S., Gregory, R. I. \& Diederichs, S. Many roads to maturity: microRNA biogenesis pathways and their regulation. Nat. Cell Biol. 11, 228-234 (2009). 
92. Ryland, G. L. et al. MicroRNA genes and their target 3'-untranslated regions are infrequently somatically mutated in ovarian cancers. PloS One 7, e35805 (2012).

93. Calin, G. A. et al. Human microRNA genes are frequently located at fragile sites and genomic regions involved in cancers. Proc. Natl. Acad. Sci. U. S. A. 101, 2999-3004 (2004).

94. Calin, G. A. et al. Frequent deletions and down-regulation of micro- RNA genes miR15 and miR16 at $13 q 14$ in chronic lymphocytic leukemia. Proc. Natl. Acad. Sci. U. S. A. 99, 15524-15529 (2002).

95. Klein, U. et al. The DLEU2/miR-15a/16-1 cluster controls B cell proliferation and its deletion leads to chronic lymphocytic leukemia. Cancer Cell 17, 28-40 (2010).

96. Schotte, D. et al. MicroRNA characterize genetic diversity and drug resistance in pediatric acute lymphoblastic leukemia. Haematologica 96, 703-711 (2011).

97. Dixon-Mclver, A. et al. Distinctive patterns of microRNA expression associated with karyotype in acute myeloid leukaemia. PloS One 3, e2141 (2008).

98. Vasilatou, D., Papageorgiou, S., Pappa, V., Papageorgiou, E. \& Dervenoulas, J. The role of microRNAs in normal and malignant hematopoiesis. Eur. J. Haematol. 84, 1-16 (2010).

99. Fabbri, M. et al. MicroRNAs and noncoding RNAs in hematological malignancies: molecular, clinical and therapeutic implications. Leukemia 22, 1095-1105 (2008).

100. Ma, H., Wu, Y., Choi, J.-G. \& Wu, H. Lower and upper stem-single-stranded RNA junctions together determine the Drosha cleavage site. Proc. Natl. Acad. Sci. 110, 2068720692 (2013).

101. Yi, R., Qin, Y., Macara, I. G. \& Cullen, B. R. Exportin-5 mediates the nuclear export of premicroRNAs and short hairpin RNAs. Genes Dev. 17, 3011-3016 (2003).

102. Haase, A. D. et al. TRBP, a regulator of cellular PKR and HIV-1 virus expression, interacts with Dicer and functions in RNA silencing. EMBO Rep. 6, 961-967 (2005).

103. Meister, G. Argonaute proteins: functional insights and emerging roles. Nat. Rev. Genet. 14, 447-459 (2013).

104. Jiang, H. et al. Markov State Models Reveal a Two-Step Mechanism of miRNA Loading into the Human Argonaute Protein: Selective Binding followed by Structural Rearrangement. PLoS Comput. Biol. 11, e1004404 (2015).

105. Iwasaki, S. et al. Hsc70/Hsp90 chaperone machinery mediates ATP-dependent RISC loading of small RNA duplexes. Mol. Cell 39, 292-299 (2010).

106. Kim, Y. \& Kim, V. N. MicroRNA Factory: RISC Assembly from Precursor MicroRNAs. Mol. Cell 46, 384-386 (2012). 
107. Shen, J. \& Hung, M.-C. Signaling-Mediated Regulation of MicroRNA Processing. Cancer Res. 75, 783-791 (2015).

108. Shen, J. et al. EGFR modulates microRNA maturation in response to hypoxia through phosphorylation of AGO2. Nature 497, 383-387 (2013).

109. Du, J. et al. HIF-1a deletion partially rescues defects of hematopoietic stem cell quiescence caused by Cited2 deficiency. Blood 119, 2789-2798 (2012).

110. Almog, N. et al. Consensus micro RNAs governing the switch of dormant tumors to the fast-growing angiogenic phenotype. PloS One 7, e44001 (2012).

111. Davis, B. N., Hilyard, A. C., Lagna, G. \& Hata, A. SMAD proteins control DROSHAmediated microRNA maturation. Nature 454, 56-61 (2008).

112. Zhang, J. et al. miR-221/222 promote malignant progression of glioma through activation of the Akt pathway. Int. J. Oncol. 36, 913-920 (2010).

113. Garofalo, M. et al. miR-221\&222 Regulate TRAIL Resistance and Enhance Tumorigenicity through PTEN and TIMP3 Downregulation. Cancer Cell 16, 498-509 (2009).

114. Chun-Zhi, Z. et al. MicroRNA-221 and microRNA-222 regulate gastric carcinoma cell proliferation and radioresistance by targeting PTEN. BMC Cancer 10, 367 (2010).

115. Kim, Y.-K. et al. Functional links between clustered microRNAs: suppression of cell-cycle inhibitors by microRNA clusters in gastric cancer. Nucleic Acids Res. 37, 1672-1681 (2009).

116. Grimson, A. et al. MicroRNA Targeting Specificity in Mammals: Determinants Beyond Seed Pairing. Mol. Cell 27, 91-105 (2007).

117. Chen, L. et al. Downregulation of miR-221/222 sensitizes glioma cells to temozolomide by regulating apoptosis independently of p53 status. Oncol. Rep. 27, 854-860 (2012).

118. Pineau, P. et al. miR-221 overexpression contributes to liver tumorigenesis. Proc. Natl. Acad. Sci. U. S. A. 107, 264-269 (2010).

119. Fernandez, S. et al. miR-340 inhibits tumor cell proliferation and induces apoptosis by targeting multiple negative regulators of p27 in non-small cell lung cancer. Oncogene 34, 3240-3250 (2015).

120. Frenquelli, M. et al. MicroRNA and proliferation control in chronic lymphocytic leukemia: functional relationship between miR-221/222 cluster and p27. Blood 115, 3949-3959 (2010). 
121. Le, T. V. T., Seo, Y., Ryu, C. J., Lee, H. R. \& Park, H.-J. Increased expression of p27 is associated with the cisplatin resistance in gastric cancer cell line YCC-3. Arch. Pharm. Res. 33, 1127-1132 (2010).

122. Sarkar, S. et al. Down-regulation of miR-221 inhibits proliferation of pancreatic cancer cells through up-regulation of PTEN, p27kip1, p57kip2, and PUMA. Am. J. Cancer Res. 3, 465-477 (2013).

123. Chu, I. M., Hengst, L. \& Slingerland, J. M. The Cdk inhibitor p27 in human cancer: prognostic potential and relevance to anticancer therapy. Nat. Rev. Cancer 8, 253-267 (2008).

124. Chen, Y. et al. Quiescence and attenuated DNA damage response promote survival of esophageal cancer stem cells. J. Cell. Biochem. 113, 3643-3652 (2012).

125. Di Martino, M. T. et al. In vitro and in vivo anti-tumor activity of miR-221/222 inhibitors in multiple myeloma. Oncotarget 4, 242-255 (2013).

126. Lwin, T. et al. Cell adhesion induces p27Kip1-associated cell-cycle arrest through downregulation of the SCFSkp2 ubiquitin ligase pathway in mantle-cell and other non-Hodgkin B-cell lymphomas. Blood 110, 1631-1638 (2007).

127. Medina, R. et al. MicroRNAs 221 and 222 Bypass Quiescence and Compromise Cell Survival. Cancer Res. 68, 2773-2780 (2008).

128. Wagner, M. et al. Metabolic stabilization of p27 in senescent fibroblasts correlates with reduced expression of the F-box protein Skp2. Exp. Gerontol. 37, 41-55 (2001). 


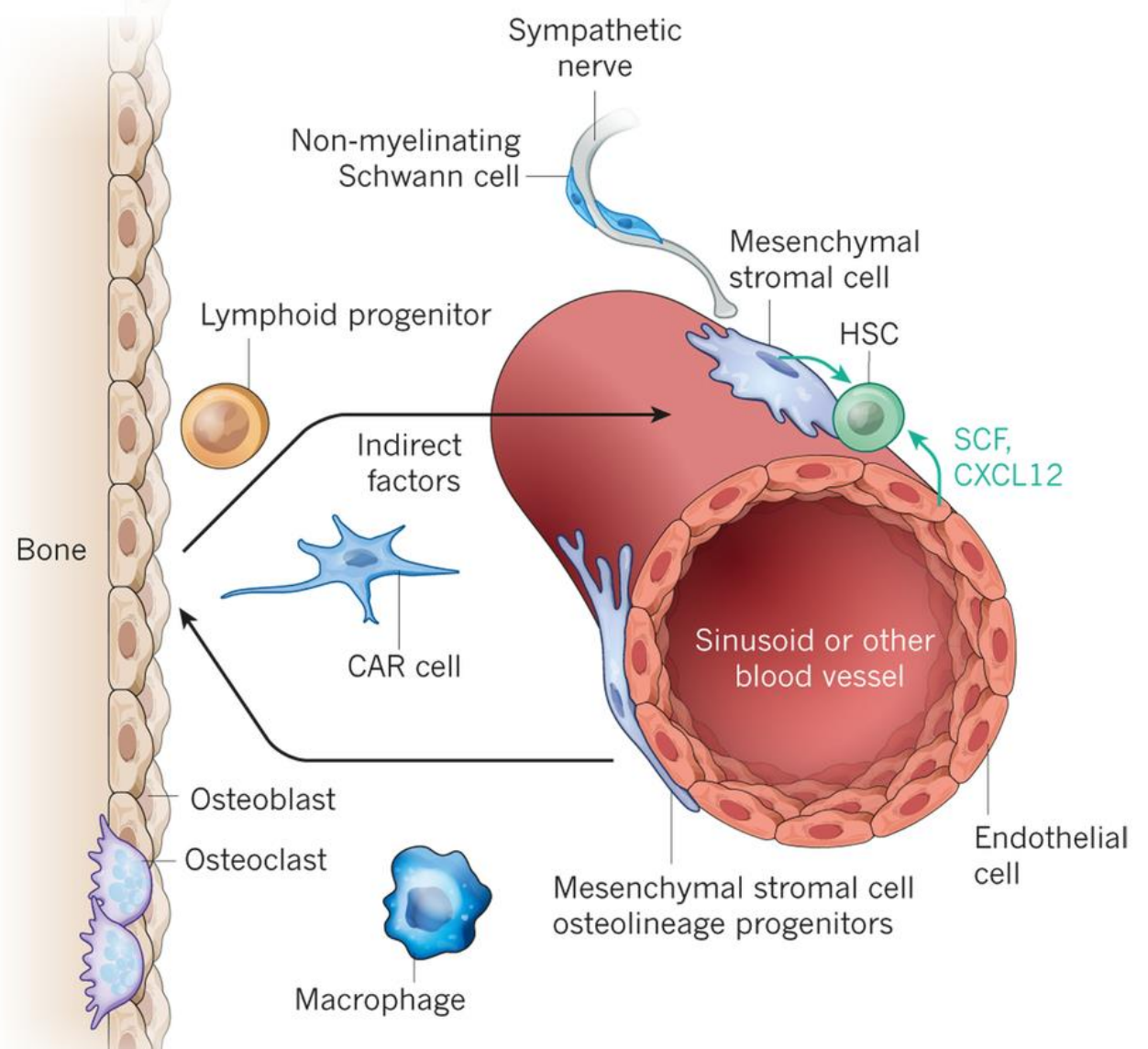

Figure 1. Haematopoietic stem cells (HSCs) and restricted haematopoietic progenitors occupy distinct niches in the bone marrow.

Morrison, S. J. \& Scadden, D. T. The bone marrow niche for haematopoietic stem cells. Nature 505, 327-334 (2014).

Permissions License number: $\mathbf{3 8 2 6 8 0 0 6 0 2 6 8 5}$ 


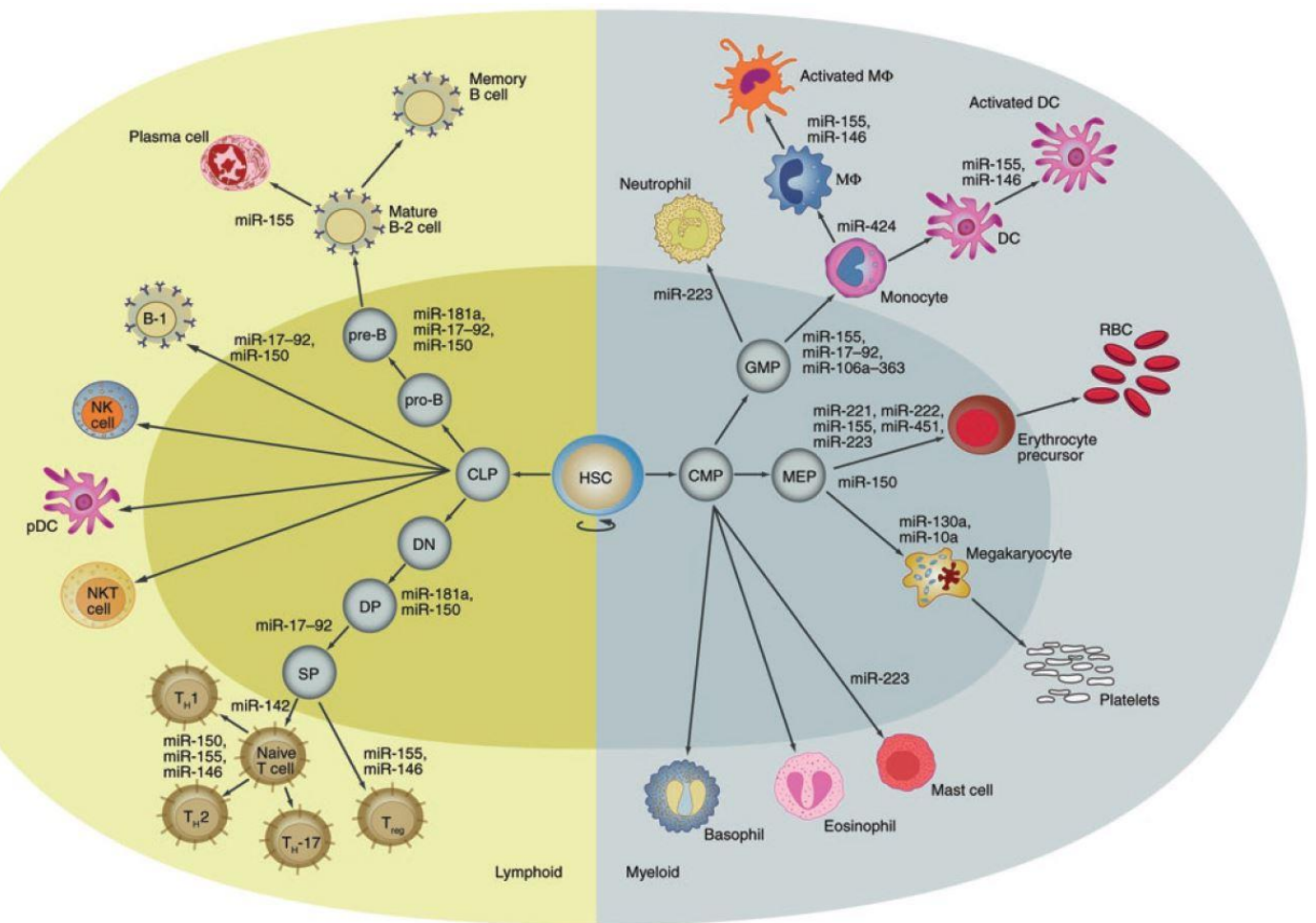

Figure 2. Involvement of miRNAs in hematopoiesis and immune system function

Baltimore, D., Boldin, M. P., O'Connell, R. M., Rao, D. S. \& Taganov, K. D. MicroRNAs: new regulators of immune cell development and function. Nat. Immunol. 9, 839-845 (2008).

Permissions License number: $\mathbf{3 8 2 7 3 8 1 1 6 9 8 5 4}$ 


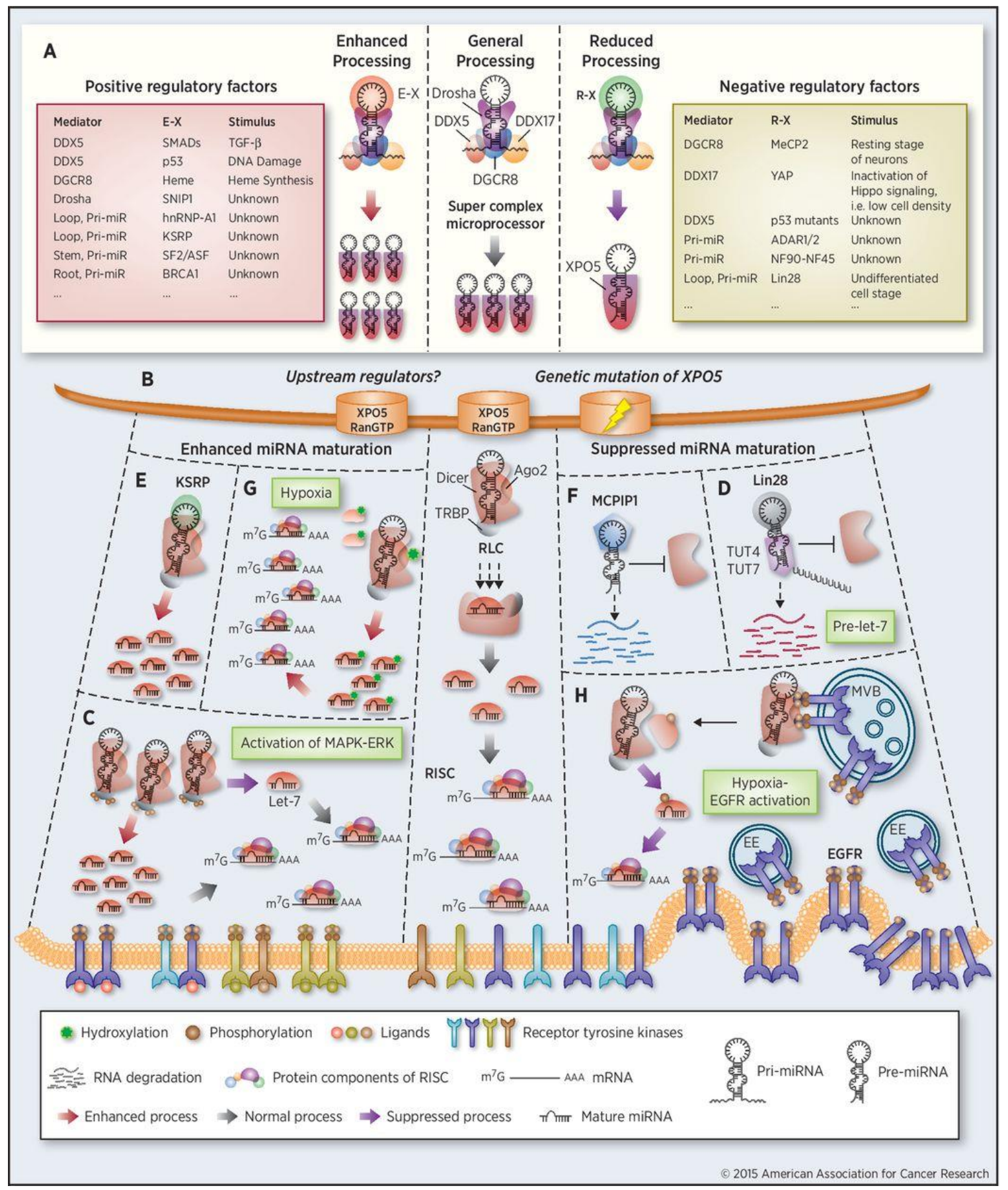

Figure 3. Canonical linear processing and alternative routes of miRNA maturation

Shen, J. \& Hung, M.-C. Signaling-Mediated Regulation of MicroRNA Processing. Cancer Res. 75, 783791 (2015).

Permissions License number: $\mathbf{3 8 2 7 3 8 0 3 1 0 4 5 4}$ 


\section{Chapter II}

\section{Modeling chemotherapy resistant leukemia in vitro}

Slone, William L. ${ }^{1, \dagger}$, Moses, Blake S. ${ }^{1, \dagger}$, Evans, Rebecca ${ }^{1}$, Piktel, Debbie ${ }^{1}$, Martin, Karen H. ${ }^{1,2}$, Petros, William ${ }^{1}$, Craig, Michael ${ }^{1}$, and Gibson, Laura F. ${ }^{1,3}$

†These authors contributed equally to this work

${ }^{1}$ Alexander B. Osborn Hematopoietic Malignancy and Transplantation Program of the Mary Babb Randolph Cancer Center, ${ }^{2}$ Department of Neurobiology and Anatomy and ${ }^{3}$ Department of Microbiology, Immunology and Cell Biology, Robert C. Byrd Health Sciences Center, West Virginia University School of Medicine, USA

KEYWORDS: Leukemia, Chemotherapy, Microenvironment, Resistance, Niche, Marrow

This work has been published as a manuscript in JoVE:

Slone WL, Moses BS, Evans R, Piktel D, Martin KH, Petros W, Craig M, Gibson LF. Modeling Chemotherapy Resistant Leukemia In Vitro. J Vis Exp JoVE 2016.

Video protocol can be found at:

http://www.jove.com/video/53645/modeling-chemotherapy-resistant-leukemia-in-vitro 
SHORT ABSTRACT: The current report summarizes a protocol that can be utilized to model the influence of the bone marrow microenvironment niche on leukemic cells with emphasis placed on enrichment of the most chemoresistant subpopulation.

LONG ABSTRACT: It is well established that the bone marrow microenvironment provides a unique site of sanctuary for hematopoietic diseases that both initiate and progress in this site. The model presented in the current report utilizes human primary bone marrow stromal cells and osteoblasts as two representative cell types from the marrow niche that influence tumor cell phenotype. The in vitro co-culture conditions described for human leukemic cells with these primary niche components support the generation of a chemoresistant subpopulation of tumor cells that can be efficiently recovered from culture for analysis by diverse techniques. A strict feeding schedule to prevent nutrient fluxes followed by gel type 10 cross-linked dextran (G10) particles recovery of the population of tumor cells that have migrated beneath the adherent bone marrow stromal cells (BMSC) or osteoblasts (OB) generating a "phase dim" (PD) population of tumor cells, provides a consistent source of purified therapy resistant leukemic cells. This clinically relevant population of tumor cells can be evaluated by standard methods to investigate apoptotic, metabolic, and cell cycle regulatory pathways as well as providing a more rigorous target in which to test novel therapeutic strategies prior to pre-clinical investigations targeted at minimal residual disease. 
INTRODUCTION: The overall goal of the method described is to provide an efficient, costeffective in vitro approach that supports investigation of the mechanisms that underlie bone marrow supported survival of leukemic cells during chemotherapy exposure. It is well documented that surviving residual tumor cells that persist after treatment contribute to relapse of disease that is often more aggressive than that at diagnosis and is often less effectively treated $^{1-8}$. Models that include leukemic cells in isolation, such as those limited to culture of cells in media alone, for testing of therapeutic approaches do not factor in these critical signals, or the heterogeneity of disease that occurs in response to availability of niche derived cues in which tumor cell subpopulations with very specific interactions with niche cells derive enhanced protection. Standard 2D co-culture models that co-culture bone marrow derived stromal cells and leukemic cells have somewhat addressed the contribution of the marrow niche and have shown that interaction with bone marrow microenvironment cells increases their resistance to chemotherapy and alters their growth characteristics ${ }^{9-14}$. These models however often fail to recapitulate long term survival of tumor cells and do not accurately inform the outcomes associated with the most resistant leukemic cell populations that contribute to MRD. In vivo models remain critical and define the "gold standard" for investigation of innovative therapies prior to clinical trials but they are often challenged by the time and cost required to test hypotheses related to resistant tumors and relapse of disease. As such, development of more informative 2D models would be of benefit for pilot investigations to better inform the design of subsequent murine based pre-clinical design.

The $2 \mathrm{D}$ in vitro model presented in this report lacks the complexity of the true in vivo microenvironment, but provides a cost effective and reproducible means to interrogate tumor interactions with the microenvironment that lends itself specifically to enrichment of the 
chemoresistant subpopulation of tumor cells. This distinction is valuable as evaluation of the entire population of tumor cells may mask the phenotype of a minor group of therapy resistant tumor cells that comprise the most important target. An additional advantage is the scalability of the model to fit the analysis of interest. Bulk cultures can be established for those analyses requiring significant recovery of tumor cells, while small scale co-cultures in multi-well plates can be utilized for PCR based analysis or microscopy based evaluations.

Based on this need we developed an in vitro model to address the heterogeneity of disease that is characteristic of B-lineage acute lymphoblastic leukemia (ALL). We demonstrate that ALL cells, which share many characteristics in common with their healthy counterparts, localize to distinct compartments of BMSC or OB co-culture. Three populations of tumor cells are generated that have distinct phenotypes that are valuable for investigation of therapeutic response. Specifically, we demonstrate that (ALL) cells recovered from the "phase dim" (PD) population of co-culture are consistently refractory to therapy with survival that approximates tumor cells that have not been exposed to cytotoxic agents. These ALL cells, from either established cell lines or primary patient samples, migrate beneath adherent stromal cells or osteoblast layers but can be captured following trypsinization of cultures and separation of cell types by utilization of gel type 10 cross-linked dextran (G10) particle columns ${ }^{15}$.

Here we present a setup of a 2D co-culture that can be employed to model interactions between bone marrow microenvironment stromal cells (BMSC/OB) and leukemic cells. Of particular importance is the observation that leukemic cells form three spatial subpopulations relative to the stromal cell monolayer and that the PD population represents a chemotherapy resistant tumor population due to its interaction with the BMSC or OB. Furthermore, we demonstrate how 
to effectively isolate the leukemic cell populations by G10 columns. Of note, we have found that isolation of these subpopulations allows for downstream analysis of the most resistant PD population to determine potential modes of resistance that are conferred to these cells due to their interaction with the bone marrow microenvironment stromal cells or osteoblasts. Techniques that we have utilized downstream of this co-culture and isolation model include flow cytometric evaluation, proteomic analysis and targeted protein expression evaluation as well as more recently developed laser ablation electrospray ionization (LAESI) and Seahorse analysis to evaluate metabolic profiles. Through use of this model in combination with the techniques above we have found that the PD population of leukemic cells has a chemotherapy resistant phenotype that is unique when compared to leukemic cells cultured in media alone or those recovered from the other subpopulations in the same co-culture. As such, this model lends itself to more rigorous evaluation to test strategies targeting the most chemotherapy resistant leukemic cells which derive their resistant phenotype through interaction with the bone marrow microenvironment.

\section{Protocol:}

\section{Advanced preparation}

1.1) Preparing G10 particles.

1.1.1) Prepare G10 slurry by adding $50 \mathrm{ml} 1 \times$ PBS to $10 \mathrm{~g}$ G10 particles. Mix by inversion and allow G10 to settle out of phosphate buffered saline (PBS) at $4^{\circ} \mathrm{C}$ overnight.

1.1.2) The day of G10 column separation, aspirate PBS from settled G10 particles and add $50 \mathrm{ml}$ fresh PBS. Mix by inversion. Repeat twice, adding $50 \mathrm{ml}$ fresh PBS to settled G10 particles and store at $4^{\circ} \mathrm{C}$ until ready to use.

1.2) Culturing BMSC and OB. 
1.2.1) Both $\mathrm{BMSC}$ or $\mathrm{OB}$ are maintained at $37{ }^{\circ} \mathrm{C}$ in $6 \% \mathrm{CO}_{2}$ and grown on $10 \mathrm{~cm}$ tissue culture plates until $90 \%$ confluency is reached.

1.2.2) BMSC or OB cells are trypsinized and split $1: 2$ onto new $10 \mathrm{~cm}$ plates. The cells are grown to these standards until needed for leukemic co-culturing.

\section{Establishing and maintaining co-culture}

2.1) Add $5-20 \times 10^{6}$ leukemic cells in $10 \mathrm{ml}$ of tumor specific culture media onto an $80-90 \%$ confluent BMSC or OB plate.

NOTE: Our lab maintains co-cultures at $37^{\circ} \mathrm{C}$ in $5 \% \mathrm{O}_{2}$ to better recapitulate the bone marrow microenvironment which has been shown to range from 1 to $7 \%{ }^{16-18}$. However, maintaining co-cultures at this oxygen tension is not critical for the establishment of the three leukemic subpopulations and is at the discretion of the lab.

2.2) Every $4^{\text {th }}$ day remove all but $1 \mathrm{ml}$ of media (including leukemic cells in suspension) and replace with $9 \mathrm{ml}$ fresh leukemic culture media.

NOTE: When removing $9 \mathrm{ml}$ of media from plate, be careful not to disturb the BMSC or OB adherent layer. Remove media by tilting plate to the side and aspirate media in the corner of the plate. Additionally, when adding fresh media, be sure to add drop wise in the corner of the plate against the sidewall to ensure minimal disruption of the BMSC or OB adherent layer.

2.3) After the $12^{\text {th }}$ day of co-culture, rinse leukemic cells from BMSC or OB layer by pipetting culture media from dish up and down gently over the dish approximately 5 to 10 times and then collect in $15 \mathrm{ml}$ conical tube. Reseed onto new $80-90 \%$ confluent BMSC or OB plate as described in step 2.1.

NOTE: The gentle rinsing of the co-culture as described in step 2.3 will remove $S$ and PB leukemic cells without disrupting the BMSC or OB monolayer. This allows only tumor cells to be transferred to the next co-culture plate. This 12 day cycle can be repeated as many times as needed based on user needs.

\section{Preparing G10 bead columns}

NOTE: If sterile downstream analysis or culturing is required following G10 column separation the following steps should be carried out using sterile technique and G10 columns should be setup in a sterile biological hood.

3.1) Pre-warm cell culture media to $37^{\circ} \mathrm{C}$ in water bath ( $30 \mathrm{ml}$ per column).

3.2) Using a $10 \mathrm{ml}$ disposable syringe, remove and discard plunger.

3.3) Add glass wool to syringe.

3.3.1) Using tweezers, pull apart glass wool into thin loose strands. Add multiple layers of lightly packed glass wool to the syringe until $2 / 3$ of the syringe is filled with glass wool. 
NOTE: The glass wool is crucial to prevent loose G10 particles from contaminating the leukemic cell collection. Make sure glass wool is packed enough to support the G10 particles, but not too densely packed to block media flow through the column.

3.4) Attach 1-way stopcock to the tip of the syringe in the closed position.

3.5) Clamp syringe column to ring stand high enough so a $50 \mathrm{ml}$ conical tube (collection tube) can be placed underneath stopcock. Place collection tube under syringe column.

3.6) Using a $10 \mathrm{ml}$ pipette add, drop-wise, G10 particles resuspended in PBS to the column on top of the glass wool. Continue adding G10 particles until a $\sim 2 \mathrm{ml}$ pellet (as measured by graduations on syringe) of G10 particles forms on top of the glass wool.

3.7) Equilibrate the G10 column with pre-warmed media.

3.7.1) Add $2 \mathrm{ml}$ of pre-warmed media to column. Open stopcock valve slowly so that media flows out of the column drop-wise.

3.7.2) Repeat step 3.7.1 until a total of $10 \mathrm{ml}$ of pre-warmed media have been ran across the column.

NOTE: If G10 particles are seen in the flow through in the collection tube, either 1) add more G10 particles to maintain 2 $\mathrm{ml}$ pellet making sure no additional G10 particles escape from the column or 2) replace column with an unused one and repeat steps 3.5-3.7.1.

3.7.4) Once the pre-warmed media drains from the column, close the stopcock and discard collection tube with flow through.

3.7.5) Add new collection tube under column. Column is ready to be loaded with media + cell mixture.

NOTE: Columns should be used immediately and not allowed to dry.

\section{Separating 3 subpopulations within co-culture}

4.1) Collection of suspension (S) tumor subpopulation.

4.1.1) Aspirate media from co-culture plate with pipette and gently reapply the same media to rinse the plate and collect media containing leukemic cells in a $15 \mathrm{ml}$ conical tube. The leukemic cells collected are the S subpopulation.

4.2) Collection of Phase Bright (PB) tumor subpopulation.

4.2.1) Add $10 \mathrm{ml}$ fresh media back onto co-culture plate. Rinse vigorously by pipetting added media up and down approximately 5 times to remove adherent leukemic cells but not hard enough to dislodge adherent BMSC/OB component. 
4.2.2) Aspirate with pipette and collect media in a $15 \mathrm{ml}$ conical tube. The collected cells are the PB subpopulation.

4.3) Collection of Phase Dim (PD) tumor subpopulation.

4.3.1) Rinse plate with $1 \mathrm{ml}$ PBS to remove remaining media. Trypsinize co-culture plate with $3 \mathrm{ml}$ trypsin and place into $37^{\circ} \mathrm{C}$ incubator for $5 \mathrm{~min}$.

4.3.2) Remove plate out of incubator and gently tap sides of the plate to dislodge adherent $\mathrm{BMSC} / \mathrm{OB}$.

4.3.3) Add $1 \mathrm{ml}$ fetal bovine serum (FBS) and pipette up and down 3-5 times to break apart large cell aggregates.

4.3.4) Collect media with cells in a $15 \mathrm{ml}$ conical tube. These cells are the unpurified PD subpopulation with BMSC/OB as well.

4.4) Centrifuge 3 isolated subpopulations at $400 \mathrm{x} \mathrm{g}$ for $7 \mathrm{~min}$. Aspirate and discard supernatant then individually resuspend pellets in $1 \mathrm{ml}$ pre-warmed media. Cells are ready to be loaded onto a G10 column.

\section{Loading co-culture cells onto G10 column}

NOTE: Make sure stopcock is completely closed before adding media containing cells to G10 column. Also, each subpopulation must be ran over a separate G10 column so not to introduce any bias between populations in downstream analysis.

5.1) Using a $1000 \mu \mathrm{l}$ pipette, add $1 \mathrm{ml}$ of each cell subpopulation in pre-warmed media to a separate G10 column drop-wise. The media containing the cells should remain on top or within $\mathrm{G} 10$ pellet.

5.2) Allow cells to incubate on $\mathrm{G} 10$ pellet for $20 \mathrm{~min}$ at RT.

NOTE: Stopcock remains closed for duration of incubation.

\section{Collecting leukemic cells from G10 column}

6.1) Add 1-3 ml pre-warmed media to each G10 column.

6.2) Open stopcock valve and allow media to slowly exit the column drop-wise.

NOTE: It is crucial to maintain a slow flow rate from the column or the G10 pellet containing $\mathrm{BMSC} / \mathrm{OB}$ can wash out of the column and contaminate the isolated leukemic cells. 
6.3) Continue to add pre-warmed media in small increments $(1-2 \mathrm{ml})$ to $\mathrm{G} 10$ column until a total of 15 to $20 \mathrm{ml}$ has run through column and has been collected. Close stopcock valve and cap collection tube.

NOTE: If a G10 particle pellet is seen at the bottom of collection tube, gently remove media from the tube leaving G10 particle pellet undisturbed and transfer to new tube.

6.4) Centrifuge collected media at $400 \times \mathrm{g}$ for $7 \mathrm{~min}$ at RT.

6.5) Remove supernatant and resuspend cell pellet in buffer appropriate for downstream application.

6.6) Cells are now a pure population of leukemic cells free of BMSC or OB contamination and are ready to be applied to downstream applications at user discretion.

NOTE: Leukemic cell viability should remain unchanged when passing cells through G10 columns.

Representative results: Successful setup and culture of this co-culture model will result in the establishment of 3 subpopulations of leukemic cells relative to the adherent BMSC or OB monolayer. Figure 1 shows how ALL cells seeded into a BMSC monolayer initially appear as only a single population of suspended leukemic cells. Over the course of 4 days leukemic cells interact with the BMSC to form 3 spatial subpopulations of leukemic cells (suspended (S), phase bright (PB), and phase dim (PD)). While the 3 subpopulations of tumor cells can commonly be seen after 24 hours of co-culture with BMSC or OB we co-culture the cells for 4 days to allow the full dynamics and interactions between the leukemic cells and BMSC/OB cells to take place before any manipulation or experimentation takes place (Figure 1). Also, note that we maintain the co-cultures at an oxygen tension of $5 \%$ to recapitulate bone marrow physiology, which has been reported to range from $1-7 \%{ }^{16-18}$.

A vast majority of downstream analysis requires the separation of the leukemic cells from the BMSC or OB. To achieve this we use G10 columns to harvest a pure population of leukemic 
cells (Figure 2A). Following trypsinization of BMSC and PD REH cells a mixed population is seen by two distinct forward/side populations by flow cytometry (Figure 2B, top panel). Following G10 separation a pure population of only REH ALL cells is recovered, which was confirmed by forward/side scatter flow cytometry (Figure2B, bottom panel).

Use of this co-culture model and the ability to isolate leukemic cells from 3 subpopulations when in co-culture with BMSC or OB allows for interrogation of leukemic cell phenotype with relation to its spatial location relative to the adherent BMSC or OB monolayer. Of particular interest, is that ALL cells recovered from the PD population of a BMSC or OB co-culture have little to no cell death following exposure to cytotoxic chemotherapy (Figure $3 \mathbf{A}, \mathbf{B}$ ).

Discussion: Minimal residual disease (MRD) which contributes to relapse of disease continues to be a major clinical challenge in the treatment of aggressive refractory ALL, as well as, a host of other hematological malignancies. The bone marrow microenvironment is the most common site of relapse in $A L L^{3,8}$. As such, models that model the bone marrow microenvironment are vital tools to test hypotheses related to leukemic tumor cell survival and maintenance of MRD during chemotherapy exposure. While mouse models define the gold standard for testing questions related to drug efficacy, 2D co-culture continues to be a cost effective methodology for testing hypotheses and drug strategies related to bone morrow microenvironment support of leukemic cell survival. Many groups have shown that co-culture of leukemic cells with BMSC or OB provides a survival advantage when challenged with chemotherapy agents $9,10,12-14,19-21$. Work modeling normal immature CD34+ hematopoietic cells in co-culture with mesenchymal stem cells (MSC) revealed that hematopoietic cells will interact with the adherent monolayer of MSCs to form three distinct spatial populations of hematopoietic cells ${ }^{22,23}$. Proliferation and 
differentiation of the CD34+ cells was effected relative to their location within the co-culture ${ }^{22}$. We have expanded on this observation to test questions related to bone marrow microenvironment stromal cell support of a resistant population of tumor cells within a 2D coculture and its isolation for downstream analysis.

Unlike standard 2D co-culture models which typically sample leukemic cells by removal of the suspended tumor, our model shows that co-culture represents a more dynamic interaction in which leukemic cells in co-culture with BMSC or OB form three subpopulations relative to the BMSC or OB monolayer (Figure 1). The tumor subpopulations that form are suspended (S) tumor, which is freely floating in the media; phase bright (PB) that is adhered to the surface of the BMSC or OB; and the phase dim (PD) which have buried beneath the BMSC or OB monolayer (Figure 1). In this model, we found that a strict feeding and reseeding schedule is important to achieve consistent results in a co-culture model and therefore we feed the cocultures at 4 day intervals and transfer tumor to new BMSC or OB monolayers every 12 days. This may require modification for alternative tumor types as needed. The number of tumor cells that will migrate below the BMSC or OB to form the PD population may vary between different leukemic cells. This can be a limitation of the model, when the number of PD tumor cells are low making it difficult to collect enough cells for downstream analysis. In some cases this problem can be overcome by establishing replicate co-cultures to allow for pooling of the three individual subpopulations.

As this model relies on tumor cell interaction with the BMSC or OB it is important to have an effective method to remove stromal cell contamination to address specific biology of the leukemic cells. To accomplish this separation of tumor cells from stroma we use G10 columns. Proper setup and use of these columns is crucial for isolation of pure tumor populations for 
downstream analysis. As highlighted in Figure 2B, proper execution of the G10 column separation results in recovery of tumor cells at greater than $99 \%$ purity. This allows for downstream analysis of the leukemic cells without complication of interpretation of results that would result from stromal cell contamination. It is important to note that all leukemic cell types whether cell lines or primary patient samples will vary slightly in their ability to pass through the G10 columns. Before use in large scale experiments users should determine the number of leukemic cells they must input to recover the desired amount needed for their specific downstream needs. In addition, the amount of wash media ran over the G10 column post incubation can be increased to try and increase the number of cells recovered. Care should be taken to insure that the additional washes do not cause stromal cell contamination which can be determined post wash by cell counts or flow cytometry analysis of flow through.

In establishing this model, we observed that leukemic cells recovered from the PD population have increased viability compared to leukemic cells grown in media alone, as well as to those recovered from the S or PB populations in the same co-culture when exposed to cytotoxic chemotherapy (Figure $3 \mathrm{a}-\mathrm{b}$ ). This is significant because it represents a population of leukemic cells in vitro that derive pronounced protection from chemotherapy. This provides a useful tool to test treatment strategies aimed at targeting the most resistant tumor population, which is supported by the bone marrow microenvironment. Furthermore, because these leukemic cells are so well protected by the BMSC or OB co-culture it is amenable to in vitro combination treatment strategies, that in media alone or standard co-culture models would appear to or would completely kill the tumor which is not always representative of effects seen in resistant microenvironment supported leukemic populations. 
Finally, we believe that use of this model can provide valuable insight into the interactions between BMSC/OB, and leukemic cells that are responsible for resistance to chemotherapy treatment, lead to MRD, and subsequently relapse. This model provides an in vitro platform to design experiments which will better inform downstream pre-clinical models. Though we show use of this model to test interactions between bone marrow stromal cells and ALL derived leukemic cells, we are hopeful that future directions and applications of this model will be useful in a variety of malignancies in which the bone marrow microenvironment provides a site of sanctuary for tumors during chemotherapeutic intervention.

Acknowledgments: Supported by National Institutes of Health (NHLBI) R01 HL056888 (LFG), National Cancer Institute (NCI) RO1 CA134573NIH (LFG), P30 GM103488 (LFG), WV CTRIDEA NIH 1 U54 GM104942, the Alexander B. Osborn Hematopoietic Malignancy and Transplantation Program, and the WV Research Trust Fund. We are grateful for the support of Dr. Kathy Brundage and the West Virginia University Flow Cytometry Core Facility, supported by NIH S10-OD016165 and the Institutional Development Award (IDeA) from the NIH Institute of General Medical Sciences of the National Institutes of Health (CoBRE P30GM103488 and INBRE P20GM103434).

Disclosures: The authors have no competing financial interests. 


\section{References:}

1. Ayala, F., Dewar, R., Kieran, M. \& Kalluri, R. Contribution of bone microenvironment to leukemogenesis and leukemia progression. Leukemia 23, (12) 2233-2241 (2009). doi:10.1038/leu.2009.175

2. Coustan-Smith, E., Sancho, J., et al. Clinical importance of minimal residual disease in childhood acute lymphoblastic leukemia. Blood 96, (8) 2691-2696 (2000).

3. Gaynon, P. S., Qu, R. P., et al. Survival after relapse in childhood acute lymphoblastic leukemia. Cancer 82, (7) 1387-1395 (1998). doi:10.1002/(SICl)10970142(19980401)82:7<1387::AID-CNCR24>3.0.CO;2-1

4. Kikuchi, M., Tanaka, J., et al. Clinical significance of minimal residual disease in adult acute lymphoblastic leukemia. Int. J. Hematol. 92, (3) 481-489 (2010). doi:10.1007/s12185-0100670-1

5. Krause, D. S., Scadden, D. T. \& Preffer, F. I. The hematopoietic stem cell niche-home for friend and foe? Cytometry B Clin. Cytom. 84B, (1) 7-20 (2013). doi:10.1002/cyto.b.21066

6. Meads, M. B., Hazlehurst, L. A. \& Dalton, W. S. The Bone Marrow Microenvironment as a Tumor Sanctuary and Contributor to Drug Resistance. Clin. Cancer Res. 14, (9) 2519-2526 (2008). doi:10.1158/1078-0432.CCR-07-2223

7. Nguyen, K., Devidas, M., et al. Factors Influencing Survival After Relapse From Acute Lymphoblastic Leukemia: A Children's Oncology Group Study. Leuk. Off. J. Leuk. Soc. Am. Leuk. Res. Fund UK 22, (12) 2142-2150 (2008). doi:10.1038/leu.2008.251

8. Szczepanek, J., Styczyński, J., Haus, O., Tretyn, A. \& Wysocki, M. Relapse of Acute Lymphoblastic Leukemia in Children in the Context of Microarray Analyses. Arch. Immunol. Ther. Exp. (Warsz.) 59, (1) 61-68 (2011). doi:10.1007/s00005-010-0110-1

9. Boyerinas, B., Zafrir, M., Yesilkanal, A. E., Price, T. T., Hyjek, E. M. \& Sipkins, D. A. Adhesion to osteopontin in the bone marrow niche regulates lymphoblastic leukemia cell dormancy. Blood 121, (24) 4821-4831 (2013). doi:10.1182/blood-2012-12-475483

10. Bradstock, K., Bianchi, A., Makrynikola, V., Filshie, R. \& Gottlieb, D. Long-term survival and proliferation of precursor-B acute lymphoblastic leukemia cells on human bone marrow stroma. Leukemia 10, (5) 813-820 (1996).

11. Clutter, S. D., Fortney, J. \& Gibson, L. F. MMP-2 is required for bone marrow stromal cell support of pro-B-cell chemotaxis. Exp. Hematol. 33, (10) 1192-1200 (2005). doi:10.1016/j.exphem.2005.06.022

12. Manabe, A., Murti, K. G., et al. Adhesion-dependent survival of normal and leukemic human B lymphoblasts on bone marrow stromal cells. Blood 83, (3) 758-766 (1994). 
13. Mudry, R. E., Fortney, J. E., York, T., Hall, B. M. \& Gibson, L. F. Stromal cells regulate survival of B-lineage leukemic cells during chemotherapy. Blood 96, (5) 1926-1932 (2000).

14. Tesfai, Y., Ford, J., et al. Interactions between acute lymphoblastic leukemia and bone marrow stromal cells influence response to therapy. Leuk. Res. 36, (3) 299-306 (2012). doi:10.1016/j.leukres.2011.08.001

15. Hathcock, K. S. Depletion of Accessory Cells by Adherence to Sephadex G-10. Curr. Protoc. Immunol.

<http://onlinelibrary.wiley.com/doi/10.1002/0471142735.im0306s08/abstract>

(2001).at

16. Berniakovich, I. \& Giorgio, M. Low oxygen tension maintains multipotency, whereas normoxia increases differentiation of mouse bone marrow stromal cells. Int. J. Mol. Sci. 14, (1) 2119-2134 (2013). doi:10.3390/ijms14012119

17. Chow, D. C., Wenning, L. A., Miller, W. M. \& Papoutsakis, E. T. Modeling pO(2) distributions in the bone marrow hematopoietic compartment. II. Modified Kroghian models. Biophys. J. 81, (2) 685-696 (2001). doi:10.1016/S0006-3495(01)75733-5

18. Holzwarth, C., Vaegler, M., et al. Low physiologic oxygen tensions reduce proliferation and differentiation of human multipotent mesenchymal stromal cells. BMC Cell Biol. 11, 11 (2010). doi:10.1186/1471-2121-11-11

19. O'Leary, H., Akers, S. M., et al. VE-cadherin Regulates Philadelphia Chromosome Positive Acute Lymphoblastic Leukemia Sensitivity to Apoptosis. Cancer Microenviron. Off. J. Int. Cancer Microenviron. Soc. 3, (1) 67-81 (2010). doi:10.1007/s12307-010-0035-6

20. Wang, L., Chen, L., Benincosa, J., Fortney, J. \& Gibson, L. F. VEGF-induced phosphorylation of Bcl-2 influences B lineage leukemic cell response to apoptotic stimuli. Leukemia 19, (3) 344-353 (2005). doi:10.1038/sj.leu.2403643

21. Wang, L., Coad, J. E., Fortney, J. M. \& Gibson, L. F. VEGF-induced survival of chronic lymphocytic leukemia is independent of Bcl-2 phosphorylation. Leukemia 19, (8) 1486-1487 (2005). doi:10.1038/sj.leu.2403837

22. Jing, D., Fonseca, A.-V., et al. Hematopoietic stem cells in co-culture with mesenchymal stromal cells--modeling the niche compartments in vitro. Haematologica 95, (4) 542-550 (2010). doi:10.3324/haematol.2009.010736

23. Jing, D., Wobus, M., Poitz, D. M., Bornhäuser, M., Ehninger, G. \& Ordemann, R. Oxygen tension plays a critical role in the hematopoietic microenvironment in vitro. Haematologica 97, (3) 331-339 (2012). doi:10.3324/haematol.2011.050815 


\section{Figure legends}

Figure 1: ALL cells in co-culture with BMSC or OB form three spatial populations. Our lab uses an in vitro co-culture system to model leukemic cell interactions with bone marrow microenvironment derived stromal cells (BMSC or OB). To establish co-culture, leukemic cells (Red) are seeded onto an $80-90 \%$ confluent monolayer of BMSC or OB (Blue), which is denoted as 'Time 0 '. Co-cultures are maintained at $37^{\circ} \mathrm{C}$ at $5 \%$ oxygen to approximate conditions of the bone marrow microenvironment. Leukemic cells will begin to form 3 subpopulations as early as 24 hours, but to allow for complete interactions to form we allow co-cultures 4 days to establish before utilizing leukemic cells for experiments. By day 4 (right panels), three subpopulations of leukemic cells will form in relation to the adherent monolayer. The schematic (top right) and the phase contrast microscopy (bottom right) show the suspended (S) leukemic cells freely floating in the media; phase bright (PB) leukemic cells which are adhered to the surface of the BMSC or OB monolayer; and the phase dim (PD) leukemic cells that have migrated beneath the BMSC or OB monolayer. Scale bar represents 10 microns.

Figure 2: Use of G10 columns allows for separation of ALL cells from BMSC/OB. (A) Demonstration of the process of using a G10 column to separate ALL cells from BMSC/OB coculture to achieve a pure population of tumor cells for downstream analysis. From left to right, a mixture of ALL cells and BMSC/OB cells is added to the top of the G10 column; (Center) cell mixture will settle in the G10 slurry and should be incubated at RT for 20 min (Note: Stopcock is in the closed position throughout first two steps); (right) leukemic cells are recovered by opening the stopcock and rinsing column with pre-warmed media. (B) Top panel shows before G10 separation that there is a mixed population of cells containing BMSC (blue gate) and REH ALL cells (red gate) by evaluating forward (FSC) and side scatter (SSC) analysis. Bottom panel, 
following G10 separation only the pure population of REH ALL cells (red gate) remain with less than $1 \%$ stromal cell contamination (blue gate).

Figure 3: PD leukemic cells have increased resistance to chemotherapy exposure. SD-1 leukemic cells recovered from the PD population of a BMSC co-culture (A) do not display

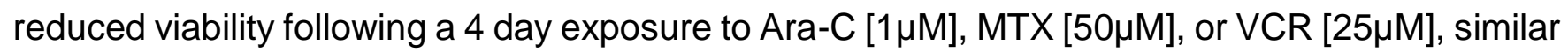
to untreated controls (note that a second dose of Ara-C added at 48 hours to account for any drug loss due to stability). Leukemic cells from the media alone, S, and PB populations have significantly reduced viability as determined by trypan blue exclusion. SD-1 leukemic cells cocultured with OB cells display similar trends in viability (B). Results are expressed as mean \pm SEM. $\left({ }^{*}\right)$ denotes $p<0.05$, unpaired t-test relative to untreated controls. 


\section{Time 0}

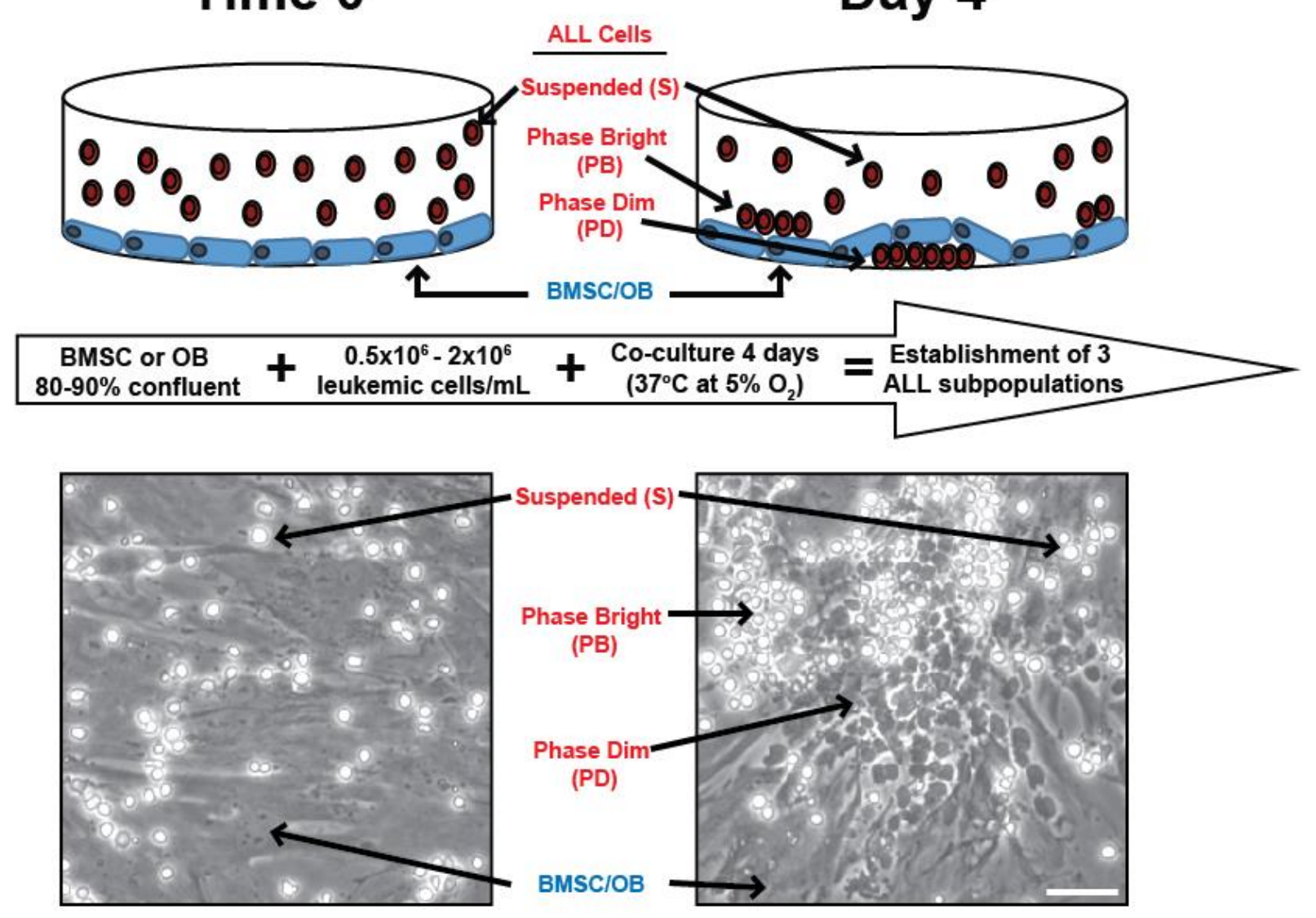

Figure 1: ALL cells in co-culture with BMSC or OB form three spatial populations 

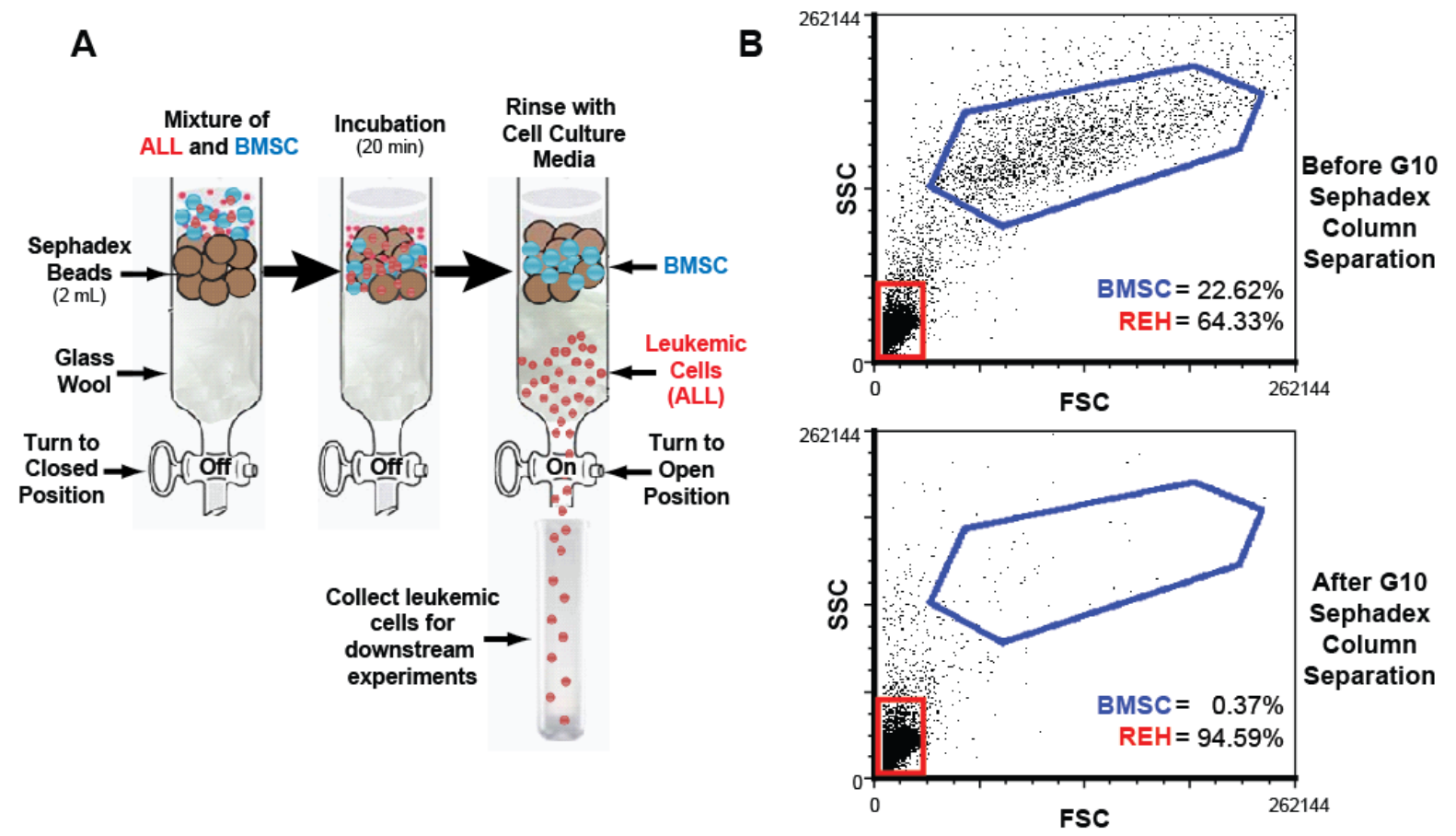

Figure 2: Use of G10 columns allows for separation of ALL cells from BMSC/OB 

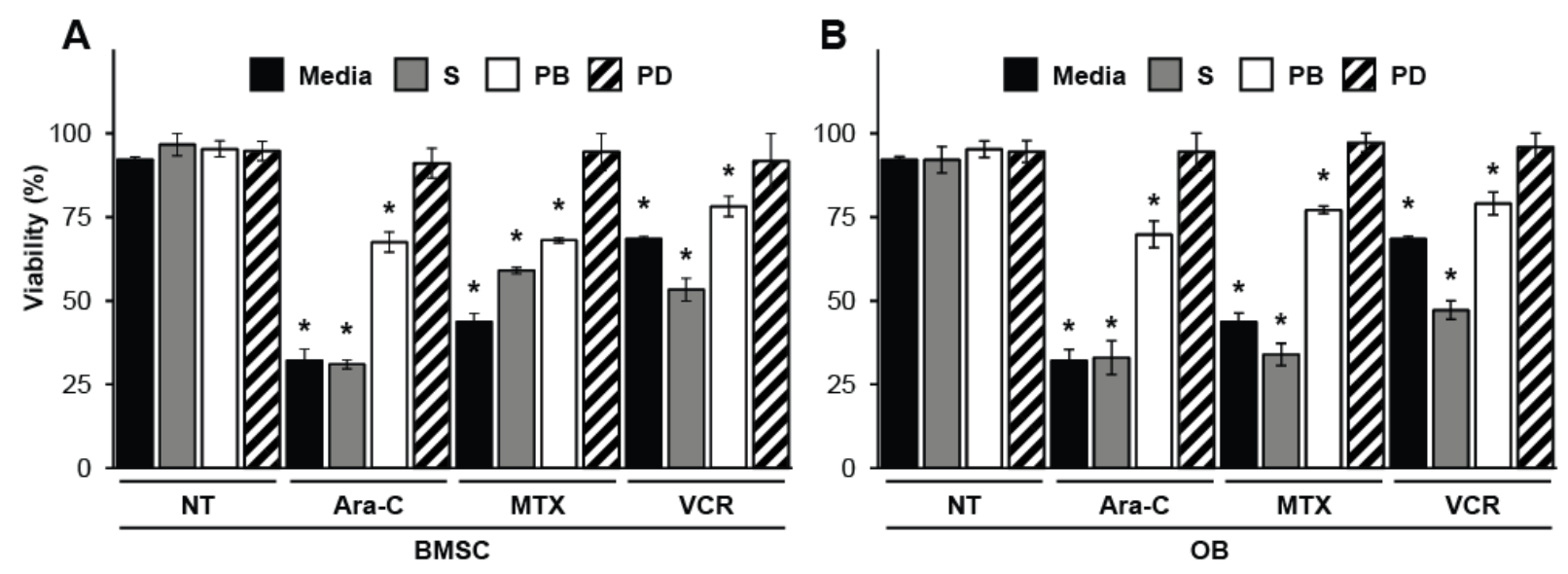

Figure 3: PD leukemic cells have increased resistance to chemotherapy exposure 


\section{Chapter III}

\section{Bone Marrow Microenvironment Modulation of Acute Lymphoblastic Leukemia Phenotype}

Blake S Moses ${ }^{1, \dagger}$, William L Slone ${ }^{1, \dagger}$, Patrick Thomas ${ }^{1}$, Rebecca Evans ${ }^{1}$, Debbie Piktel ${ }^{1}$, Peggi M Angel $^{2}$, Callee M Walsh², Pamela S Cantrell ${ }^{2}$, Stephanie L Rellick ${ }^{3}$, Karen H Martin ${ }^{1,4}$, James W Simpkins ${ }^{3,5,6}$ and Laura F Gibson ${ }^{1,7, *}$

†These authors contributed equally to this work

${ }^{1}$ Alexander B. Osborn Hematopoietic Malignancy and Transplantation Program of the Mary Babb Randolph Cancer Center, Robert C. Byrd Health Sciences Center, West Virginia University School of Medicine, USA; ${ }^{2}$ Protea Bioscience, Morgantown West Virginia, USA;

${ }^{3}$ Department of Physiology \& Pharmacology, West Virginia University School of Medicine, USA; ${ }^{4}$ Department of Neurobiology and Anatomy, West Virginia University School of Medicine, USA; ${ }^{5}$ Center for Basic and Translational Stroke Research, West Virginia University School of Medicine, USA; ${ }^{6}$ Center for Neuroscience, West Virginia University School of Medicine, USA; ${ }^{7}$ Department of Microbiology, Immunology and Cell Biology, Robert C. Byrd Health Sciences Center, West Virginia University School of Medicine, USA

Key Words: Model, Bone Marrow Microenvironment, Leukemia, Chemoresistance, Co-culture

\section{This work has been published as a manuscript in Experimental Hematology:}

Moses BS, Slone WL, Thomas P, Evans R, Piktel D, Angel PM et al. Bone marrow microenvironment modulation of acute lymphoblastic leukemia phenotype. Exp Hematol 2016; 44: 50-59.e2. 


\section{Abstract}

Acute lymphoblastic leukemia (ALL) treatment regimens have dramatically improved the survival of ALL patients. However, chemoresistant minimal residual disease (MRD) that persists following cessation of therapy contributes to aggressive relapse. The bone marrow microenvironment (BMM) is an established "site of sanctuary" for ALL as well as myeloid lineage hematopoietic disease, with signals in this unique anatomical location contributing to drug resistance. Several models have been developed to recapitulate the interactions between the BMM and ALL cells. However, many in vitro models fail to accurately reflect the level of protection afforded to the most resistant sub-set of leukemic cells during co-culture with BMM elements. Pre-clinical in vivo models have advantages, but can be costly, and are often not fully informed by optimal in vitro studies. In the current report we describe an innovative extension of 2D co-culture wherein ALL cells uniquely interact with bone marrow derived stromal cells. Tumor cells in this model bury beneath primary human bone marrow derived stromal cells or osteoblasts, termed "phase dim" (PD) ALL, and exhibit a unique phenotype characterized by altered metabolism, distinct protein expression profiles, increased quiescence, and pronounced chemotherapy resistance. Investigation focused on the PD subpopulation may more efficiently inform pre-clinical design and investigation of MRD and relapse that arises from BMM supported leukemic tumor cells. 


\section{Introduction}

The bone marrow microenvironment (BMM) is a well-established "site of sanctuary" in a host of malignancies, with the most common being of hematopoietic origin[1-8]. In leukemia, the BMM serves as the site of initiation and progression of disease. The BMM is also the most common site of relapse, where leukemic cells respond to signals that are critical for the support of "healthy" steady-state hematopoiesis[2,9,10]. Quiescence, metabolism, and survival pathways are all influenced by the BMM and are pathways known to be co-opted by leukemic cells in the marrow niche to promote treatment resistance[5,7,11]. Studies from many laboratories have furthered our understanding of the interplay between leukemic cells and the BMM, however, relapse of disease continues to be a clinical challenge.

A number of models have been employed to recapitulate the interactions between the bone marrow niche and leukemic cells. In vivo murine models have provided insight and have become standard pre-clinical models in which to test novel therapeutic strategies[12-14]. While in vivo models define the gold standard they are labor intensive, time consuming, and costly to test hypotheses related to relapse of disease. Also, while the BMM can be effectively imaged during disease progression or treatment response, sequential sampling of tumor recovered from the niche is only achievable upon termination of experiments, resulting in evaluation of snapshots in time. Often, ongoing analyses are limited to peripheral circulating tumor that does not reflect the most treatment-resistant subpopulation of interest. Standard 2D in vitro models, while lacking the complexity of the in vivo microenvironment, provide an alternative means to interrogate tumor interactions with the microenvironment. Several groups have demonstrated that 2D coculture with primary human bone marrow stromal cells (BMSC) and osteoblasts (HOB) protect 
human leukemic cells from chemotherapy induced death[2,6,8,11,15]. However, standard in vitro models lack the ability to predict long term survival of sub-sets of resistant leukemic cells, and as a result, are not ideal for evaluation of mechanisms that underlie MRD.

Studies including co-culture of healthy hematopoietic stem cells with mesenchymal stromal cells (MSC) revealed that co-culture models exhibit a more dynamic nature than was previously appreciated. Hematopoietic cells interacted with MSCs in three distinct spatial compartments[16]. The subpopulations included uniquely identifiable suspended (S), phase bright (PB), or phase dim (PD) tumor cells when evaluated by light microscopy. Differences in the hematopoietic stem cell phenotype correlated with location of the hematopoietic cell relative to adherent MSC. Of particular relevance to the current study was the observation that the "phase dim" (PD) population of hematopoietic cells that buried beneath the MSC monolayer was immature and quiescent, two characteristics that have been associated with chemotherapy resistance[16,17]. In addition, it has previously been described that tumor cells closely associated with BMSC or HOB niches in vivo are more resistant to chemotherapy-induced apoptosis[11,18].

Based on previous works we sought to determine whether B- lineage acute lymphoblastic leukemia (ALL) cells, which share many common characteristics with their healthy pre- and proB cell counterparts, would localize to distinct compartments of BMSC or HOB co-culture resulting in distinct subpopulations for investigation of therapeutic resistance. We demonstrate that ALL cells recovered from the PD population of co-culture are phenotypically distinct, and exhibit many characteristics of refractory disease described in vivo. PD derived tumor cells are resistant to therapy with survival that approximates tumor cells that have not been exposed to cytotoxic 
agents. When compared to the other subpopulations recovered from the same co-culture, PD leukemic cells, in addition to their marked survival during chemotherapy exposure, were characterized by increased quiescence and elevated glycolytic activity. Our observations suggest that a biologically relevant model of minimal residual disease can be utilized in vitro that benefits from the inclusion of relevant human derived BMM constituents and targeted evaluation of the most resistant component of ALL. The PD leukemic cells in this model lend themselves to more rigorous drug screening than can be achieved when total leukemic populations are evaluated. Importantly, this novel approach of focus on the PD tumor cells may also more efficiently inform pre-clinical design to investigate MRD and relapse, with specific consideration of resistant subpopulations supported by the BMM.

\section{Materials and Methods}

\section{Cell lines and culture conditions}

Bcr;Abl (Ph+) lymphoblastic cell lines Tom-1 (DSMZ-ACC 578), Nalm-27 (Fujisaki Cancer Center), Nalm-30 (Fujisaki Cancer Center), and Sup-B15 (ATCC-CRL-1929) and (Ph-) REH (ATCC-CRL-8286) and Nalm-6 (ATCC-CRL-1567) were utilized. De-identified primary bone marrow stromal cells (BMSC) were provided by the Mary Babb Randolph Cancer Center (MBRCC) Biospecimen Processing Core and the West Virginia University Department of Pathology Tissue Bank. BMSC cultures were established as previously described[19]. Human osteoblasts (HOB) were purchased (PromoCell, Heidelberg, Germany), and cultured according to the supplier's recommendations. Co-cultures were established by seeding leukemic cells onto $80-90 \%$ confluent BMSC or HOB monolayers. Cultures were fed every 4 days and tumor cells collected for inclusion in experiments with remaining leukemic cells moved to new primary BMSC 
or $\mathrm{HOB}$ adherent layers every 12 days. Cultures were maintained in $5 \% \mathrm{O}_{2}$ to model normal bone marrow oxygen tension, reported to range from 1-7\%[20-22]. Suspended (S) leukemic cells floating freely in the media were removed by gentle pipetting. Phase bright (PB) tumor cells, that were loosely adherent to the top of BMSC or $\mathrm{HOB}$, were harvested by vigorous pipetting. Phase dim (PD) leukemic cells that were buried firmly beneath adherent BMSC or HOB were recovered by trypsinization of the adherent layer and PD tumor. The S, PB, and PD tumor populations were separated from BMSC/HOB by size exclusion with G10 Sephadex (Sigma, St Louis, MO, USA) column separation[23,24].

\section{Microscopy}

Phase contrast images were acquired using a Leica DMIL LED microscope and processed by Leica application suite version 4.0 software (Buffalo Grove, IL, USA). Confocal images were acquired using an upright LSM 510 Zeiss microscope and processed using Zen2009 software (Thornwood, NY, USA). Fluorescence intensity for image acquisition was only altered when fluorescence intensities were not compared between samples.

\section{Subpopulation tracking}

The three ALL subpopulations were isolated from co-culture as described above. Each subpopulation (S, PB and PD) was individually stained with CellTracker ${ }^{\mathrm{TM}}$ Green, CellTracker ${ }^{\mathrm{TM}}$ Violet, or CellTracker ${ }^{\mathrm{TM}}$ Deep Red (Life Technologies, Grand Island, NY, USA) following the manufacturer's protocol. An equal number of cells from each population was combined and cultured on coverslips with confluent BMSC or HOB for 1, 4 and 48 hours. Coverslips were extensively washed with PBS to remove S and PB subpopulations, fixed with 4\% 
paraformaldehyde, and stained with phalloidin-TRITC (Sigma). Slides were mounted with Prolong® Gold anti-fade (Life Technologies), and evaluated by confocal microscopy.

\section{Chemotherapeutic agents}

Cytarabine (Ara-C) (Selleckchem, Houston, TX, USA; Cat \# S1648), Methotrexate (MTX) (Selleckchem, Cat \# S1210) and Vincristine (VCR) (Selleckchem, Cat \# S1241) were stored per manufacturer recommendations, and diluted in base media immediately prior to use. Experimental concentrations of Ara-C [1 $\mu \mathrm{M}]$, MTX [50 $\mu \mathrm{M}]$, or VCR [25 $\mu \mathrm{M}]$ were used to approximate clinically relevant doses in ALL[25-29].

\section{Evaluation of leukemic cell viability}

ALL cells were cultured in media alone, or co-cultured with BMSC or HOB for 4 days to establish S, PB, and PD tumor populations. At day 4, cultures were provided fresh media and exposed to Ara-C, MTX, or VCR for 4 days. Cells treated with Ara-C were exposed to a second dose at 48 hours. Viability was evaluated by trypan blue exclusion in triplicate samples.

\section{Annexin V/PI staining}

Cell culture and chemotherapy exposure were completed as described above. Following drug exposure ALL cells were stained using an Annexin V (FITC)/ propidium iodide ( $\mathrm{PI}$ ) apoptosis detection kit (Trevigen, Gaithersburg, MD, USA; Cat \# 4830-01-K) according to the recommended protocol of the manufacturer. Collection and analysis were performed in triplicate using the LSRFortessa (Becton Dickenson, San Jose, CA, USA).

\section{Co-culture of tumor cells with non-bone marrow derived adherent cells}


ALL cells were cultured in media alone, or co-cultured with sheep choroid plexus epithelial cells (SCP) (ATCC-CRL-1700), 3T3 mouse embryonic fibroblasts (3T3) (ATCC-CRL-1658), mouse embryonic fibroblasts (MEF) (ATCC-CRL-2991), human embryonic kidney cells (293T) (ATCCCRL-3216), or HT-1080 human fibrosarcoma derived cells (HT) (ATCC-CCL-121). Leukemic cells were cultured with adherent layers for 4 days to establish S, PB, and PD tumor populations comparable to those established with human $\mathrm{BMSC} / \mathrm{HOB}$. At day 4, cultures were exposed to Ara-C and evaluated for viability by trypan blue exclusion in triplicate as described above.

\section{In vitro relapse model}

ALL cells were grown in co-culture with BMSC or $\mathrm{HOB}$ for 4 days. At day 4 , cultures were provided fresh media and exposed to Ara-C for 72 hours. Following Ara-C exposure, $\mathrm{S}$ and PB ALL cell subpopulations were harvested as previously described and viability enumerated by trypan blue exclusion. Co-cultures, in which PD tumor cells remained buried beneath adherent $\mathrm{BMSC} / \mathrm{HOB}$, were rinsed to remove residual Ara-C and subsequently repopulation was monitored. ALL cells that comprised the regenerated S and PB fractions were enumerated at 5 day intervals at which time fresh media was provided. Cultures were maintained until tumor burden compromised BMSC or HOB monolayers.

\section{Western blot analysis}

Specific targets of glycolytic regulation were detected by rabbit mAb Hexokinase 1 (Cell Signaling Technologies, Danvers, MA, USA; C35C4; Cat \# 2024) and rabbit mAb Hexokinase 2 (C64G5; Cat \# 2867). Following incubation with horseradish peroxidase-conjugated secondary antibodies, signal was visualized using enhanced chemiluminescence (Amersham, Piscataway, NJ, USA). Densitometry was quantified by ImageJ with signal normalized to GAPDH. 


\section{Ki-67 staining}

ALL subpopulations were either cytospun following G10 Sephadex purification following coculture or analysis was completed on ALL cells during co-culture with BMSC or HOB grown on coverslips. Cells were fixed with $4 \%$ paraformaldehyde, washed with PBS, permeabilized with $0.1 \%$ Triton X-100 (Sigma) in PBS, and incubated with rabbit anti-Ki-67 followed by Alexa 488 anti-rabbit. Phalloidin-TRITC was used to visualize the actin cytoskeleton. Cells were washed with PBS and mounted to glass slides (coverslip staining) or coverslips (cytospins) with Prolong ${ }^{\circledR}$ Gold anti-fade/DAPI. Images were acquired by confocal microscopy and a minimum of 50 cells were counted to quantitate percent positive Ki-67 cells in triplicate.

\section{Cell cycle analysis}

$\mathrm{G}_{0}$ accumulation of ALL cells was investigated by evaluation of the DNA/RNA content quantitated by Hoechst33342/Pyronin Y (H/PY) (Sigma) double staining as previously described.[30] To evaluate the overall cell cycle profile of ALL cells, leukemic cells were collected from media or the PD population of co-culture after 12 days. ALL cells were fixed in $70 \%$ ethanol, treated with RNase (Sigma), and stained with PI for DNA analysis. All samples were performed in triplicate and processed on a FACSFortessia flow cytometer, and analyzed by FCS Express 4 software.

\section{Oxygen consumption and Extracellular Acidification analysis}

Leukemic cells $(800,000$ cells/well) were collected from media alone or isolated from BMSC/HOB co-culture and incubated in an XFe96 cell culture microplate coated with Cell-Tak (BD Biosciences). The XFe 96 Analyzer with XF Assay Media containing sodium pyruvate and glucose was used to determine Oxygen Consumption Rate [OCR] measurements, or with XF 
Base Media with L-glutamine to determine Extracellular Acidification Rate [ECAR] measurements. The XF plate was calibrated overnight with XF Calibrant at $37^{\circ} \mathrm{C}$. On the day of the measurements, tumor cells were plated directly in XF media, and basal measurements (OCR or ECAR) were collected at three time points. All analysis was performed using XFe 96 Analyzer (Seahorse Bioscience, North Billerica, MA, USA)

\section{Laser Ablation Electrospray Ionization (LAESI) and LC-MS/MS}

Leukemic cells cultured in medium alone or harvested from the PD population of BMSC or HOB co-culture were analyzed by LAESI-MS for metabolic profiling. Quantitative proteomic LCMS/MS analyses were performed on the following cell treatments: leukemic cells grown in media alone and co-culture with BMSC, BMSC/HOB, and HOB (Protea Biosciences, Morgantown, WV, USA). Detailed methodology and statistical analyses are included in Supplementary Materials and Methods.

\section{Statistical analysis}

Results are expressed as mean \pm SEM. An unpaired t-test was performed to analyze results of cell viability data, H/PY, and KI67 quantitation (Graph Pad Software, La Jolla, CA, USA). Results of basal ECAR and OCR rates were analyzed by One-way ANOVA with Dunnett's post hoc (Sigma Plot, San Jose, CA, USA). A p value of $<0.05$ was considered statistically significant as detailed in figure legends. Error bars throughout figures are represent standard error (SEM). 


\section{Results}

\section{ALL cells in co-culture with BMSC or HOB form three distinct spatial compartments.}

A panel of ALL cell lines formed three spatially and phenotypically distinct populations during coculture with BMSC (Figure 1) or HOB (DNS). ALL cells were separated into suspended tumor (S), which are not in physical contact with $\mathrm{BMSC} / \mathrm{HOB}$, phase bright (PB) that are loosely adherent to BMSC/HOB and phase $\operatorname{dim}(\mathrm{PD})$ subpopulations which bury beneath the BMSC or HOB monolayer (Figure 1). Each individual subpopulation re-establishes the PD subpopulation when collected and placed into subsequent co-cultures. When individual ALL subpopulations (S, $\mathrm{PB}$, and PD) were removed from BMSC or $\mathrm{HOB}$ co-culture, stained with distinct dyes and replated for 1-48h of interaction with BMM, no unique affinity was observed within any group of ALL cells to repopulate the PD compartment (Figure 2).

\section{ALL cells located in the PD population of BMSC or HOB co-culture demonstrate pronounced resistance to chemotherapy-induced death.}

PD ALL cells in BMSC/HOB co-culture have pronounced protection from chemotherapy-induced death when compared to media alone, S, or PB tumor cells following exposure to Ara-C, methotrexate (MTX), or vincristine (VCR) (Figure 3A-B and DNS). ALL cells readily establish three subpopulations (S, PB and PD) when co-cultured with several types of adherent layers established from sites other than the bone marrow, however, the PD population is not protected from Ara-C induced cell death (Figure 3C). Furthermore, we determined if surviving PD tumor cells from human BMSC or HOB co-culture could reconstitute the culture upon conclusion of chemotherapy exposure to simulate a purposefully simplified "in vitro relapse". Following a quiescent period of approximately 15 to 20 days, ALL cells from the chemotherapy resistant PD 
population migrated from beneath the stromal layers and initiated proliferation to re-populate the cultures (Figure 3D).

\section{ALL cells influenced by BMM have altered cell cycle distribution and quiescence.}

PD ALL cells have an increased $G_{0} / G_{1}$ fraction compared to media alone ALL cells (Figure 4A). The $G_{0} / G_{1}$ combined fraction was further investigated to determine the sub-set of PD ALL cells that are specifically in the $\mathrm{G}_{0}$ (quiescent) phase by H/PY double staining. Corresponding to the increase in $G_{0} / G_{1}, P D$ cells have an increase in the percentage of cells in $G_{0}$ compared to ALL cells in media alone (Figure 4B). Ki-67 staining was completed for analysis of the PD ALL population (Figure 4C) with PD ALL cells consistently having diminished Ki-67 staining when compared to media controls (Figure 4C-D). In addition to cell cycle analysis and Ki-67 expression alterations, global proteomic analysis was performed. As shown in Figure 5, proteins involved in cell cycle progression and DNA accessibility were altered in the leukemic cells influenced by the BMM. For a select group of histone-related proteins, alterations were seen in SUP-B15 ALL cells co-cultured with BMSC versus those co-cultured with HOB.

\section{BMSC/HOB cues alter ALL metabolic profiles.}

PD ALL cells have an increased level of glycolytic activity reflected by increased extracellular acidification rate (ECAR) when compared to ALL cells in media alone (Figure 6A). In agreement with increased basal glycolytic activity, PD ALL cells also have increased Hexokinase 1 and 2 protein levels (Figure 6B). While glycolytic activity was increased in the PD population, basal levels of oxidative phosphorylation are significantly diminished in leukemic cells in co-culture (Figure 6C). Metabolomic analysis was completed to compare global changes between leukemic 
cells in the presence (PD) or absence (media alone) of microenvironment cues with clustering of $\mathrm{m} / \mathrm{z}$ according to expression level reflecting distinct metabolic profiles (Figure 6D).

\section{Discussion}

In this study, using an extension of 2D co-culture techniques we have demonstrated that a panel of ALL cell lines when in co-culture with BMSC or HOB form three distinct spatial compartments: $\mathrm{S}, \mathrm{PB}$, and PD. Of these, the PD population is the most resistant and quiescent subpopulation generated by BMM interactions in vitro, and provides a valuable tool that can be applied for studying aggressive, resistant leukemia for targeted intervention. To evaluate whether the three individual groups of ALL cells had specific affinity for the location from which they were isolated, cell tracking experiments were completed. Leukemic cells in our model behave stochastically, and did not preferentially reconstitute the location from which they were isolated (Figure 2). S, PB or PD derived ALL cells readily buried under BMSC or HOB ("became PD"). This observation suggests a very dynamic phenotype, driven by the specific cues in distinct locations, versus a sustained phenotypic alteration or ALL cell "memory".

Our laboratory has previously shown that in general BMSC provide chemotherapy protection to leukemic cells via soluble factors[32,33] and adhesion interactions in standard 2D cocultures[15,34-36]. When the attention was directed to the PD subpopulation, they were shown to be the most resistant to chemotherapy exposure. Protection was specific to interactions with BMM-derived BMSC, HOB or NSG derived BMSC (Figure 3A-C, DNS). The value of our model approach is the observation that, with inclusion of just one niche component, either BMSC or 
HOB, a distinct group of tumor cells can be isolated that have altered cell cycle profiles, metabolic signatures and cytotoxic agent response. Future work can expand upon this model, increasing its complexity through methodical addition of other key bone marrow microenvironment components, such as endothelial cells[36], to better recapitulate the resistant leukemic niche in vitro to answer specific, clinically relevant questions with emphasis on interruption of signals that influence ALL cell quiescence, metabolic activity, and apoptosis.

Tumor cells that are in a quiescent state have been described by other groups to be drug resistant[37]. We observed that PD cells accumulate in the $G_{0} / G_{1}$ phase of cell cycle with a reduction in S phase (Figure 4A). Coincident with induction of quiescence, PD cells had increased p27 suggesting this may be one mechanism by which the cells are arrested in a $\mathrm{G}_{0}$ state (DNS; figure 4B). The PD population does not demonstrate $100 \%$ accumulation in $\mathrm{G}_{0}$ indicating that cell cycle interruption does not explain the entire escape from $\mathrm{S}$ phase specific drug-induced apoptosis. Even within the purified PD subpopulation multiple pathways are likely influenced by niche cells that converge on blunting apoptosis. PD ALL cells also had a reduced proliferation index measured by Ki-67 staining (Figure 4C-D), again consistent with the assertion that the BMM alters ALL proliferation, which may be one contributing factor to increased chemotherapy resistance (Figures 3-4). Future studies will be important to evaluate a broader range of drugs in this model, including those that are not $S$ phase specific, to expand our understanding of the resistant subpopulation.

Diverse protein pathways were altered in leukemic cells during co-culture with BMM cells evaluated by MS/MS analysis (Figure 5). Key pathways with significant alteration in ALL cells were those associated with cell cycle progression and DNA accessibility. Interestingly, 
differences were not only seen in ALL cells from BMM niche co-culture compared to media alone, but also in histone related protein expression between ALL cells influenced by BMSC compared to HOB. Although both cell types are derived from the bone marrow, it is not surprising that they influence ALL gene expression differently based the uniqueness of the endosteal and perivascular niches[38,39]. This reflects the complexity of the marrow niche and compartmentalization of function that is critical for regulated development of healthy hematopoietic cells through controlled differentiation, proliferation, survival and eventual egress to the periphery.

We further characterized the metabolomic profiles of the PD subpopulation compared to tumor cells grown in media alone utilizing LAESI-MS. The metabolic signatures of leukemic cells provided microenvironment cues were notably distinct from ALL cells deprived of these signals (Figure 6). This global evaluation was not intended to identify specific targets but rather to determine if overall metabolite patterns were shifted (Figure 6D). The cellular metabolism of this subpopulation of leukemic cells has been altered by the bone marrow microenvironment interactions, resulting in quiescent cells with high glycolytic potential (Figure 6A-B). This has been previously observed in quiescent fibroblasts[40], and the notion that the PD cells are "primed" for proliferation when they are released from quiescent constraints is a characteristic previously reported in activated dormant T cells[41].

A particular concern that remains in $A L L$ is the aggressive treatment strategies required to treat relapse in children with the marked potential of late effects and secondary malignancies. Against this backdrop, it is essential to expand the knowledge we obtain in vitro for efficient translation to pre-clinical modeling, subsequent novel drug trials, and generation of new treatment 
paradigms for patients. Clearly limitations are significant in modeling a complex and dynamic disease such as ALL in vitro. The unique leukemic co-culture model described with an emphasis on a functionally distinct, quiescent and chemoresistant PD subpopulation provides a valuable tool for future analysis. Further dissection of the molecular pathways regulated by the BMM and the "sanctuary" that is created for leukemic cells to generate refractory disease still needs to be extensively studied in order to achieve a higher percentage of disease free survival in leukemia patients.

\section{Acknowledgements}

The authors thank Dr. Michael Craig for his assistance in acquiring primary patient ALL samples and Ian Hare for manuscript editing. We are grateful for the support of Dr. Kathy Brundage and the West Virginia University Flow Cytometry Core Facility, supported by NIH S10-OD016165 and the Institutional Development Award (IDeA) from the NIH Institute of General Medical Sciences of the National Institutes of Health (CoBRE P30GM103488 and INBRE P20GM103434). Imaging experiments were performed in the West Virginia UniversityMicroscope Imaging Facility, supported by the Mary Babb Randolph Cancer Center and NIH grants P20 RR016440, P30 GM103488 and P20 GM103434.

Funding Source: NIH NHLBI R01 HL056888 (LFG), NIH NCI R01 CA134573NIH (LFG), P30 GM103488 (LFG), WV CTR-IDEA NIH 1 U54 GM104942, the Alexander B. Osborn Hematopoietic Malignancy and Transplantation Program, and the WV Research Trust Fund.

Conflict of Interest: Angel PM, Walsh CM, and Cantrell PS receive compensation as employees of Protea Biosciences. 


\section{References}

1. Barcellos-de-Souza P, Gori V, Bambi F, Chiarugi P. Tumor microenvironment: Bone marrow-mesenchymal stem cells as key players. Biochim Biophys Acta BBA - Rev Cancer. 2013 Dec;1836(2):321-35.

2. Bradstock K, Bianchi A, Makrynikola V, Filshie R, Gottlieb D. Long-term survival and proliferation of precursor-B acute lymphoblastic leukemia cells on human bone marrow stroma. Leukemia. 1996 May;10(5):813-20.

3. Duan C-W, Shi J, Chen J, Wang B, Yu Y-H, Qin X, et al. Leukemia Propagating Cells Rebuild an Evolving Niche in Response to Therapy. Cancer Cell. 2014 Jun 16;25(6):778-93.

4. Ghajar $\mathrm{CM}$, Peinado $\mathrm{H}$, Mori $\mathrm{H}$, Matei IR, Evason $\mathrm{KJ}$, Brazier $\mathrm{H}$, et al. The perivascular niche regulates breast tumour dormancy. Nat Cell Biol. 2013 Jul;15(7):807-17.

5. Krause DS, Scadden DT, Preffer FI. The hematopoietic stem cell niche-home for friend and foe? Cytometry B Clin Cytom. 2013;84B(1):7-20.

6. Manabe A, Murti KG, Coustan-Smith E, Kumagai M, Behm FG, Raimondi SC, et al. Adhesion-dependent survival of normal and leukemic human $B$ lymphoblasts on bone marrow stromal cells. Blood. 1994 Feb 1;83(3):758-66.

7. Meads MB, Hazlehurst LA, Dalton WS. The Bone Marrow Microenvironment as a Tumor Sanctuary and Contributor to Drug Resistance. Clin Cancer Res. 2008 May 1;14(9):2519-26.

8. Tesfai Y, Ford J, Carter KW, Firth MJ, O'Leary RA, Gottardo NG, et al. Interactions between acute lymphoblastic leukemia and bone marrow stromal cells influence response to therapy. Leuk Res. 2012 Mar;36(3):299-306.

9. Szczepanek J, Styczyński J, Haus O, Tretyn A, Wysocki M. Relapse of Acute Lymphoblastic Leukemia in Children in the Context of Microarray Analyses. Arch Immunol Ther Exp (Warsz). 2011 Feb 1;59(1):61-8.

10. Colmone A, Amorim M, Pontier AL, Wang S, Jablonski E, Sipkins DA. Leukemic Cells Create Bone Marrow Niches That Disrupt the Behavior of Normal Hematopoietic Progenitor Cells. Science. 2008 Dec 19;322(5909):1861-5.

11. Boyerinas B, Zafrir M, Yesilkanal AE, Price TT, Hyjek EM, Sipkins DA. Adhesion to osteopontin in the bone marrow niche regulates lymphoblastic leukemia cell dormancy. Blood. 2013 Jun 13;121(24):4821-31. 
12. Jacoby E, Chien CD, Fry TJ. Murine Models of Acute Leukemia: Important Tools in Current Pediatric Leukemia Research. Front Oncol [Internet]. 2014 May 7 [cited 2014 Jul 28];4. Available from: http://www.ncbi.nlm.nih.gov/pmc/articles/PMC4019869/

13. Liem NLM, Papa RA, Milross CG, Schmid MA, Tajbakhsh M, Choi S, et al. Characterization of childhood acute lymphoblastic leukemia xenograft models for the preclinical evaluation of new therapies. Blood. 2004 May 15;103(10):3905-14.

14. Samuels AL, Beesley AH, Yadav BD, Papa RA, Sutton R, Anderson D, et al. A pre-clinical model of resistance to induction therapy in pediatric acute lymphoblastic leukemia. Blood Cancer J. 2014 Aug 1;4(8):e232.

15. Mudry RE, Fortney JE, York T, Hall BM, Gibson LF. Stromal cells regulate survival of Blineage leukemic cells during chemotherapy. Blood. 2000 Sep 1;96(5):1926-32.

16. Jing D, Fonseca A-V, Alakel N, Fierro FA, Muller K, Bornhauser M, et al. Hematopoietic stem cells in co-culture with mesenchymal stromal cells--modeling the niche compartments in vitro. Haematologica. $2010 \mathrm{Apr} ; 95(4): 542-50$.

17. Moore N, Lyle S. Quiescent, Slow-Cycling Stem Cell Populations in Cancer: A Review of the Evidence and Discussion of Significance. J Oncol [Internet]. 2010 Sep 29 [cited 2013 May 29];2011. Available from: http://www.hindawi.com/journals/jo/2011/396076/abs/

18. Saito Y, Uchida N, Tanaka S, Suzuki N, Tomizawa-Murasawa M, Sone A, et al. Induction of cell cycle entry eliminates human leukemia stem cells in a mouse model of AML. Nat Biotechnol. 2010 Mar;28(3):275-80.

19. Gibson LF, Fortney J, Landreth KS, Piktel D, Ericson SG, Lynch JP. Disruption of bone marrow stromal cell function by etoposide. Biol Blood Marrow Transplant J Am Soc Blood Marrow Transplant. 1997 Aug;3(3):122-32.

20. Berniakovich I, Giorgio M. Low oxygen tension maintains multipotency, whereas normoxia increases differentiation of mouse bone marrow stromal cells. Int $\mathrm{J}$ Mol Sci. 2013;14(1):2119-34.

21. Chow DC, Wenning LA, Miller WM, Papoutsakis ET. Modeling $\mathrm{pO}(2)$ distributions in the bone marrow hematopoietic compartment. II. Modified Kroghian models. Biophys J. 2001 Aug;81(2):685-96.

22. Holzwarth C, Vaegler M, Gieseke F, Pfister SM, Handgretinger R, Kerst G, et al. Low physiologic oxygen tensions reduce proliferation and differentiation of human multipotent mesenchymal stromal cells. BMC Cell Biol. 2010;11:11. 
23. Hathcock KS. Depletion of Accessory Cells by Adherence to Sephadex G-10. In: Current Protocols in Immunology [Internet]. John Wiley \& Sons, Inc.; 2001 [cited 2015 Apr 16]. Available from: http://onlinelibrary.wiley.com/doi/10.1002/0471142735.im0306s08/abstract

24. Slone WS, Moses BS, Evans R, Piktel D, Martin KH, Petros W, et al. Modeling chemotherapy resistant leukemia in vitro. $\mathrm{J}$ Vis Exp. In press.

25. Liedtke M, Dunn T, Dinner S, Coutré SE, Berube C, Gotlib J, et al. Salvage therapy with mitoxantrone, etoposide and cytarabine in relapsed or refractory acute lymphoblastic leukemia. Leuk Res. 2014 Dec;38(12):1441-5.

26. Weinstein HJ, Griffin TW, Feeney J, Cohen HJ, Propper RD, Sallan SE. Pharmacokinetics of continuous intravenous and subcutaneous infusions of cytosine arabinoside. Blood. 1982 Jun;59(6):1351-3.

27. Joannon P, Oviedo I, Campbell M, Tordecilla J. High-dose methotrexate therapy of childhood acute lymphoblastic leukemia: lack of relation between serum methotrexate concentration and creatinine clearance. Pediatr Blood Cancer. 2004 Jul;43(1):17-22.

28. Bhojwani D, Sabin ND, Pei D, Yang JJ, Khan RB, Panetta JC, et al. Methotrexate-induced neurotoxicity and leukoencephalopathy in childhood acute lymphoblastic leukemia. J Clin Oncol Off J Am Soc Clin Oncol. 2014 Mar 20;32(9):949-59.

29. Van den Berg HW, Desai ZR, Wilson R, Kennedy G, Bridges JM, Shanks RG. The pharmacokinetics of vincristine in man: reduced drug clearance associated with raised serum alkaline phosphatase and dose-limited elimination. Cancer Chemother Pharmacol. 1982;8(2):215-9.

30. Shen H, Boyer M, Cheng T. Flow cytometry-based cell cycle measurement of mouse hematopoietic stem and progenitor cells. Methods Mol Biol Clifton NJ. 2008;430:77-86.

31. Wang L, Clutter S, Benincosa J, Fortney J, Gibson LF. Activation of transforming growth factor-beta1/p38/Smad3 signaling in stromal cells requires reactive oxygen species-mediated MMP-2 activity during bone marrow damage. Stem Cells Dayt Ohio. 2005 Sep;23(8):1122-34.

32. Clutter SD, Fortney J, Gibson LF. MMP-2 is required for bone marrow stromal cell support of pro-B-cell chemotaxis. Exp Hematol. 2005 Oct;33(10):1192-200.

33. O'Leary H, Akers SM, Piktel D, Walton C, Fortney JE, Martin KH, et al. VE-cadherin Regulates Philadelphia Chromosome Positive Acute Lymphoblastic Leukemia Sensitivity to Apoptosis. Cancer Microenviron Off J Int Cancer Microenviron Soc. 2010;3(1):67-81.

34. Wang L, Coad JE, Fortney JM, Gibson LF. VEGF-induced survival of chronic lymphocytic leukemia is independent of Bcl-2 phosphorylation. Leukemia. 2005 Aug;19(8):1486-7. 
35. Wang L, Chen L, Benincosa J, Fortney J, Gibson LF. VEGF-induced phosphorylation of Bcl-2 influences B lineage leukemic cell response to apoptotic stimuli. Leukemia. 2005 Mar;19(3):344-53.

36. Ayala $F$, Dewar $R$, Kieran $M$, Kalluri R. Contribution of bone microenvironment to leukemogenesis and leukemia progression. Leukemia. 2009 Sep 3;23(12):2233-41.

37. Li L, Bhatia R. Stem Cell Quiescence. Clin Cancer Res. 2011 Aug 1;17(15):4936-41.

38. Morrison SJ, Scadden DT. The bone marrow niche for haematopoietic stem cells. Nature. 2014 Jan 16;505(7483):327-34.

39. Mendelson A, Frenette PS. Hematopoietic stem cell niche maintenance during homeostasis and regeneration. Nat Med. 2014 Aug;20(8):833-46.

40. Lemons JMS, Feng X-J, Bennett BD, Legesse-Miller A, Johnson EL, Raitman I, et al. Quiescent Fibroblasts Exhibit High Metabolic Activity. PLoS Biol. 2010 Oct 19;8(10):e1000514.

41. Krauss S, Brand MD, Buttgereit F. Signaling Takes a Breath - New Quantitative Perspectives on Bioenergetics and Signal Transduction. Immunity. 2001 Oct;15(4):497-502.

\section{Supplemental methods:}

\section{Culture conditions}

Co-cultures were established by seeding leukemic cells onto $80-90 \%$ confluent BMSC or HOB monolayers. Cultures were fed every 4 days and tumor cells collected for inclusion in experiments with remaining leukemic cells moved to new primary BMSC or HOB adherent layers every 12 days. Cultures were maintained in $5 \% \mathrm{O}_{2}$ to model normal bone marrow oxygen tension, reported to range from $1-7 \%[1-3]$. Suspended (S) leukemic cells floating freely in the media were removed by gentle pipetting. Phase bright (PB) tumor cells, that were loosely adherent to the top of BMSC or $\mathrm{HOB}$, were harvested by vigorous pipetting. Phase dim (PD) leukemic cells that were buried firmly beneath adherent BMSC or HOB were recovered by trypsinization of the adherent layer and PD tumor. The S, PB, and PD tumor populations were 
separated from BMSC/HOB by size exclusion with G10 Sephadex (Sigma, St Louis, MO, USA) column separation[4].

\section{Microscopy}

Phase contrast images were acquired using a Leica DMIL LED microscope and processed by Leica application suite version 4.0 software (Buffalo Grove, IL, USA). Confocal images were acquired using an upright LSM 510 Zeiss microscope and processed using Zen2009 software (Thornwood, NY, USA). Fluorescence intensity for image acquisition was only altered when fluorescence intensities were not compared between samples.

\section{Co-culture of tumor cells with non-bone marrow derived adherent cells}

ALL cells were cultured in media alone, or co-cultured with sheep choroid plexus epithelial cells (SCP) (ATCC-CRL-1700), 3T3 mouse embryonic fibroblasts (3T3) (ATCC-CRL-1658), mouse embryonic fibroblasts (MEF) (ATCC-CRL-2991), human embryonic kidney cells (293T) (ATCCCRL-3216), or HT-1080 human fibrosarcoma derived cells (HT) (ATCC-CCL-121). Leukemic cells were cultured with adherent layers for 4 days to establish S, PB, and PD tumor populations comparable to those established with human $\mathrm{BMSC} / \mathrm{HOB}$. At day 4 , cultures were exposed to Ara-C and evaluated for viability by trypan blue exclusion in triplicate.

\section{In vitro relapse model}

ALL cells were grown in co-culture with BMSC or HOB for 4 days. At day 4, cultures were provided fresh media and exposed to Ara-C for 72 hours. Following Ara-C exposure, $\mathrm{S}$ and PB ALL cell subpopulations were harvested as previously described and viability enumerated by trypan blue exclusion. Co-cultures, in which PD tumor cells remained buried beneath adherent 
$\mathrm{BMSC} / \mathrm{HOB}$, were rinsed to remove residual Ara-C and subsequently repopulation was monitored. ALL cells that comprised the regenerated S and PB fractions were enumerated at 5 day intervals at which time fresh media was provided. Cultures were maintained until tumor burden compromised BMSC or HOB monolayers.

\section{Western blot analysis}

Specific targets of glycolytic regulation were detected by rabbit mAb Hexokinase 1 (Cell Signaling Technologies, Danvers, MA, USA; C35C4; Cat \# 2024) and rabbit mAb Hexokinase 2 (C64G5; Cat \# 2867). Following incubation with horseradish peroxidase-conjugated secondary antibodies, signal was visualized using enhanced chemiluminescence (Amersham, Piscataway, NJ, USA). Densitometry was quantified by ImageJ with signal normalized to GAPDH.

\section{Ki-67 staining}

ALL subpopulations were either cytospun following G10 Sephadex purification following coculture or analysis was completed on ALL cells during co-culture with BMSC or HOB grown on coverslips. Cells were fixed with $4 \%$ paraformaldehyde, washed with PBS, permeabilized with $0.1 \%$ Triton X-100 (Sigma) in PBS, and incubated with rabbit anti-Ki-67 followed by Alexa 488 anti-rabbit. Phalloidin-TRITC was used to visualize the actin cytoskeleton. Cells were washed with PBS and mounted to glass slides (coverslip staining) or coverslips (cytospins) with Prolong® Gold anti-fade/DAPI. Images were acquired by confocal microscopy and a minimum of 50 cells were counted to quantitate percent positive Ki-67 cells in triplicate. 


\section{Seahorse analysis}

Leukemic cells $(800,000$ cells/well) were collected from media alone or isolated from BMSC/HOB co-culture and incubated in an XFe96 cell culture microplate coated with Cell-Tak (BD Biosciences). The XFe 96 Analyzer with XF Assay Media containing sodium pyruvate and glucose was used to determine Oxygen Consumption Rate [OCR] measurements, or with XF Base Media with L-glutamine to determine Extracellular Acidification Rate [ECAR] measurements. The XF plate was calibrated overnight with XF Calibrant at $37^{\circ} \mathrm{C}$. On the day of the measurements, tumor cells were plated directly in XF media, and basal measurements (OCR or ECAR) were collected at three time points.

\section{Laser Ablation Electrospray lonization (LAESI)}

Prior to direct analysis by laser ablation electrospray ionization (LAESI-MS) each cell pellet $\left(5 \times 10^{6}\right.$ cells) was centrifuged at $1,000 \times g$ for 2 minutes at $4^{\circ} \mathrm{C}$. The entire pellet $(\sim 3 \mu \mathrm{L})$ was dispensed onto a glass microscope slide for LAESI-MS analyses. In vivo molecular profiling was performed on the cells with a LAESI DP-1000 Direct lonization source interfaced with a Thermo QExactive mass spectrometer (Thermo Scientific). Electrospray solution (50\% methanol/0.1\% acetic acid) flowed at $1 \mu \mathrm{L} /$ min through a stainless steel emitter tip (320 $\mu \mathrm{m}$ OD and $100 \mu \mathrm{m}$ ID; New Objective, Woburn, MA) at an electrospray voltage $4 \mathrm{kV}$. Three technical replicates (250 laser pulses at $10 \mathrm{~Hz}$ with a laser energy $600 \mu \mathrm{J}$ ) were performed per three biological replicates. The LAESI peltier stage was cooled to $4^{\circ} \mathrm{C}$. Full scan mass spectrometer profiles were collected over a mass range of $\mathrm{m} / \mathrm{z} 50$ to 750 at 35,000 mass resolution with $\mathrm{m} / \mathrm{z} 37[5] .1012$ selected for real-time mass accuracy lockmass correction.

\section{Post-analysis processing and multivariate statistics}


Post LAESI-MS acquisition, the spectra were averaged across each technical replicate per biological replicate (approximately 175 scans). Multivariate statistics were applied in order to compare media treatment to BMSC and HOB, respectively. Mass Profiler Professional (Agilent, version 13 build 211261) was used to determine significantly altered $\mathrm{m} / \mathrm{z}$ using a Benjamini Hochberg false discovery rate corrected $p$-value $<0.01$ from ANOVA testing1. Putatively altered $\mathrm{m} / \mathrm{z}$ visualized using the heatmap function.

\section{Proteomics}

\section{iTRAQ sample preparation}

Cell pellets were lysed $150 \mu \mathrm{L}$ of $0.1 \mathrm{M}$ TEAB with $2 \%$ SDS, vortexed and sonicated for 20 minutes in an ice bath, followed by centrifugation at $12,000 \mathrm{~g}$ for 10 minutes. Supernatant was quantified by BCA, and $200 \mu \mathrm{g}$ of protein from each cell type was precipitated using cold acetone in a 6:1 acetone to sample ratio, chilling at $-20^{\circ} \mathrm{C}$ overnight. Proteins were reduced and alkylated, and trypsin digested overnight. The iTRAQ labeling (Applied Biosciences) was performed according to manufacturer's instructions, labeling for two hours, followed by adding an excess $350 \mu \mathrm{L}$ of water and incubating for 30 minutes to stop the labeling reaction. Samples Media, $\mathrm{BMSC}, \mathrm{BMSC} / \mathrm{HOB}$, and $\mathrm{HOB}$ samples were labeled with tagged with the 115, 1116, 117, 118 reagents, respectively. Samples were frozen to $-80^{\circ} \mathrm{C}$ followed by overnight lyophilization, and cleaned up using strong cation exchange (SCX) SpinTips (Protea Biosciences). Samples were lyophilized after cleanup, and reconstituted in $40 \mu \mathrm{L}$ of $0.1 \%$ formic acid $/ 5 \%$ acetonitrile.

\section{LC-MS/MS}

Samples were separated by reverse phase chromatography using a Shimadzue LC-20AD HPLC system eluting over 90 minutes using a C18 column (Kinetex $100 \times 2.1 \mathrm{~mm} \mathrm{C18}$, Phenomenex). 
Gradient was $0-3$ minutes $2 \%$ B, 3-70 minutes $2-40 \% \mathrm{~B}, 70-80$ minutes $90 \%$ B followed by a column wash $80-85$ minutes $90 \%$ B using a flow rate of $200 \mu \mathrm{L} /$ minute. Mobile phase A was $0.1 \%$ formic acid in water, mobile phase $B$ was $0.1 \%$ formic acid in acetonitrile. Peptides were eluted with a positive ion mode applied voltage of $3.5 \mathrm{kV}$ into a QTrap 5500 (AB Sciex). Using data independent acquisition, the 3 most intense multiply charged ions with ion intensities above a threshold of 50000 in each regular MS scan were subjected to MS/MS analyses.

\section{Data analysis}

MS/MS data were searched against the Swissprot human database downloaded January 7 , 2015. Data were searched with the Paragon search algorithm (Applied Biosciences) through the ProteinPilot software using trypsin as the enzyme, statics modifications of Cysteine and MMTS (Methylthio, the labeling reagent), dynamic modifications of deamidation (N,Q) and oxidation (M). Autobias was applied for quantification using GAPDH as a control to evaluate quantification. Altered proteins were designated as those with $p$-value $<0.05$ relative to Media. The web applications ToppCluster and WebGestalt were used for enrichment analysis and graphical representation of biological processes and pathways[6,7].

\section{Statistical analysis}

Results are expressed as triplicate mean \pm SEM. An unpaired t-test were performed for viability, H/PY, and KI67 quantitation (Graph Pad Software, La Jolla, CA, USA). Seahorse results were analyzed by One-way ANOVA with Dunnett's post hoc (Sigma Plot, San Jose, CA, USA). p value of $<0.05$ was considered statistically significant. 


\section{Supplemental references}

1. Berniakovich I, Giorgio M. Low oxygen tension maintains multipotency, whereas normoxia increases differentiation of mouse bone marrow stromal cells. Int $\mathrm{J}$ Mol Sci. 2013;14(1):2119-34.

2. Chow DC, Wenning LA, Miller WM, Papoutsakis ET. Modeling $\mathrm{pO}(2)$ distributions in the bone marrow hematopoietic compartment. II. Modified Kroghian models. Biophys J. 2001 Aug;81(2):685-96.

3. Holzwarth C, Vaegler M, Gieseke F, Pfister SM, Handgretinger R, Kerst G, et al. Low physiologic oxygen tensions reduce proliferation and differentiation of human multipotent mesenchymal stromal cells. BMC Cell Biol. 2010;11:11.

4. Hathcock KS. Depletion of Accessory Cells by Adherence to Sephadex G-10. Current Protocols in Immunology [Internet]. John Wiley \& Sons, Inc.; 2001 [cited 2015 Apr 16]. Available from: http://onlinelibrary.wiley.com/doi/10.1002/0471142735.im0306s08/abstract

5. Benjamini Y, Hochberg Y. Controlling the False Discovery Rate: A Practical and Powerful Approach to Multiple Testing. J R Stat Soc Ser B Methodol. 1995 Jan 1;57(1):289_ 300.

6. Kaimal V, Bardes EE, Tabar SC, Jegga AG, Aronow BJ. ToppCluster: a multiple gene list feature analyzer for comparative enrichment clustering and network-based dissection of biological systems. Nucleic Acids Res. 2010 Jul;38(Web Server issue):W96-102.

7. Zhang B, Kirov S, Snoddy J. WebGestalt: an integrated system for exploring gene sets in various biological contexts. Nucleic Acids Res. 2005 Jul 1;33(Web Server issue):W741-8. 


\section{Figure legends}

Figure 1. Human acute lymphoblastic leukemia cells (ALL) occupy three functionally distinct spatial compartments during co-culture with BMSC. The left panels show suspended ALL tumor cells from representative cell lines (REH, Nalm-27 or Tom-1) grown in media alone. Right panels demonstrate co-culture dynamics with leukemic cells forming three functionally distinct populations in relation to the BMSC monolayer. Cells were co-cultured for 48 to $72 \mathrm{~h}$ prior to acquiring images. The three ALL populations include suspended (S) cells which refract light, appear bright and are freely floating in culture media; phase bright (PB) tumor cells that are loosely attached to the surface of the adherent BMSC monolayer; and phase dim (PD) tumor cells which are beneath the BMSC monolayer and appear as phase dim cells upon light microscopy. Arrows highlight the PD subpopulation of ALL cells in co-culture with BMSC, which are enlarged in the inset for more detailed visualization. Scale bar $=10 \mu \mathrm{m}$.

Figure 2. Each subpopulation of Nalm-27 ALL cells re-established the PD fraction when provided BMM niche cells. The S, PB and PD ALL subpopulations were collected from co-culture and individually stained with blue, far red and green fluorophores for visualization, respectively. Each subpopulation associated with BMSC (top panel) and HOB (bottom panel) observed after 48h. Co-cultures were vigorously rinsed to remove S and PB tumor cells to visualize only PD tumor cells shown in the representative images. Actin was visualized by Phalloidin-TRITC staining. Levels including gamma were adjusted and a median filter was applied for image clarity with no comparison of intensity. Scale bar $=10 \mu \mathrm{m}$. 
Figure 3. PD leukemic cells have pronounced resistance to chemotherapy induced death. (A) Leukemic cells recovered from the PD population of an HOB co-culture have significantly increased viability following exposure to Ara-C [1 $\mu \mathrm{M}]$, MTX [50 $\mu \mathrm{M}]$, or VCR [25 $\mu \mathrm{M}]$ determined by trypan blue exclusion or (B) Annexin V-FITC/PI staining when compared to matched controls that are exposed to cytotoxic agents in media alone. (C In contrast to human BMSC or HOB coculture, leukemic cells recovered from the PD population of non-bone marrow derived adherent layers do not have increased viability compared to untreated controls during exposure to Ara-C. (D) PD leukemic cells undergo a quiescent recovery period following Ara-C exposure, followed by an aggressive period of proliferation to repopulate the $S$ and PB populations. $\left({ }^{*}\right)$ denotes $p<$ 0.05 , unpaired t-test when compared to media alone or untreated controls.

Figure 4. BMM cells influence the PD subpopulation cell cycle profile and increase quiescence. (A) PD cells have a higher percentage of cells in the $G_{0} / G_{1}$ phase and a reduction in $S$ phase compared to media alone leukemic cells as measured by PI staining. (B) H/PY staining revealed the PD cells have a higher percentage of cells in $G_{0}$ when compared to tumor cells cultured in media alone. (C) Assessing Ki-67 (green) expression by confocal microscopy, the PD cells had a reduction in Ki-67 positive cells. TRITC staining: red, DNA staining: blue, Ki-67: green. Scale bar equal $=10 \mu \mathrm{m} .\left(^{*}\right)$ denotes $p<0.05$, unpaired t-test when compared to media alone.

Figure 5. BMM alters global protein expression in ALL cells. The heat map shown represents differentially regulated proteins comparing Sup-B15 ALL cells co-cultured with BMSC or HOB to those grown in media alone. GAPDH was used as a control to normalize expression in all groups. 
A p-value $<0.05$ for comparisons of co-culture relative to media alone was required for designation of a difference in protein abundance.

Figure 6. PD cells isolated from bone marrow niche co-culture have a distinct metabolic phenotype when compared to ALL cells in the absence of microenvironment signals. (A) REH cells recovered from the PD population have increased basal glycolytic rates compared to tumor in media alone or their S and PB counterparts from the same BMSC or HOB co-culture as indicated by the increase in extracellular acidification rate (ECAR). (B) Western blot analyses indicated increased Hexokinase 1 and Hexokinase 2 protein expression in PD ALL cells compared to tumor cells maintained in media alone. (C) REH cells in co-culture with BMSC or HOB have decreased basal oxygen consumption compared to media alone controls as reflected by diminished oxygen consumption rate (OCR). (D) Laser ablation electrospray ionization mass spectrometry (LAESI-MS) metabolomic analysis of Nalm-27 cells cultured in media alone or recovered from the PD population of BMSC or HOB co-culture showed global changes of metabolites between ALL cells populations. Heat map represents differentially expressed metabolite ions ( $\mathrm{m} / \mathrm{z}$ values), $\mathrm{p}$-value $<0.01$. $\left(^{*}\right)$ denotes $\mathrm{p}<0.05$ by One-way ANOVA with Dunnett's post hoc when compared to media alone. 

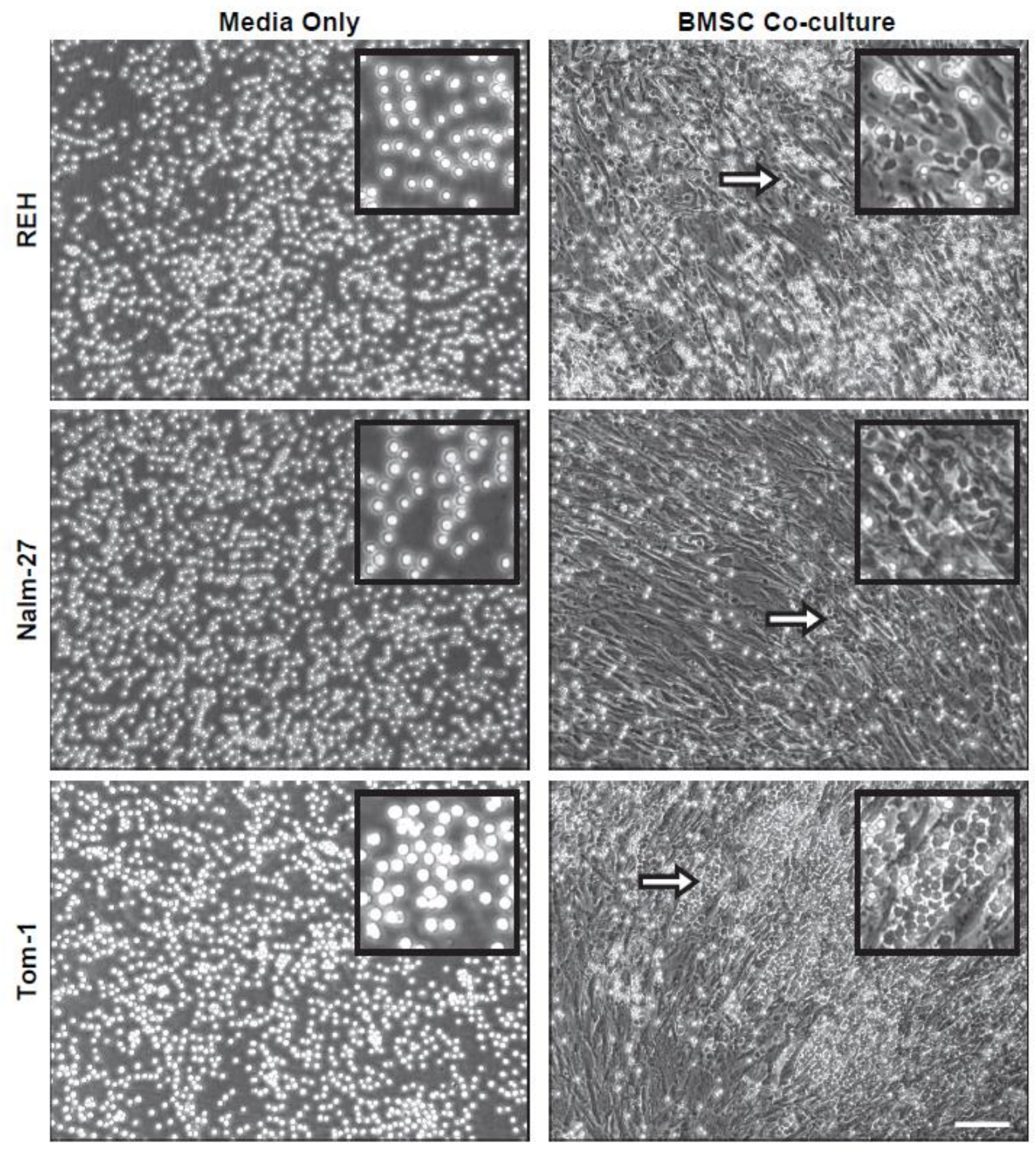

Figure 1. Human acute lymphoblastic leukemia cells (ALL) occupy three functionally distinct spatial compartments during co-culture with BMSC 

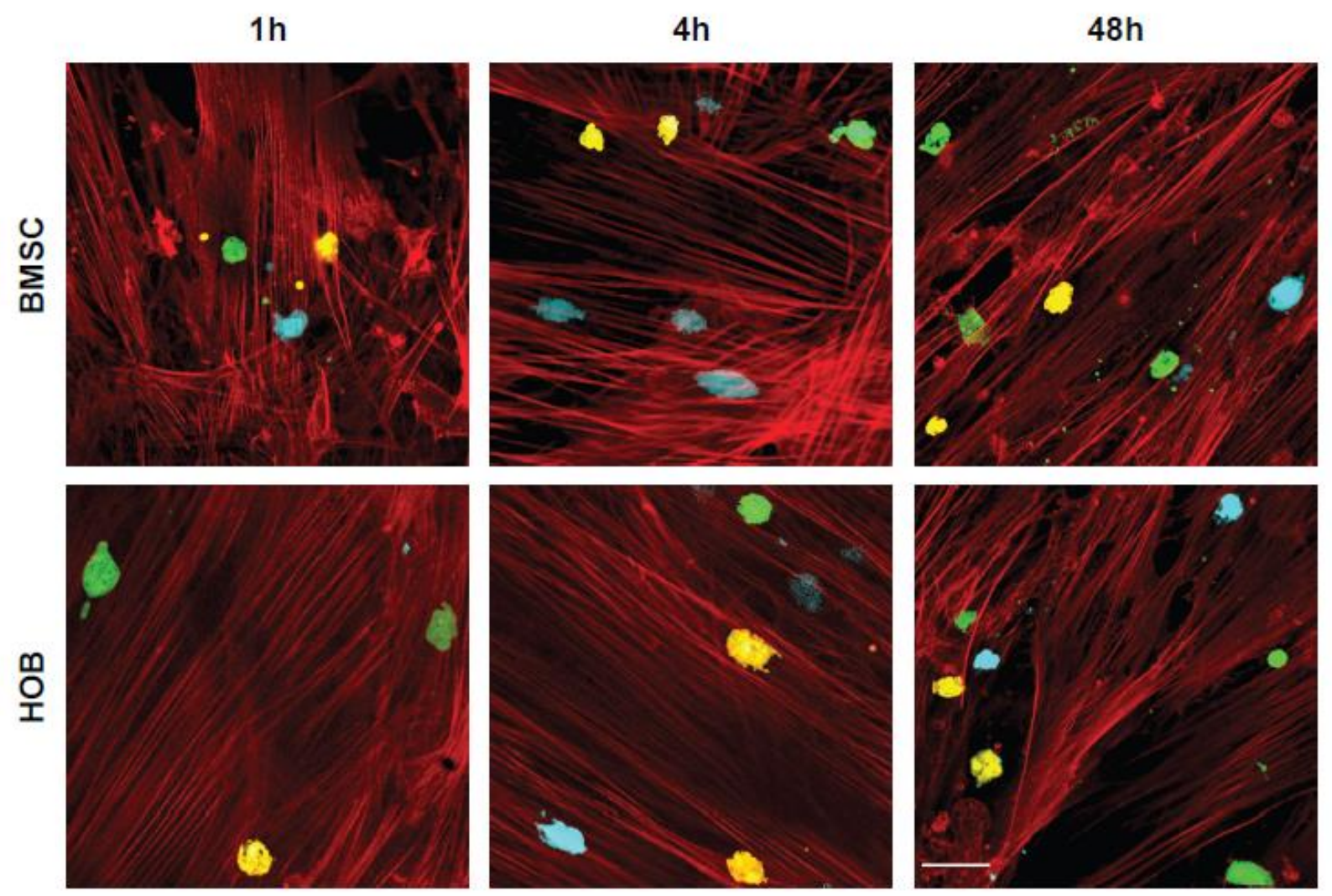

Figure 2: Each subpopulation of Nalm-27 ALL cells re-established the PD fraction when provided BMM niche cells 

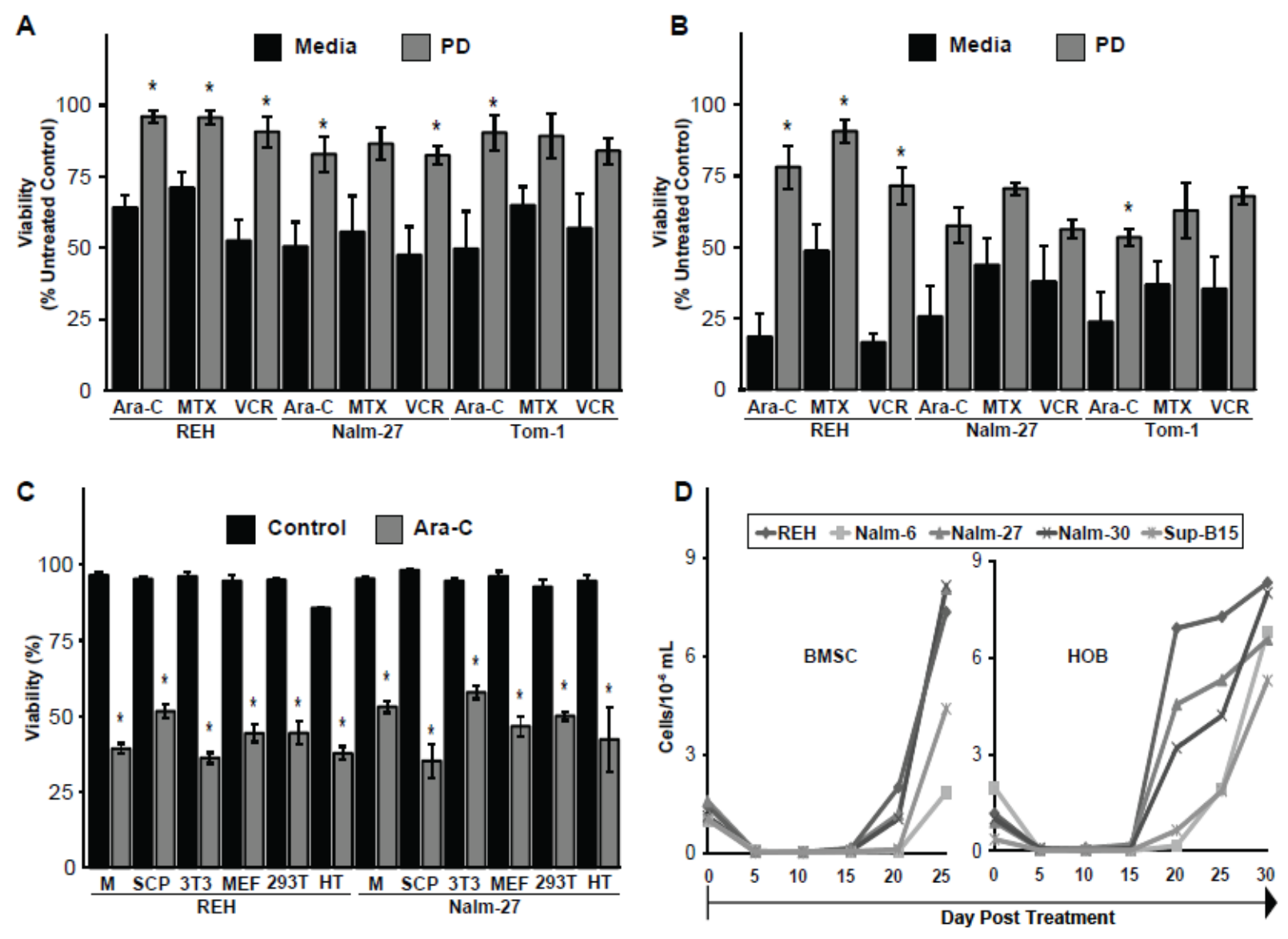

Figure 3: PD leukemic cells have pronounced resistance to chemotherapy induced death 
A

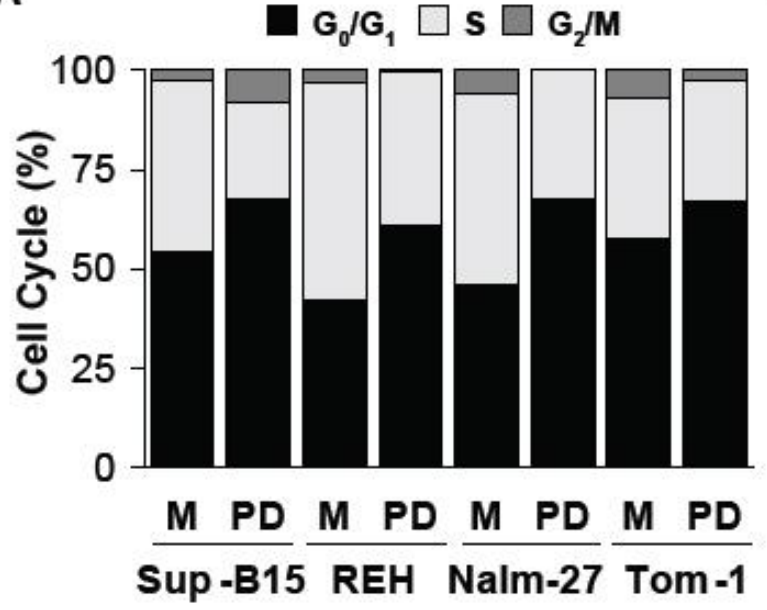

B

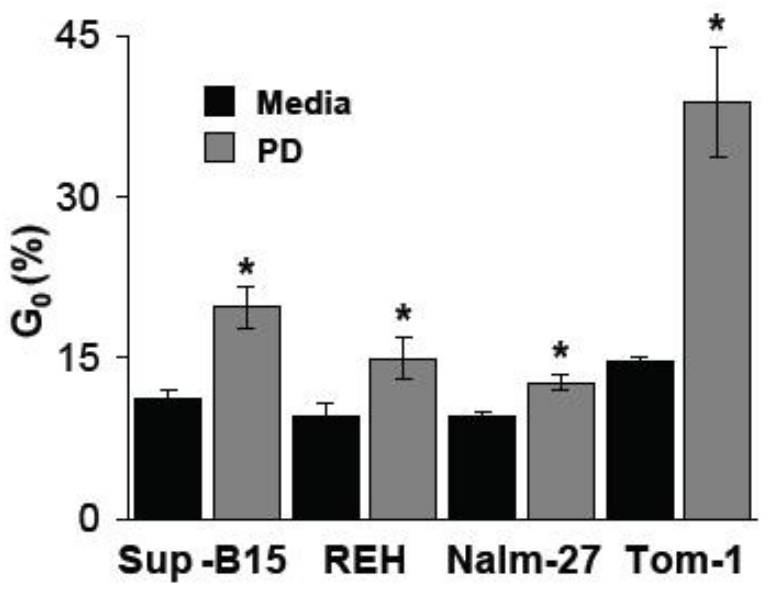

C
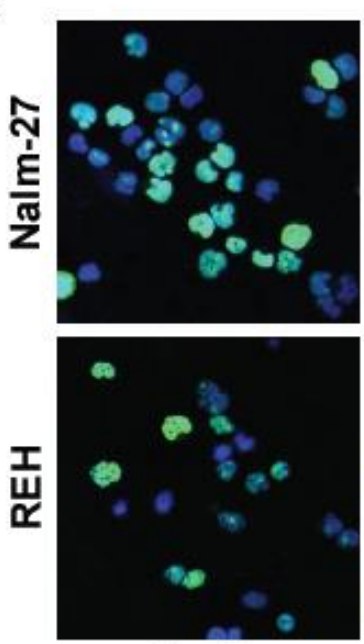

Media
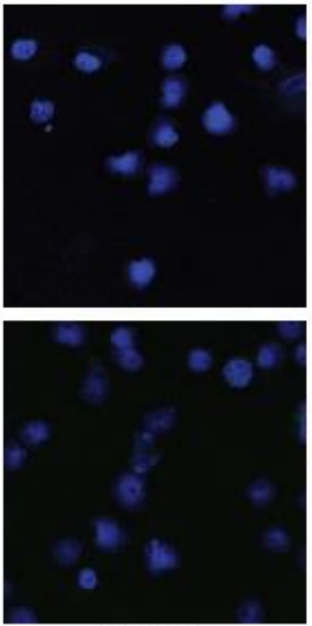

BMSC
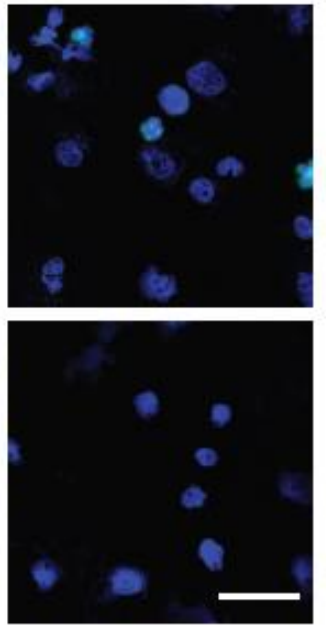

HOB
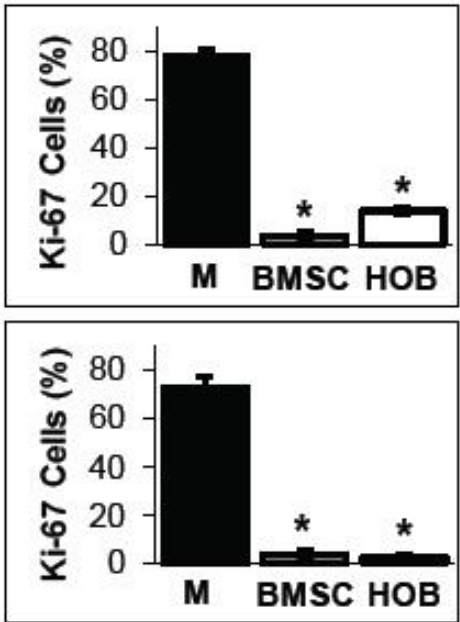

Figure 4: BMM cells influence the PD subpopulation cell cycle profile and increase quiescence 


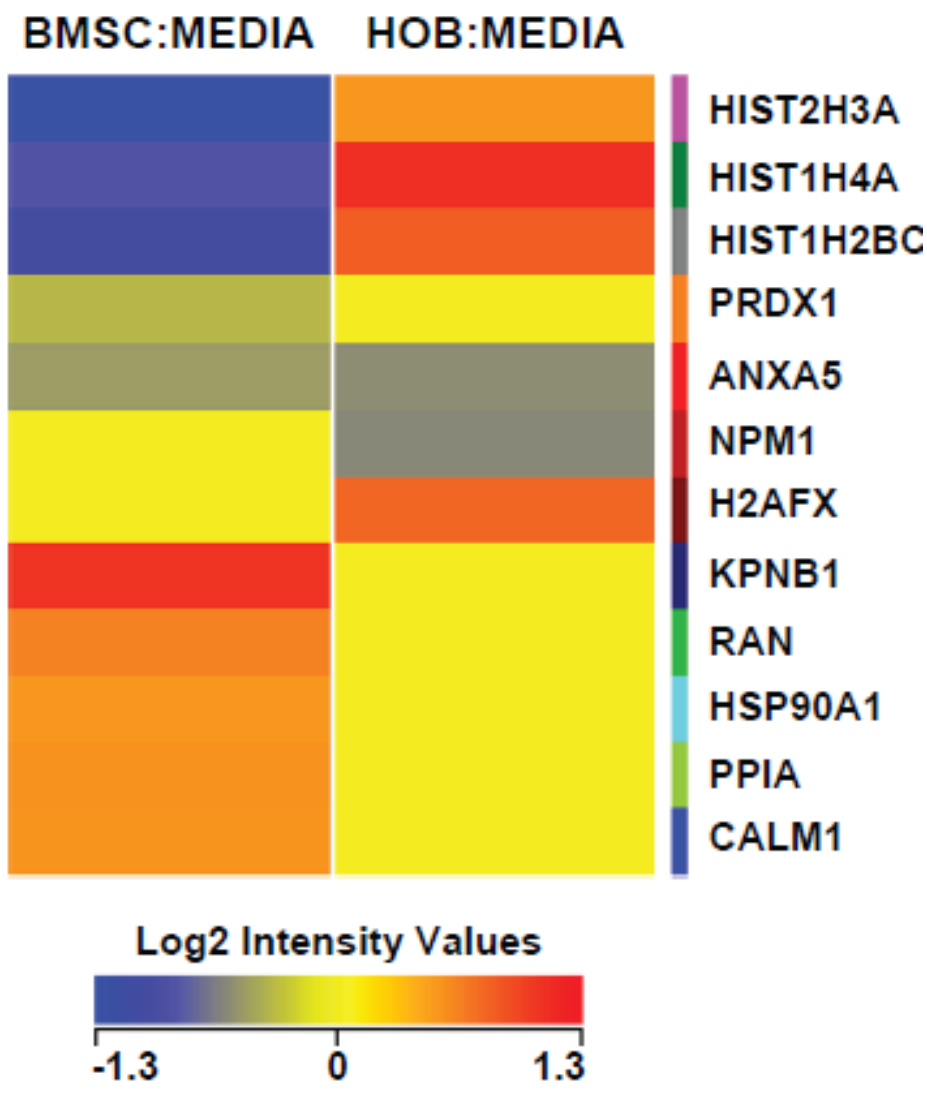

Figure 5: BMM alters global protein expression in ALL cells 

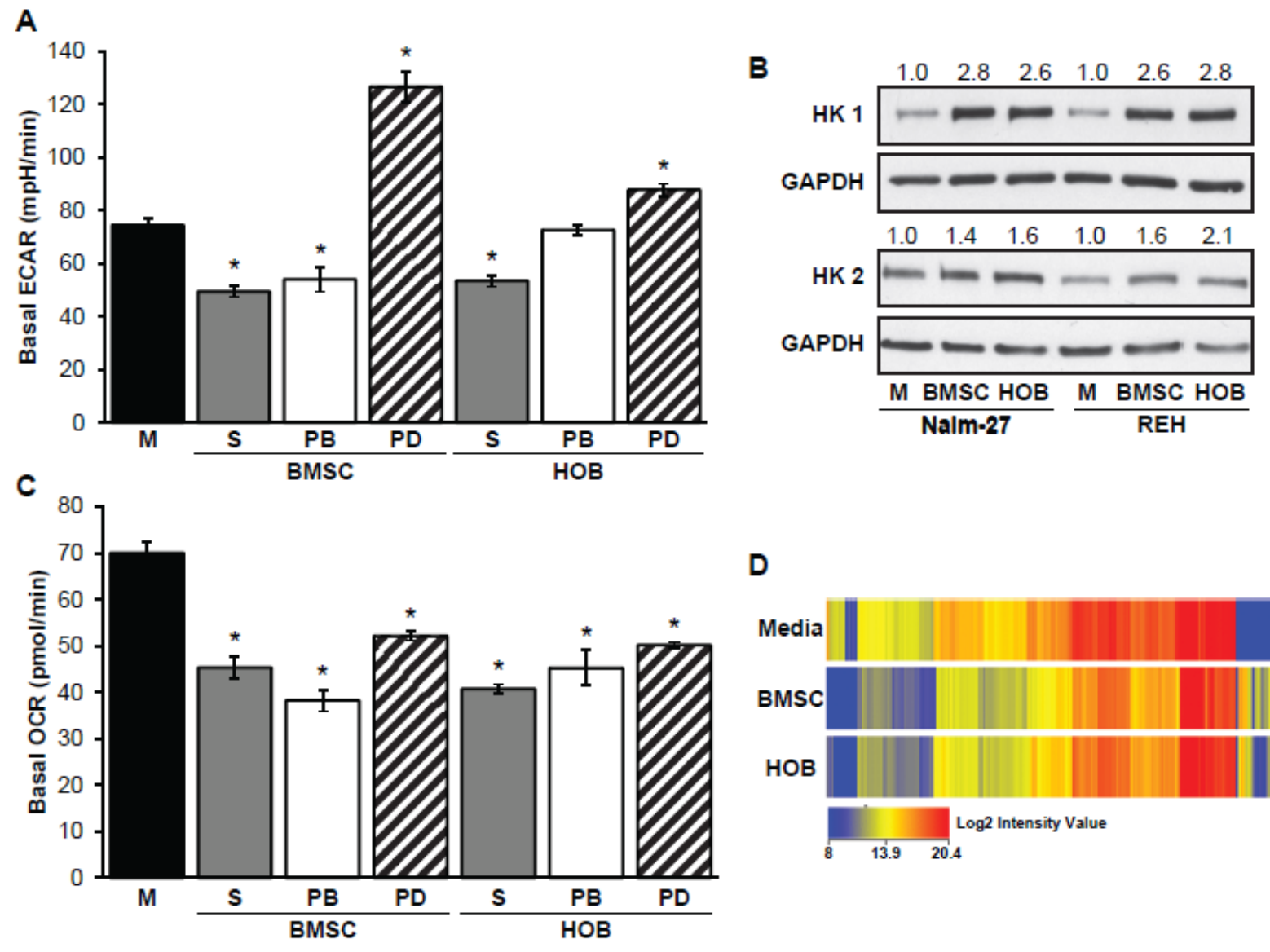

D

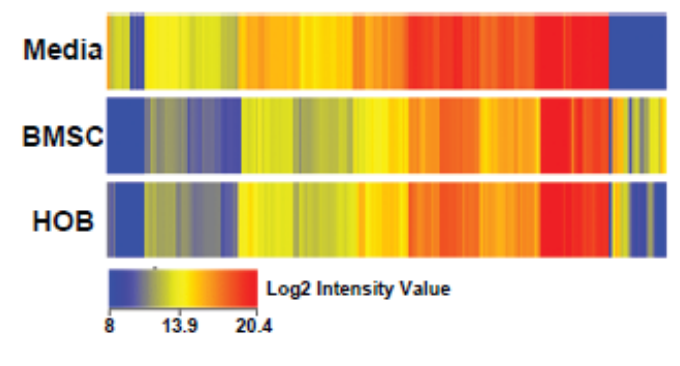

Figure 6: PD cells isolated from bone marrow niche co-culture have a distinct metabolic phenotype when compared to ALL cells in the absence of microenvironment signals 


\section{Chapter IV}

\section{Microenvironment Regulation of miR-221/222 in Acute Lymphoblastic Leukemia}

Blake S Moses ${ }^{1}$, Rebecca Evans ${ }^{1}$, William L Slone ${ }^{1}$, Debbie Piktel ${ }^{1}$, Ivan Martinez ${ }^{2}$, Michael D Craig $^{1}$ and Laura F Gibson ${ }^{1,2}$

${ }^{1}$ Alexander B. Osborn Hematopoietic Malignancy and Transplantation Program of the Mary Babb Randolph Cancer Center, Robert C. Byrd Health Sciences Center, West Virginia University School of Medicine, USA; ${ }^{2}$ Department of Microbiology, Immunology and Cell Biology, Robert C. Byrd Health Sciences Center, West Virginia University School of Medicine, USA

Keywords: Microenvironment, MicroRNA, Acute Lymphoblastic Leukemia, Quiescence, Chemosensitivity

This work is under revision from Molecular Cancer Research. 


\section{Abstract:}

Acute lymphoblastic leukemia (ALL) has many features in common with normal B-cell progenitors, including their ability to respond to diverse signals from the bone marrow microenvironment (BMM) resulting in regulation of cell cycle progression and survival. Bone marrow derived cues influence many elements of both steady state hematopoiesis and hematopoietic tumor cell phenotype through modulation of gene expression. miRNAs define one regulatory class of small non-coding RNAs that have been shown to be increasingly important in diverse settings of malignancy. In the current study miRNA profiles were globally altered in ALL cells following exposure to primary human bone marrow niche cells including bone marrow stromal cells (BMSC) and osteoblasts (HOB). Specifically, mature miR-221 and miR-222 transcripts were decreased in ALL cells co-cultured with BMSC or $\mathrm{HOB}$, coincident with an increase in the previously validated target, CDKN1B (p27). Increased p27 protein in ALL cells exposed to BMSC or $\mathrm{HOB}$ is consistent with accumulation of tumor cells $\mathrm{G}_{0}$ phase of the cell cycle and resistance to chemotherapy induced death. Overexpression of miR-221 in ALL cells during BMSC or HOB co-culture prompted cell cycle progression and sensitization of ALL cells to cytotoxic agents, blunting the protective influence of the BMM. These novel observations suggest that BMM regulation of miR-221/222 may contribute to marrow niche supported tumor cell quiescence and survival of residual cells.

Implications sentence: Niche influenced miR-221/222 may define a novel therapeutic target in ALL to be combined with existing cytotoxic agents to more effectively eradicate refractory disease that contributes to relapse. 


\section{Introduction:}

Acute lymphoblastic leukemia ( $A L L)$ is a disease that initiates, progresses and frequently relapses in the bone marrow. Within the marrow space tumor cells occupy the same niche that supports healthy hematopoiesis and have the capacity to respond to cues in that niche which regulate diverse processes including hematopoietic cell quiescence $(1,2)$. As such, it is not surprising that the bone marrow is the site of initiation, progression, and often relapse of aggressive hematopoietic malignancies (3). Bone marrow derived signals influence many elements of both steady state hematopoietic cell development and tumor cell biology through modulation of gene expression. Cues from human bone marrow stromal cells (BMSC) and osteoblasts $(\mathrm{HOB})$, elements of the bone marrow niche that influence leukemic cell biology, have been shown to influence crucial signaling associated with resistant ALL survival and progression $(4,5)$. We have previously reported microenvironment influence on survival pathways (6-9) and the maintenance of a "tumor stem cell" phenotype (10) driven by alteration of tumor cell gene expression profiles and regulation of protein expression or activity. In the current study we investigated tumor cell microRNA (miRNA) regulation influenced by stromal cells or osteoblasts as a novel mechanism by which the bone marrow niche may influence leukemic cells.

miRNAs define one non-coding RNA regulatory class that has been shown to be increasingly important in hematopoietic cell biology (11). MiRNAs are small single-stranded noncoding RNA molecules around 22-nucleotides (nt) long that regulate target genes posttranscriptionally. Binding of miRNAs to complementary sequences in the 3'-UTR of target mRNA prevents their translation through either translation termination, mRNA cleavage, or mRNA destabilization. This regulation is mediated through the RNA induced silencing complex (RISC). 
miRNAs are essential in normal cell development and maintenance, and their dysfunction has been shown to induce tumorigenesis in a variety of settings (12).

Regulation of miRNAs can occur transcriptionally, as well as during their processing and maturation (miRNA biogenesis) into active mature miRNAs. The canonical miRNA biogenesis is based on a stepwise processing machinery. MiRNAs are transcribed by RNA polymerase II to produce a 5'-cap and 3' polyadenylated primary miRNA (pri-miRNA) with one or more imperfect loop structures that are recognized by DGCR8 and cleaved by the enzyme Drosha in the nucleus. Cleavage of the pri-miRNA stem loop structure generates a precursor miRNA (premiRNA) that is recognized and transported to the cytoplasm by the Exportin-5 protein. The premiRNA is cleaved by the enzyme Dicer (mature miRNA), and loaded into the RNA-induced silencing complex (RISC) containing Argonuate $(13,14)$. Deficiencies in miRNA biogenesis have been shown to contribute to promotion and progression of disease (15) and patient outcome (16) in various malignancies.

Our lab has previously shown ALL cells associated with the bone marrow microenvironment (BMM) have altered cell cycle kinetics coincident with protection from several conventional chemotherapeutic agents (17). Two miRNAs described to regulate leukemic cell proliferation are miR-221 and miR-222 (18). They are clustered miRNAs that are located on the small arm of the $\mathrm{X}$ chromosome where they are transcribed on a single pri-miRNA by RNA polymerase II and regulate a nearly identical set of genes due to conservation of their seed sequence. A well validated miR-221/222 target gene in numerous cancers (18-20), including ALL (21), is the cell cycle inhibitor cyclin-dependent kinase inhibitor 1B (CDKN1B; p27). The expression of $p 27$ has been shown to blunt cell cycle progression at the $G_{0} / G_{1}$ transition with levels of p27 being higher in quiescent cells compared to those that are actively cycling (22). 
Manipulation of either miR-221 or miR-222 has the potential to result in cell cycle progression of previously quiescent cells, increasing the efficacy of $S$ phase specific chemotherapeutic agents in inducing apoptosis.

The current study demonstrates that exposure of tumor cells to signals from either human primary BMSC or HOB reduce ALL levels of mature miR-221/222 without overt changes in miRNA stability. Notable changes in the expression of miRNA biogenesis proteins, which may contribute to a blunting in mature miR-221/222, were observed in ALL cells following co-culture with either BMSC or HOB. Constitutive overexpression of miR-221/222 resulted in sustained proliferation and chemosensitivity of ALL cells, even during BMSC or HOB co-culture. These data suggest potential niche regulation of miRNAs may define a novel upstream signaling pathway that promotes tumor cell quiescence and coincident resistance to chemotherapy. The ability to interrupt BMM regulation of miR-221/222 in ALL cells provides a possible novel point of therapeutic intervention to eradicate quiescent, chemoresistant ALL cells that contribute to relapse of disease following cessation of treatment.

\section{Methods:}

Cell lines and Culture Conditions. In the following experiments, Philadelphia chromosome positive $(\mathrm{Ph}+)$ lymphoblastic cell lines SUP-B15 (ATCC \#CRL-1926) and Nalm-27 (Fujisaki Cancer Center) and Ph- REH (ATCC\#CRL-8286) were utilized. Cell line identity is routinely monitored by B-cell surface immunostaining and fluorescence in situ hybridization (FISH) analysis for Philadelphia gene status. In addition, primary human leukemic cells were acquired from the West Virginia University Health Sciences Center and West Virginia University Cancer Institute Biospecimen Processing Core and the Department of Pathology Tissue Bank. Primary 
patient sample $1(\mathrm{P} 1)$ is a patient with ALL at diagnosis and primary patient sample $2(\mathrm{P} 2)$ is a patient with CML in blast crisis (blasts considered active lymphoid disease). For primary patient samples, a pathology report accompanying the corresponding tissue of origin confirmed the identity of the samples. Representative elements of the microenvironment are modeled through use of BMSC and $\mathrm{HOB}$. BMSC are isolated from patients who have not received chemotherapy and have no evidence of marrow disease. HOBs (PromoCell) are isolated from femoral trabecular bone tissue from the knee or hip joint region. In tumor-BMSC/HOB co-culture, ALL cells are seeded at $0.5-1.0 \times 10^{6}$ cells $/ \mathrm{ml}$ on $\sim 85 \%$ confluent stromal layer and fed every 4 days at which time leukemic cells are collected for inclusion in experiments with remaining leukemic cells moved to new primary BMSC or HOB adherent layers consistently every 12 days. Cultures are maintained in $5 \% \mathrm{O}_{2}$ to model normal bone marrow oxygen tension, reported to range from $1-7 \%$ (23). The tumor population used in this study comprise of ALL cells which physically interact with the stromal adherent layer as opposed to the ALL cells in media suspension. The adherent tumor cell subpopulation, which we previously discribed to be the most chemotherapy resistant, were separated from the stromal layers by size exclusion with G10 Sephadex (Sigma) previously described (24) and used experiments described below.

Chemotherapeutic reagents. Cytarabine (Ara-C; Selleckchem, Cat \# S1648) and Vincristine (VCR; Selleckchem, Cat \# S1241) were stored per manufacturer recommendations and were diluted in base media immediately prior to use. Experimental concentrations of Ara-C $[1 \mu \mathrm{M}]$ or VCR $[25 \mu \mathrm{M}]$ were used to approximate clinically relevant doses reported as serum levels in ALL patients $(25,26)$.

Evaluation of leukemic cell viability. ALL cells were cultured in media alone or co-cultured with $\mathrm{BMSC}$ or $\mathrm{HOB}$ for 4 days to establish tumor-adherent cell interactions. At day 4 , cultures 
were provided fresh media and exposed to Ara-C or VCR for 48 hours. Viability was evaluated by trypan blue exclusion in triplicate samples.

Antibodies and western blot analysis. Rabbit polyclonal anti-p27 (Cat \# 3686), Drosha (Cat \# 3364), Dicer (Cat \# 5362), and Ago1 (Cat \# 5053) were purchased from Cell Signaling Technology and used at a 1:1000 dilution. Mouse polyclonal anti-GAPDH was purchased from Research Diagnostics Inc. RDI. Protein was isolated by lysing cells and concentration was determined using the bicinchoninic acid (BCA) protein assay (Pierce). Proteins were resolved on SDS-PAGE gels and transferred to nitrocellulose membranes. Membranes were blocked in TBS 5\%/nonfat dry milk $0.05 \%$ Tween-20 and probed with the indicated primary antibodies. After incubation with horseradish peroxidase-conjugated secondary antibodies, signal was visualized using enhanced chemiluminescence reagents (Amersham). Densitometry was performed by scanning the developed X-ray film (BioExcell) and quantified using ImageJ.

RNA isolation and quantitative real-time PCR (qRT-PCR). RNA was isolated from leukemic cells using the MirVana RNA isolation kit with TURBO DNase I digestion (Life Technologies). One-step qRT-PCRs for primary miRNA transcripts were performed in triplicate using $50 \mathrm{ng}$ of RNA per well, with the QuiantiTect SYBR Green RT-PCR kit (Qiagen) and mature miRNA levels were performed in triplicate using $20 \mathrm{ng}$ of RNA per well measured by 2-step qRT-PCR with TaqMan reagents (Life Technologies) on an Applied Biosystems 7500 real-time PCR machine. GUSB and U6 were used as loading controls. The primer sequence for primary miR-221/222 transcript; forward- TGGTAGTAGGTA AGTCCCAGAA and reverseTCAACACAACTGCCTACTGC. Primer sets designed to amplify mature miR-221/222 were purchased from Life Technologies. 
miRNA microarray profiling and target gene annotation. For initial profiling to identify subsequent targets for more in depth investigation, total RNA was isolated from Sup-B15 ALL cells cultured in media only or in co-culture with BMSC or HOB from triplicate independent cultures. RNA was processed by LC Sciences and miRNA microarray assays completed as previously described (27). Mature miRNAs in SUP-B15 cells co-cultured with BMSC or HOB that had a mean relative intensity of 500 or greater ( 0 to 30000 intensity scale) and a $P$ value $<0.05$ when compared to Sup-B15 cells grown in media without any BMSC or HOB exposure were further analyzed. Heatmap was created using GenePattern software. Using the prediction software TargetScan (28) and DIANA TarBase (29), a list of predicted target genes based on the seed sequence of the miRNA and validated target genes based on previously published work was generated for investigation.

Generation of miRNA overexpressing and sponge leukemic cells. To generate the miR221 overexpressing lenti-viral vector, a fragment of approximately 1 kilobase corresponding to the precursor miRNA and the surrounding sequences was amplified from normal genomic DNA. A large portion of miRNA surrounding sequence was included in the attempt to allow correct processing of pre-miR-221 to its mature form and to induce overexpression while preserving a physiologic mechanism of miRNA production. miRNA sponge expressing ALL cells were generated using antisense miRNA binding sites modified from (30). Two binding sites were designed for miR-221 and miR-222 per sponge sequence.

Cell proliferation assay. ALL cells were labeled with cell retention dye CellTrace-FarRed (Life Technologies) as described by manufacturer instructions. Cells were then cultured under normal growth conditions for 4 days in either media only or co-culture with BMSC or HOB. Tumor cell samples were fixed with $3.7 \%$ formaldehyde and CellTrace fluorescence intensity was measured 
by flow cytometry using LSRFortessia (BD Pharmingen). Proliferation indices were calculated using FCS Express4.

Immunofluorescence imaging. Confocal images were acquired using an upright LSM 510 Zeiss microscope and processed using Zen2009 software and Adobe Photoshop with fluorescence intensity held constant for any experiment in which image acquisition would be compared across samples. ALL sub-populations (tumor cells floating freely in co-culture versus those physically attached to or beneath adherent BMSC or HOB) were cytospun on glass slides following G10 Sephadex purification. Cells were fixed with 4\% PFA, blocked in 1x PBS 5\% FBS $0.3 \%$ Triton X-100, washed with 1x PBS, and incubated with rabbit anti-p27 (1:100) followed by anti-rabbit Alexa 647 (1:200). Slides were washed with PBS and mounted to coverslips using Prolong® Gold anti-fade/DAPI overnight (Life Technologies).

Statistical analysis. All data are presented as the mean \pm standard error (with the exception for qPCR data which was mean \pm standard deviation) and the statistical significances between conditions were determined by the Student $t$ test or 2-way ANOVA test using GraphPad software. All results are representative of at least 3 independent experiments $(p<0.05$ indicated by an * to denote statistical significance).

\section{Results:}

\section{ALL cells have reduced expression of miRNA biogenesis proteins when influenced by BMM}

It has been well documented that BMM niches that support hematopoiesis are hypoxic (31). Hypoxia and other factors associated with these niches have been reported by others to regulate miRNA biogenesis (32). To determine whether miRNA biogenesis proteins are regulated in ALL cells exposed to BMSC or HOB , Nalm-27 and REH ALL cell lines were co- 
cultured with BMSC or HOB and protein abundance measured by western blot. Drosha, a major component of the nuclear microprocessing complex during miRNA biogenesis, was downregulated in ALL cells co-cultured with BMSC or HOB compared to media only control (Fig. 1). A repression of Dicer, a cytoplasmic RNase III that cleaves precursor miRNA into mature miRNA duplexes, was also observed in ALL cells in co-culture, but not the RISC component Ago1 (Fig. 1) or Ago 2 (DNS). These data suggest an alteration in miRNA biogenesis processing in ALL cells influenced by the BMM.

\section{$\underline{\text { The BMM regulates leukemic miRNAs }}$}

To determine if leukemic cells co-cultured with BMSC or HOB have altered miRNA profiles as a result of dysregulation in the expression of proteins involved in miRNA biogenesis (Fig. 1), we performed a miRNA microarray on SUP-B15 ALL cell line co-cultured with BMSC or HOB or cultured in media only. A subset of miRNAs had altered abundance when influenced by the BMM (Fig. 2A). We focused on miR-221 and miR-222 because they had the highest significant repression in leukemic cells co-cultured with either BMSC or HOB compared to media alone control and they have been previously shown to target cell cycle and survival genes (Fig. 2B) (18). Validation by qRT-PCR of miR-221 and miR-222 levels presented a 2- to 8-fold repression in SUP-B15 cells co-cultured with BMSC or HOB relative to media alone control cells (Fig. 2C). This observation was consistent in Nalm-27 and REH ALL cell lines as well as primary patient samples when co-cultured with BMSC or HOB (Fig. 2D). Cell cycle inhibitor CDKN1B (p27) protein abundance, which is known to be negatively regulated by both miR-221 and miR$222(18,20)$, was increased in leukemic cell lines and patient samples when tumor cells were cocultured with BMSC or HOB as shown by western blot (Fig. 2E) and immunofluorescence based imaging (Fig. 2F) compared to leukemic cells grown in media alone. 
Sequestering miR-221 and miR-222 creates a more quiescent, chemoresistant ALL phenotype

To determine the contribution of miR-221/222 to ALL cell cycle progression and chemotherapy resistance, a constitutively expressed miRNA sponge targeting miR-221/222 was generated to sequester miR-221/222 by serving as a competitive binding partner to the two mature miRNAs and subsequently blunting their ability to bind to endogenous target genes (Fig. 3A). The effectiveness of sequestering the two miRNAs is shown in Figure $3 \mathrm{~A}$ by measuring intracellular p27 protein abundance by western blot in leukemic cells under media only growth conditions as a validated target. This observation was confirmed by immunofluorescence imaging of $p 27$ (Fig. 3B). Blunting miR-221/222 regulation of $p 27$ was associated with leukemic cells proliferating at a slower rate than empty vector control cells assessed by the proliferation index measured after 4 days using generational tracking (Fig. 3C). Coincident with reduced proliferation, miR-221/222 sponge cells are more chemoresistant to Ara-C and Vincristine relative to empty vector control cells (Fig. 3D).

miR-221 overexpression alters p27 abundance, proliferation rate, and chemosensitivity in ALL influenced by BMM

In order to investigate the significance of forced expression of miR-221/222 on ALL cell phenotype, including during BMM co-culture, ALL cell lines constitutively expressing pre-miR221 were developed. To confirm mature miR-221 overexpression qRT-PCR was completed with a 4- and 6-fold overexpression observed in Nalm-27 and REH ALL cells respectively (Fig. 4A). As demonstrated by western blot in Figure 4B, Nalm-27 and REH ALL cell lines overexpressing miR-221 are characterized by reduced abundance of p27, by approximately five-fold, when 
compared to empty vector controls. This observation was confirmed by immunofluorescence imaging (Fig. 4C).

Based on the observation that miR-221 overexpressing ALL cells had a marked reduction of the downstream target p27 when cultured in media only (Fig. 4), we next determined whether reduction would be maintained in ALL cells influenced by the BMM. Both Nalm-27 and REH empty vector control cells and miR-221 overexpressing cells were co-cultured with BMSC or HOB and the abundance of miR-221 and p27 transcripts and protein was evaluated by qRTPCR and western blot, respectively. ALL cells overexpressing miR-221 co-cultured with BMSC or HOB had miR-221 abundance comparable to ALL cells grown in media alone (Fig. 5A). When p27 abundance was assessed, miR-221 overexpressing cells had reduced levels of p27 when co-cultured with BMSC or HOB compared to matched empty vector control counterparts (Fig. 5B). To investigate if modulation of miR-221 in ALL cells can overcome the quiescent influence of the BMM, cell proliferation index was measured. ALL cells with empty vector or miR-221 overexpression were co-cultured with BMSC or HOB for 4 days. ALL cells with miR-221 overexpression proliferated significantly more than empty vector control cells when in media only as well as under co-cultured conditions (Fig. 5C). To determine whether ALL cells overexpressing miR-221 could overcome the protective influences of the BMM, the empty vector and miR-221 overexpressing ALL cells were co-cultured with BMSC or HOB and exposed to Ara-C or Vincristine. ALL cells overexpressing miR-221 were significantly more sensitive to chemotherapy exposure than empty vector controls, even during BMSC or HOB co-culture conditions (Fig. 5D). 


\section{BMM influences miR-221/222 biogenesis}

Based on the observation that BMSC or HOB co-culture correlated with repressed miRNA biogenesis proteins (Fig. 1) and reduced mature miR-221/222 transcript abundance (Fig. 2A), investigation of the pri-miRNA levels of miR-221/222 by qRT-PCR was completed. This aspect of the evaluation was aimed to determine if initial expression of the pri-miRNA transcript was potentially upstream of reduced mature transcript levels that were detected. Important to the experimental approach taken is that miR-221 and miR-222 are transcribed from the same primiRNA transcript. We observed that miR-221/222 primary transcript levels were unchanged in Nalm-27 and REH cells co-cultured with BMSC or HOB, but mature miR-221 was repressed in ALL cells compared to tumor cells cultured in media only (Fig. 6). Because regulation of miR221 and miR-222 does not appear to be due to transcriptional alteration, the stability of miR-221 and miR-222 when influenced by the BMM was assessed. No significant change in stability of the miRNAs being investigated was observed when leukemic cells grown in media only or cocultured with BMSC or HOB were compared after actinomycin D exposure (DNS). This observations suggests that miR-221/222 stability is unaffected by the $B M M$ and not a mechanism by which the BMM affects mature miR-221/222 levels.

\section{Discussion:}

While significant progress has been made in the treatment of $A L L$, disease relapse remains a concern that requires identification of mechanism-based innovative treatments. Specifically in children, aggressive treatment strategies required to treat relapsed ALL, with marked potential of late effects and treatment induced secondary malignancies, is a clinical challenge (33). Against this backdrop it is essential to reduce the toxicity of treatment without 
blunting efficacy. Targeting microenvironment-protected tumor cells which are typically more resistant to chemotherapy treatment $(6,7,9)$ may provide a strategy in the treatment of resistant and refractory ALL. A fundamental understanding of the mechanisms by which the microenvironment is protecting this subset of tumor cells may contribute to the development of novel therapeutic approaches.

Varied perspectives exist regarding whether therapeutic strategies should attempt to maintain cancer cells in a dormant-like state to blunt expansion versus attempting to force these cells through division rendering them responsive to cell cycle specific conventional chemotherapeutic agents. Based on data that correlate the number of tumor cells present in a patient after chemotherapy treatment with the likelihood of relapse (34), it may be ideal to eradicate quiescent residual tumor cells in sites of sanctuary like the bone marrow, when possible. For this approach to become a technical reality, we must better understand the critical elements of microenvironment supported tumor cell quiescence, which we recognize may be disease specific as well as sub-type specific given the heterogeneity within many malignancies. As such, it is not assumed that one model supports broad applicability across all types of lymphoblastic leukemia, but rather insights in a targeted setting may provide insight into signaling pathways that warrant interrogation in other settings in which the marrow microenvironment is well documented to provide a clinically problematic site of sanctuary for tumor cells.

Healthy pro-B cells rely on the bone marrow's signaling cues for survival, growth and differentiation (35) to sustain one lineage of baseline hematopoiesis. In the setting of ALL these interactions are "hijacked" and provide a sanctuary site for malignant B lineage cells that share many characteristics with their normal counterparts. Earlier work from our lab and many others 98 
has characterized altered pro-survival proteins, adhesion molecules, and stem cell characteristics in leukemic cells influenced by the BMM $(6-10,36)$. As our understanding of the complexity of mRNA species has broadened, so have the opportunities to better understand how the marrow niche may be influencing critical signaling pathways with consideration beyond traditional gene expression analysis.

The tumor microenvironment has been shown to play a role in the regulation of miRNA expression in diverse tumor types $(37,38)$, and consistent with previous observations, BMM interaction induced changes in ALL miRNA expression (Fig. 2A). Drosha and Dicer protein expression was repressed in chemotherapy resistant, quiescent BMM influenced ALL cells (Fig. 1). These observations align with recent findings that demonstrate altered miRNA biogenesis correlated to disease progression and overall patient outcome $(16,39)$. Initial interpretation of these results might suggest global repression of mature miRNAs, and in our model we do, in fact, observe that the majority of changes in miRNAs are reduced levels of transcripts being detected in ALL cells co-cultured with BMM derived cells relative to tumor cells grown in media alone (Fig. 2A; Suppl Table 1,2). However, other studies have demonstrated that miRNAs can be upregulated, even with a reduction in processing, with late stage lung cancer miR-210 providing one example through increased transcription (40). In the current study, two miRNAs down-regulated coincident with BMM interaction are miR-221 and miR-222, previously described as oncomiRs. These oncomiRs have been shown to be dysregulated in various cancer types $(41,42)$ with expression positively correlated with cell proliferation in gastric carcinoma and pancreatic cancer $(19,43)$. The most annotated target gene of miR-221/222 is the quiescence master regulator p27 (18-20). We demonstrate that p27 is abundant in the leukemic cells 
influenced by the BMM (Fig. 2D) consistent with previous observations of BMM supported ALL quiescence (17).

Targeted reduction of miR-221/222 reduced ALL cell cycle progression and increased chemotherapy resistance in the absence of any BMSC or HOB signal with a trend similar to ALL cells during co-culture of niche cells (Fig. 3). Not surprisingly, given the complexity of the BMM and interaction of multiple signaling cascades, interruption of miR-221/222 in isolation did not completely recapitulate the effects of the niche. However, these data combined with those from ALL cells constitutively overexpressing miR-221/222 suggest miR-221/222 may play a role in the promotion of the quiescent and resistant phenotype observed in ALL cells subsequent to BMM cell interaction.

Signals from BMM adherent BMSC or HOB did not significantly reduce the proliferation of leukemic cells constitutively overexpressing miR-221 (Fig. 5C) and were not able to restore chemoresistance in ALL cells when miR-221 was artificially sustained at or above baseline levels during co-culture (Fig. 5D). This suggests that the ability of the BMM to reduce miR-221 expression in leukemic cells is an important phenotypic change in ALL cells influenced by the BMM associated with increased ALL survival. However, forced miR-221 overexpression did not result in a complete loss of protection when compared to cells expressing the matched empty vector, again consistent with observations from several laboratories that have described complex contributions of the BMM protection of leukemic cells $(9,44)$. It is not suggested that any one pathway will define an absolute point at which niche protection can be eliminated, but rather an increased understanding of critical signaling pathways that may include miRNA regulation may contribute to innovative combination therapy to eradicate subsets of resistant residual cells. 
Collectively, these data suggest that the BMM regulates ALL cell quiescence and resistance from chemotherapy exposure by altering signals that converge on reduced levels of miR-221/222. The alteration does not appear to be due to transcriptional regulation of primary miR-221/222 transcript (Fig. 6), but potentially by the microenvironment effecting key components in miRNA biogenesis. This observation is consistent with pathways described in breast cancer (45) and in normal vascular smooth muscle cells (46) influenced by hypoxia or TGF- $\beta$, respectively. Anatomical niches that support hematopoietic cells in the BMM have been well characterized as being hypoxic (31) which raises the possibility of hypoxia as a key influence on healthy or malignant hematopoietic cell miRNA profiles resulting in regulation of quiescence. In addition, stromal elements have been reported by several labs to be a source of marrow TGF$\beta(47,48)$ and our laboratory has previously described increased activation of TGF- $\beta$ subsequent to chemotherapy (49). Exposure of hematopoietic tumors to both baseline and increased bioavailable TGF- $\beta$ in the niche could result in an unintended result of tumor cell quiescence during treatment regulated, in part, by TGF- $\beta$ regulated miRNA pathways.

The potential for the eradication of the quiescent leukemic cells that persist following traditional treatment makes the miR-221/222-p27 pathway intriguing as a future clinical target in residual disease. Although miRNA therapy is in early stages of development, there have been great strides made not only in the delivery, but also the specificity of miRNA therapy (50). Because novel miRNA based therapies are being developed it is important to understand the mechanisms by which miRNAs are being modulated in specific disease settings, such as therapy resistant $A L L$, in order to target upstream regulators. Targeted modulation of miRNA expression may provide an innovative approach to achieving the ultimate therapeutic goal of increasing disease-free survival with reduced overall toxicity in ALL. While relevant in general, progress is 
specifically needed in the pediatric population that comprises the predominant group of patients with the most significant long-term effects associated with aggressive therapy.

Acknowledgments: We are grateful for the support of Dr. Kathy Brundage and the West Virginia University Flow Cytometry Core Facility, supported by NIH S10-OD016165 and the Institutional Development Award (IDeA) from the NIH Institute of General Medical Sciences of the National Institutes of Health (CoBRE P30GM103488 and INBRE P20GM103434) along with Dr. Karen Martin and the West Virginia Microscope Imaging Facility, supported by the Mary Babb Randolph Cancer Center and NIH grants P20 RR016440, P30 GM103488 and P20 GM103434."

Disclosure of Potential Conflicts of Interest: No potential conflicts of interest were disclosed.

\section{References:}

1. Meads MB, Hazlehurst LA, Dalton WS. The bone marrow microenvironment as a tumor sanctuary and contributor to drug resistance. Clin Cancer Res. 2008;14:2519-26.

2. Boyerinas B, Zafrir M, Yesilkanal AE, Price TT, Hyjek EM, Sipkins DA. Adhesion to osteopontin in the bone marrow niche regulates lymphoblastic leukemia cell dormancy. Blood. 2013;121:4821-31.

3. Chiarini F, Lonetti A, Evangelisti C, Buontempo F, Orsini E, Evangelisti C, et al. Advances in understanding the acute lymphoblastic leukemia bone marrow microenvironment: From biology to therapeutic targeting. Biochim Biophys Acta BBA - Mol Cell Res [Internet]. [cited 2015 Nov 17]; Available from: http://www.sciencedirect.com/science/article/pii/ S0167488915002931 
4. Manabe A, Murti KG, Coustan-Smith E, Kumagai M, Behm FG, Raimondi SC, et al. Adhesion-dependent survival of normal and leukemic human B lymphoblasts on bone marrow stromal cells. Blood. 1994;83:758-66.

5. Shiozawa Y, Pedersen EA, Taichman RS. GAS6/Mer axis regulates the homing and survival of the E2A/PBX1-positive B-cell precursor acute lymphoblastic leukemia in the bone marrow niche. Exp Hematol. 2010;38:132-40.

6. Hall BM, Fortney JE, Taylor L, Wood H, Wang L, Adams S, et al. Stromal cells expressing elevated VCAM-1 enhance survival of B lineage tumor cells. Cancer Lett. 2004;207:22939.

7. Fortney JE, Zhao W, Wenger SL, Gibson LF. Bone marrow stromal cells regulate caspase 3 activity in leukemic cells during chemotherapy. Leuk Res. 2001;25:901-7.

8. Wang L, Fortney JE, Gibson LF. Stromal cell protection of B-lineage acute lymphoblastic leukemic cells during chemotherapy requires active Akt. Leuk Res. 2004;28:733-42.

9. Mudry RE, Fortney JE, York T, Hall BM, Gibson LF. Stromal cells regulate survival of Blineage leukemic cells during chemotherapy. Blood. 2000;96:1926-32.

10. Wang L, O'Leary H, Fortney J, Gibson LF. Ph+/VE-cadherin+ identifies a stem cell like population of acute lymphoblastic leukemia sustained by bone marrow niche cells. Blood. 2007;110:3334-44.

11. Montagner S, Dehó L, Monticelli S. MicroRNAs in hematopoietic development. BMC Immunol. 2014;15:14.

12. Lages E, Ipas H, Guttin A, Nesr H, Berger F, Issartel J-P. MicroRNAs: molecular features and role in cancer. Front Biosci Landmark Ed. 2012;17:2508-40.

13. Nguyen TA, Jo MH, Choi Y-G, Park J, Kwon SC, Hohng S, et al. Functional Anatomy of the Human Microprocessor. Cell. 2015;161:1374-87.

14. Winter J, Jung S, Keller S, Gregory RI, Diederichs S. Many roads to maturity: microRNA biogenesis pathways and their regulation. Nat Cell Biol. 2009;11:228-34.

15. Passon N, Gerometta A, Puppin C, Lavarone E, Puglisi F, Tell G, et al. Expression of Dicer and Drosha in triple-negative breast cancer. J Clin Pathol. 2012;65:320-6.

16. Lin R-J, Lin Y-C, Chen J, Kuo H-H, Chen Y-Y, Diccianni MB, et al. microRNA signature and expression of Dicer and Drosha can predict prognosis and delineate risk groups in neuroblastoma. Cancer Res. 2010;70:7841-50.

17. Moses BS, Slone WL, Thomas P, Evans R, Piktel D, Angel PM, et al. Bone Marrow Microenvironment Modulation of Acute Lymphoblastic Leukemia Phenotype. Exp Hematol. 2015. 
18. Frenquelli M, Muzio M, Scielzo C, Fazi C, Scarfò L, Rossi $C$, et al. MicroRNA and proliferation control in chronic lymphocytic leukemia: functional relationship between miR221/222 cluster and p27. Blood. 2010;115:3949-59.

19. Sarkar S, Dubaybo H, Ali S, Goncalves P, Kollepara SL, Sethi S, et al. Down-regulation of miR-221 inhibits proliferation of pancreatic cancer cells through up-regulation of PTEN, p27kip1, p57kip2, and PUMA. Am J Cancer Res. 2013;3:465-77.

20. Castagnino P, Kothapalli D, Hawthorne EA, Liu S-L, Xu T, Rao S, et al. miR-221/222 compensates for Skp2-mediated p27 degradation and is a primary target of cell cycle regulation by prostacyclin and cAMP. PloS One. 2013;8:e56140.

21. Kotani A, Ha D, Hsieh J, Rao PK, Schotte D, Boer ML den, et al. miR-128b is a potent glucocorticoid sensitizer in MLL-AF4 acute lymphocytic leukemia cells and exerts cooperative effects with miR-221. Blood. 2009;114:4169-78.

22. Zou P, Yoshihara H, Hosokawa K, Tai I, Shinmyozu K, Tsukahara F, et al. p57Kip2 and p27Kip1 Cooperate to Maintain Hematopoietic Stem Cell Quiescence through Interactions with Hsc70. Cell Stem Cell. 2011;9:247-61.

23. Chow DC, Wenning LA, Miller WM, Papoutsakis ET. Modeling $\mathrm{pO}(2)$ distributions in the bone marrow hematopoietic compartment. II. Modified Kroghian models. Biophys J. 2001;81:685-96.

24. Slone WS, Moses BS, Evans R, Piktel D, Martin KH, Petros W, et al. Modeling chemotherapy resistant leukemia in vitro. J Vis Exp. In press;

25. Liedtke M, Dunn T, Dinner S, Coutré SE, Berube C, Gotlib J, et al. Salvage therapy with mitoxantrone, etoposide and cytarabine in relapsed or refractory acute lymphoblastic leukemia. Leuk Res. 2014;38:1441-5.

26. Van den Berg HW, Desai ZR, Wilson R, Kennedy G, Bridges JM, Shanks RG. The pharmacokinetics of vincristine in man: reduced drug clearance associated with raised serum alkaline phosphatase and dose-limited elimination. Cancer Chemother Pharmacol. 1982;8:215-9.

27. $W L, Y h G, T f C, X z P, J g Y, Z y M$, et al. Identification of differentially expressed microRNAs by microarray: a possible role for microRNAs gene in medulloblastomas. Chin Med J (Engl). 2009;122:2405-11.

28. Lewis BP, Burge CB, Bartel DP. Conserved seed pairing, often flanked by adenosines, indicates that thousands of human genes are microRNA targets. Cell. 2005;120:15-20.

29. Hsu S-D, Tseng Y-T, Shrestha S, Lin Y-L, Khaleel A, Chou C-H, et al. miRTarBase update 2014: an information resource for experimentally validated miRNA-target interactions. Nucleic Acids Res. 2014;42:D78-85. 
30. Kluiver J, Slezak-Prochazka I, Smigielska-Czepiel K, Halsema N, Kroesen B-J, van den Berg A. Generation of miRNA sponge constructs. Methods. 2012;58:113-7.

31. Spencer JA, Ferraro F, Roussakis E, Klein A, Wu J, Runnels JM, et al. Direct measurement of local oxygen concentration in the bone marrow of live animals. Nature. 2014;508:26973.

32. Nallamshetty S, Chan SY, Loscalzo J. Hypoxia: a master regulator of microRNA biogenesis and activity. Free Radic Biol Med. 2013;64:20-30.

33. Malempati S, Gaynon PS, Sather H, La MK, Stork LC. Outcome After Relapse Among Children With Standard-Risk Acute Lymphoblastic Leukemia: Children's Oncology Group Study CCG-1952. J Clin Oncol. 2007;25:5800-7.

34. Zhao X-S, Liu Y-R, Zhu H-H, Xu L-P, Liu D-H, Liu K-Y, et al. Monitoring MRD with flow cytometry: an effective method to predict relapse for ALL patients after allogeneic hematopoietic stem cell transplantation. Ann Hematol. 2012;91:183-92.

35. Passa O, Tsalavos S, Belyaev NN, Petryk A, Potocnik AJ, Graf D. Compartmentalization of bone morphogenetic proteins and their antagonists in lymphoid progenitors and supporting microenvironments and functional implications. Immunology. 2011;134:349-59.

36. O'Leary H, Akers SM, Piktel D, Walton C, Fortney JE, Martin KH, et al. VE-cadherin Regulates Philadelphia Chromosome Positive Acute Lymphoblastic Leukemia Sensitivity to Apoptosis. Cancer Microenviron Off J Int Cancer Microenviron Soc. 2010;3:67-81.

37. Umezu T, Ohyashiki K, Kuroda M, Ohyashiki JH. Leukemia cell to endothelial cell communication via exosomal miRNAs. Oncogene. 2013;32:2747-55.

38. Wu H, Haag D, Muley T, Warth A, Zapatka M, Toedt G, et al. Tumor-microenvironment interactions studied by zonal transcriptional profiling of squamous cell lung carcinoma. Genes Chromosomes Cancer. 2013;52:250-64.

39. Jafarnejad SM, Sjoestroem C, Martinka M, Li G. Expression of the RNase III enzyme DROSHA is reduced during progression of human cutaneous melanoma. Mod Pathol Off $\mathrm{J}$ U S Can Acad Pathol Inc. 2013;26:902-10.

40. Puisségur M-P, Mazure NM, Bertero T, Pradelli L, Grosso S, Robbe-Sermesant K, et al. miR-210 is overexpressed in late stages of lung cancer and mediates mitochondrial alterations associated with modulation of HIF-1 activity. Cell Death Differ. 2011;18:465-78.

41. Pineau $P$, Volinia S, McJunkin K, Marchio A, Battiston C, Terris B, et al. miR-221 overexpression contributes to liver tumorigenesis. Proc Natl Acad Sci U S A. 2010;107:2649.

42. Zhang J, Han L, Ge Y, Zhou X, Zhang A, Zhang C, et al. miR-221/222 promote malignant progression of glioma through activation of the Akt pathway. Int J Oncol. 2010;36:913-20. 
43. Chun-Zhi Z, Lei H, An-Ling Z, Yan-Chao F, Xiao Y, Guang-Xiu W, et al. MicroRNA-221 and microRNA-222 regulate gastric carcinoma cell proliferation and radioresistance by targeting PTEN. BMC Cancer. 2010;10:367.

44. Zhang B, Li M, McDonald T, Holyoake TL, Moon RT, Campana D, et al. Microenvironmental protection of $\mathrm{CML}$ stem and progenitor cells from tyrosine kinase inhibitors through $\mathrm{N}$ cadherin and Wnt- $\beta$-catenin signaling. Blood. 2013;121:1824-38.

45. Shen J, Xia W, Khotskaya YB, Huo L, Nakanishi K, Lim S-O, et al. EGFR modulates microRNA maturation in response to hypoxia through phosphorylation of AGO2. Nature. 2013;497:383-7.

46. Davis BN, Hilyard AC, Lagna G, Hata A. SMAD proteins control DROSHA-mediated microRNA maturation. Nature. 2008;454:56-61.

47. Quante M, Tu SP, Tomita H, Gonda T, Wang SSW, Takashi S, et al. Bone marrow-derived myofibroblasts contribute to the mesenchymal stem cell niche and promote tumor growth. Cancer Cell. 2011;19:257-72.

48. Nemunaitis J, Tompkins CK, Andrews DF, Singer JW. Transforming growth factor beta expression in human marrow stromal cells. Eur J Haematol. 1991;46:140-5.

49. Wang L, Clutter S, Benincosa J, Fortney J, Gibson LF. Activation of transforming growth factor-beta1/p38/Smad3 signaling in stromal cells requires reactive oxygen speciesmediated MMP-2 activity during bone marrow damage. Stem Cells Dayt Ohio. 2005;23:1122-34.

50. Cheng CJ, Bahal R, Babar IA, Pincus Z, Barrera F, Liu C, et al. MicroRNA silencing for cancer therapy targeted to the tumour microenvironment. Nature. 2015;518:107-10. 


\section{Figure Legends:}

Figure 1. The BMM alters miRNA biogenesis protein expression in ALL. Drosha, Dicer, and Ago-1 protein abundance was measured in Nalm-27 and REH ALL cells in media only or cocultured with BMSC or HOB by western blot. GAPDH was used as loading control. The western blots are representative images of 3 independent experiments. M, media; $B$, BMSC; H, HOB.

Figure 2. ALL cells have miRNA alterations when influenced by the BMM. A, The heat map represents miRNA microarray data comparing SUP-B15 ALL cells co-cultured with BMSC or HOB to those grown in media only. B, The table represents miR-221 and miR-222 relative fold changes from the microarray along with experimentally validated target genes taken from TarBase (29) and predicted target genes taken from TargetScan (28). C, qRT-PCR validating miRNA microarray data measuring fold change of miR-221 and miR-222 in SUP-B15 ALL cells from the same conditions as A. D, qRT-PCR of mature miR-221 fold change in Nalm-27, REH, and 2 patient derived leukemic samples co-cultured with BMSC or HOB compared to those grown in media only. E, Western blots and F, immunofluorescence images of p27 abundance in Nalm-27, REH, SUP-B15 (excluding immunofluorescence images), and patient derived leukemic samples (due to lack of adequate sample, western blot analysis was unable to be performed for P2). Western blot values depict fold change relative to media only controls and normalized to housekeeping gene GAPDH. Error bars represent standard deviation of the mean with samples performed in triplicate. ${ }^{*}, \mathrm{P}<0.05$. Scale bars, $10 \mu \mathrm{m} . \mathrm{P} 1$, patient sample 1; P2, patient sample 2.

Figure 3. miR-221/222 sponge ALL cells have increased p27, with reduced proliferation and chemosensitivity. A, Schematic of lentiviral miRNA sponge construct along with western blot of 
p27 abundance alterations within Nalm-27 and REH miR-221/222 sponge cells. Values depict fold change relative to empty vector control and normalized to housekeeping gene GAPDH. B, Immunofluorescent images of p27 in miR-221/222 sponge cells compared to empty vector control. C, Proliferation index was measured 4 days after cell retention dye addition in cells described in A. D, The viability of these cells after 48 hour exposure to Ara-C and VCR were measured by trypan blue exclusion. Error bars represent standard error of the mean with samples performed in triplicate. ${ }^{*}, \mathrm{P}<0.05$. Western blot, immunofluorescent images and bar graphs are representative data from 3 independent experiments. Scale bars, $10 \mu \mathrm{m}$. EV, empty vector; Sp, sponge; Ara-C, cytarabine; VCR, vincristine.

Figure 4. Overexpressing miR-221 reduces p27 abundance in ALL. A, qRT-PCR of miR-221 fold change in Nalm-27 and REH cells overexpressing miR-221 compared to empty vector control. B, Western blot analysis of p27 abundance in Nalm-27 and REH cells overexpressing miR-221 or empty vector control. Values depict fold change relative empty vector control and normalized to housekeeping gene GAPDH. C, Immunofluorescent images of p27 expression under the same conditions as B. Error bars represent standard deviation of the mean with samples performed in triplicate. ${ }^{*}, \mathrm{P}<0.05$. Western blot, immunofluorescent images and bar graphs are representative data from 3 independent experiments. Scale bars, $10 \mu \mathrm{m}$. EV, empty vector; 221/ 221 OX, miR-221 overexpression.

Figure 5. miR-221 overexpression can overcome BMM regulation of ALL proliferation and survival. A, qRT-PCR of miR-221 fold change in Nalm-27 and REH overexpressing miR-221 cocultured with BMSC or HOB for 4 days compared to media only control. B, p27 abundance was measured in Nalm-27 and REH comparing empty vector control to miR-221 overexpression cells when in media only, co-cultured with BMSC or HOB by western blot. Values depict fold change 108 
relative to empty vector control and normalized to housekeeping gene GAPDH. C, Proliferation index was measured 4 days after cell retention dye was added with cells in same conditions as A,B. D, Viability of Nalm-27 and REH cells after 4 day co-culture with BMSC or HOB and exposure to Ara-C and VCR for 48 hours and measured by trypan blue exclusion. Error bars represent standard error of the mean with samples performed in triplicate. ${ }^{*}, \mathrm{P}<0.05$. Results are representative data from 3 independent experiments. Scale bars, $10 \mu \mathrm{m}$. $221 \mathrm{OX}, \mathrm{miR}-221$ overexpression; Ara-C, cytarabine; VCR, vincristine.

Figure 6. Primary transcript levels of miR-221/222 are unaltered in BMM influenced ALL. Fold change of the pri-miRNA of miR-221/222 and mature miR-221 was measured by qRT-PCR in Nalm-27 and REH cells co-cultured with BMSC or HOB relative to cells cultured with media only. Error bars represent standard deviation of the mean with samples performed in triplicate. ${ }^{*}, \mathrm{P}<$ 0.05. Results are representative data from 3 independent experiments. pri-miR, primary miRNA transcript; mature miR, mature miRNA. 


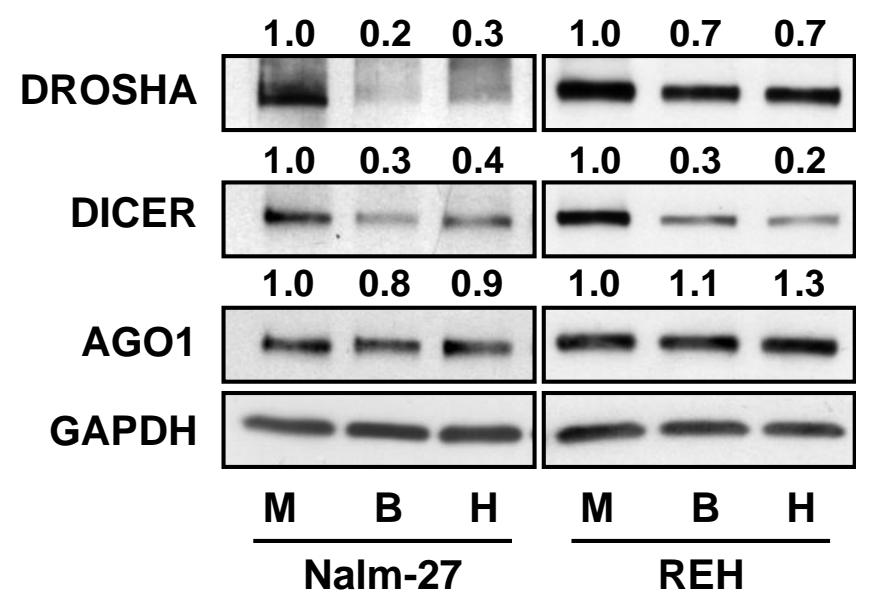

Figure 1: The BMM alters miRNA biogenesis protein expression in ALL 
A

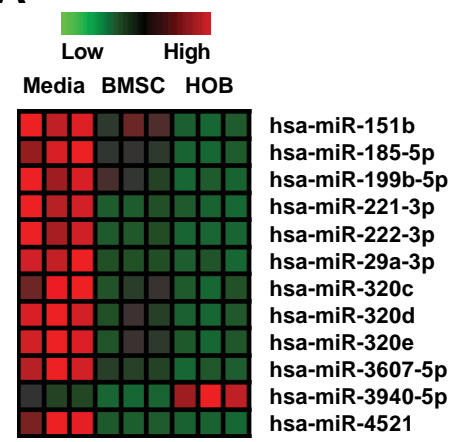

C

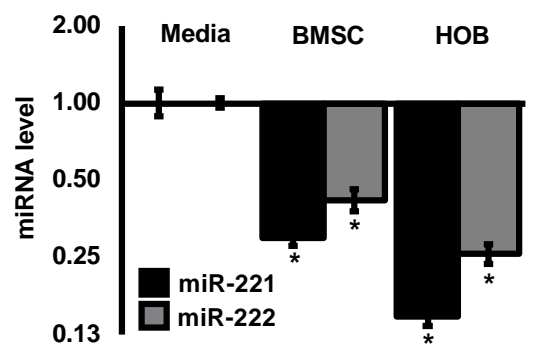

$\mathbf{E}$
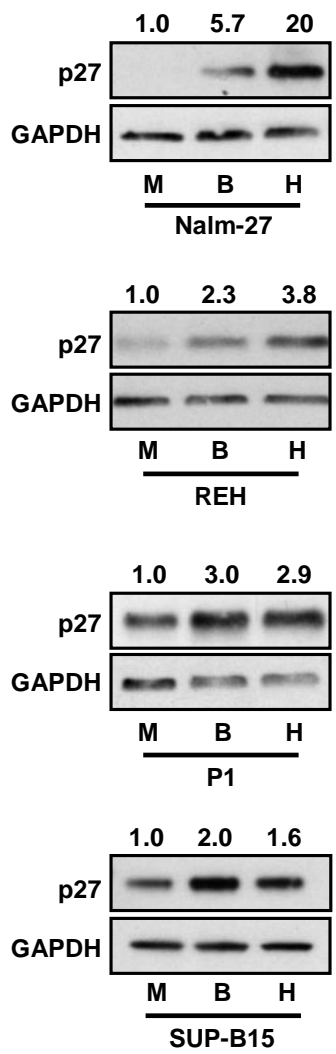

B

\begin{tabular}{|c|c|c|c|c|}
\hline MiRNA & $\begin{array}{c}\text { Fold } \\
\text { Change } \\
\text { (MA/BMS) }\end{array}$ & $\begin{array}{c}\text { Fold } \\
\text { Change } \\
\text { (MAHOB) }\end{array}$ & $\begin{array}{c}\text { Experimentally Validated } \\
\text { Target Genes }\end{array}$ & $\begin{array}{r}\text { Predicted Target } \\
\text { Genes Based on } \\
\text { Seed Sequence }\end{array}$ \\
\hline miR-222-3p & -4.26 & -7.84 & $\begin{array}{c}\text { CDKN1B, KIT, CDKN1C, } \\
\text { MMP1, SOD2, BIM, TNFSF10, } \\
\text { BBC3, PTEN, RGS6, CXCL12 }\end{array}$ & $\begin{array}{r}\text { RGS6, CD47, PI3KR1, } \\
\text { RAB1A }\end{array}$ \\
\hline miR-221-3p & -4.11 & -5.46 & $\begin{array}{c}\text { CDKN1B, KIT, CDKN1C, } \\
\text { DVL2, BIM, BNIP3L, TBK1, } \\
\text { BBC3, BMF, WEE1, CASP3, } \\
\text { CTNNB1, E2F3, LYN, FOS, } \\
\text { TNFSF10, PTEN, RGS6, IRX5, } \\
\text { CXCL12 }\end{array}$ & $\begin{array}{r}\text { RGS6, IRX5, CD47, } \\
\text { PI3KR1, RAB1A }\end{array}$ \\
\hline
\end{tabular}

D

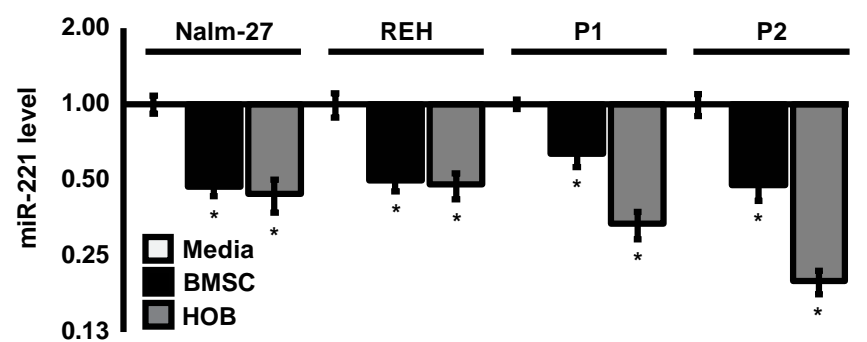

$\mathbf{F}$
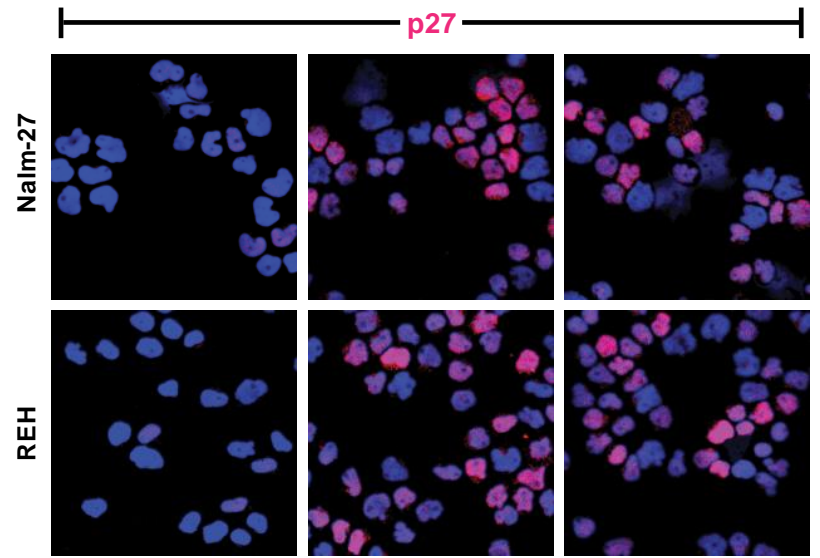

$\overline{1}$
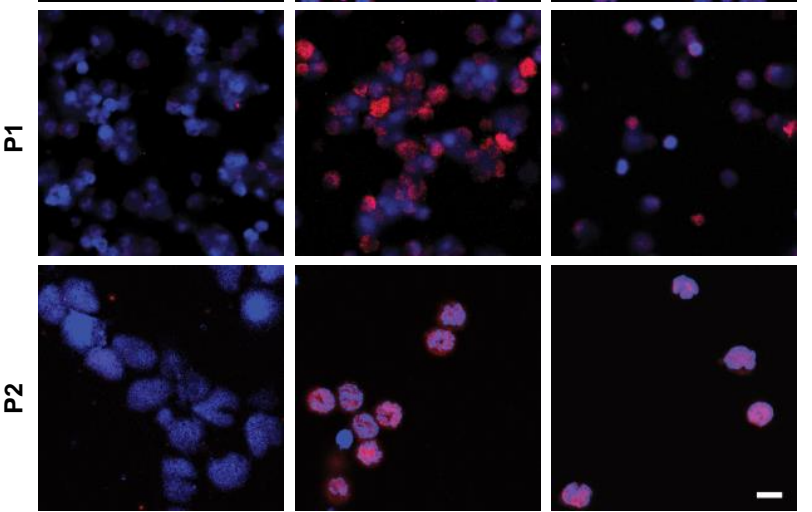

Media

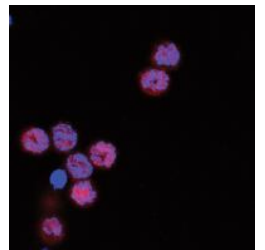

BMSC

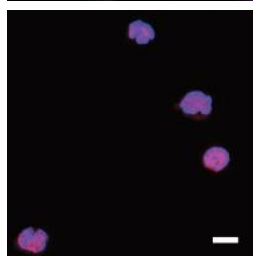

НОВ

Figure 2: ALL cells have miRNA alterations when influenced by the BMM 
A
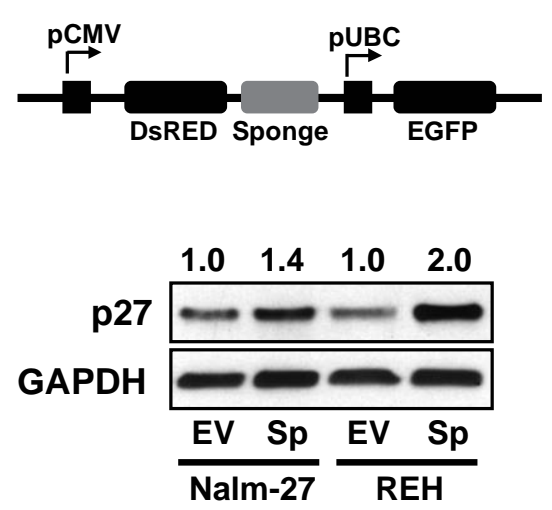

C

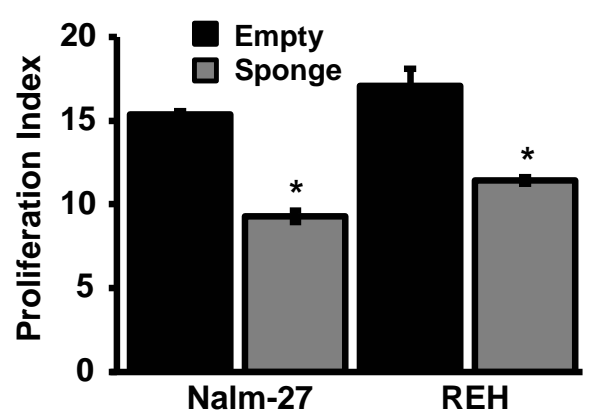

D

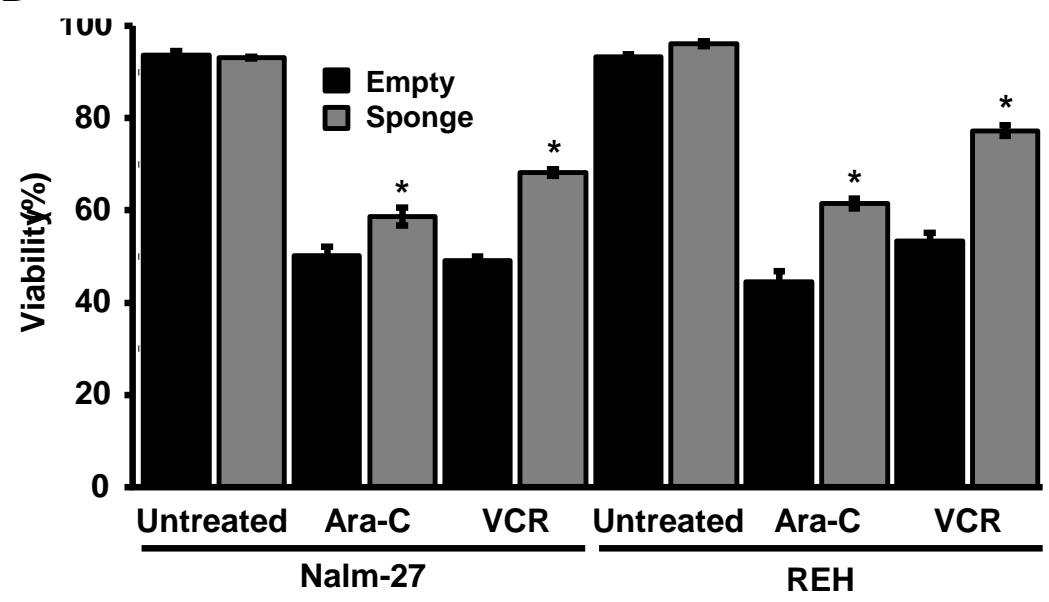

Figure 3: miR-221/222 sponge ALL cells have increased p27, with reduced proliferation and chemosensitivity 
A

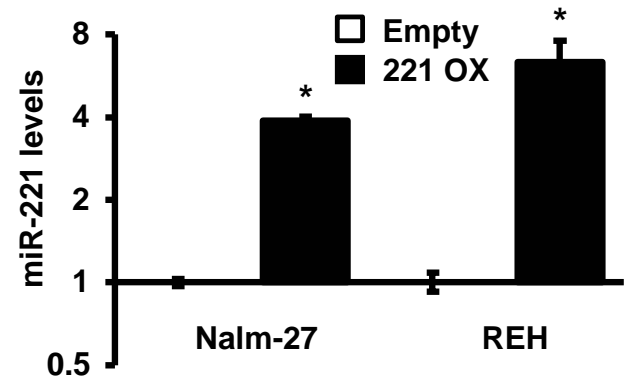

B

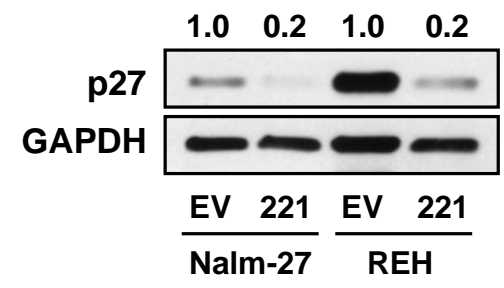

C

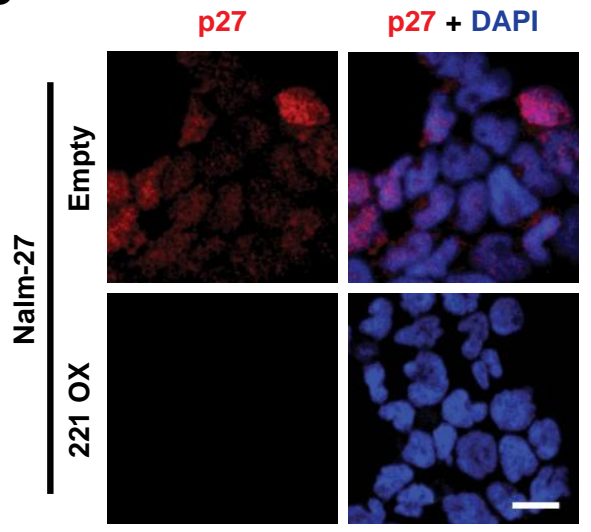

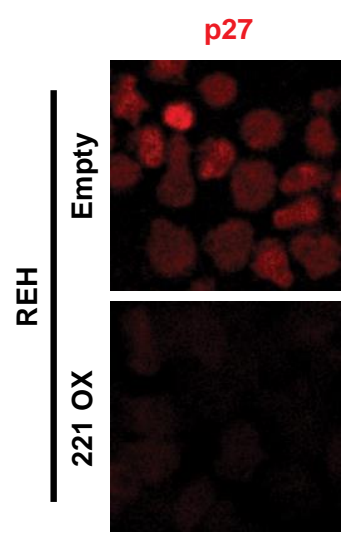

p27 + DAPI

Figure 4: Overexpressing miR-221 reduces p27 abundance in ALL 
A

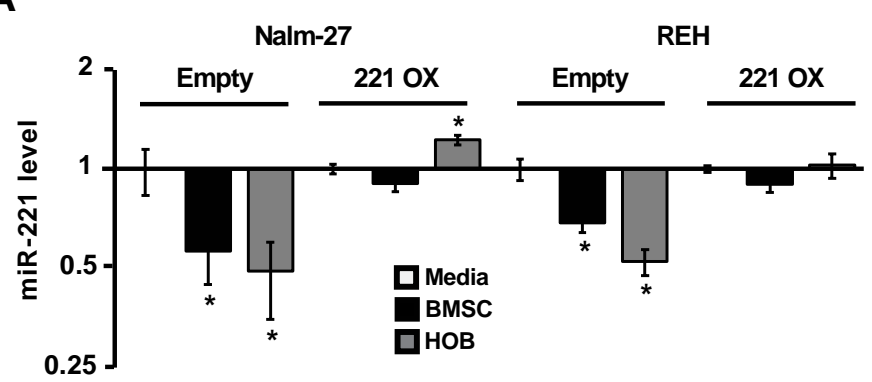

B

C
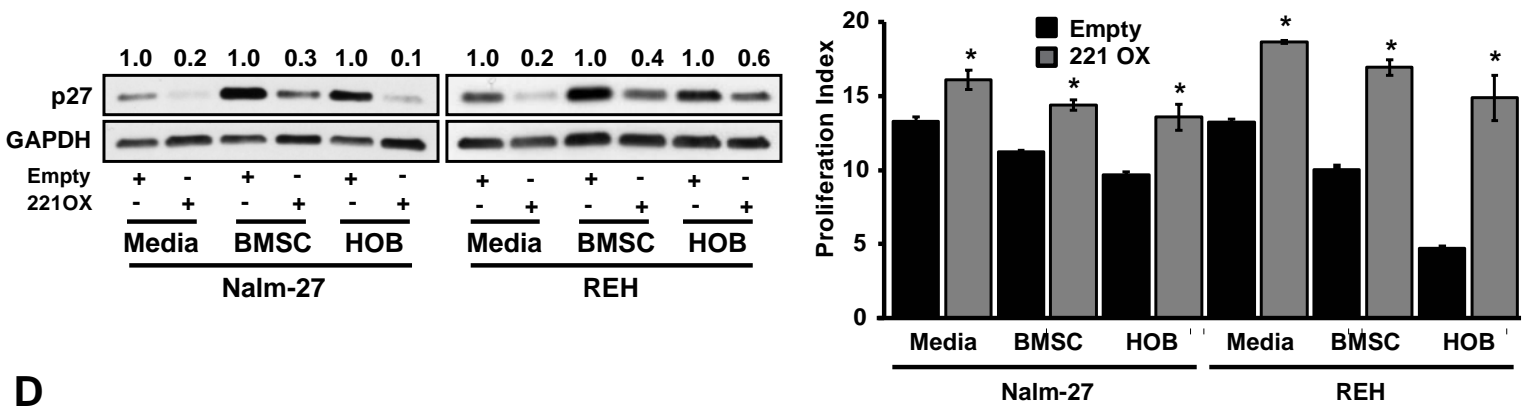

D
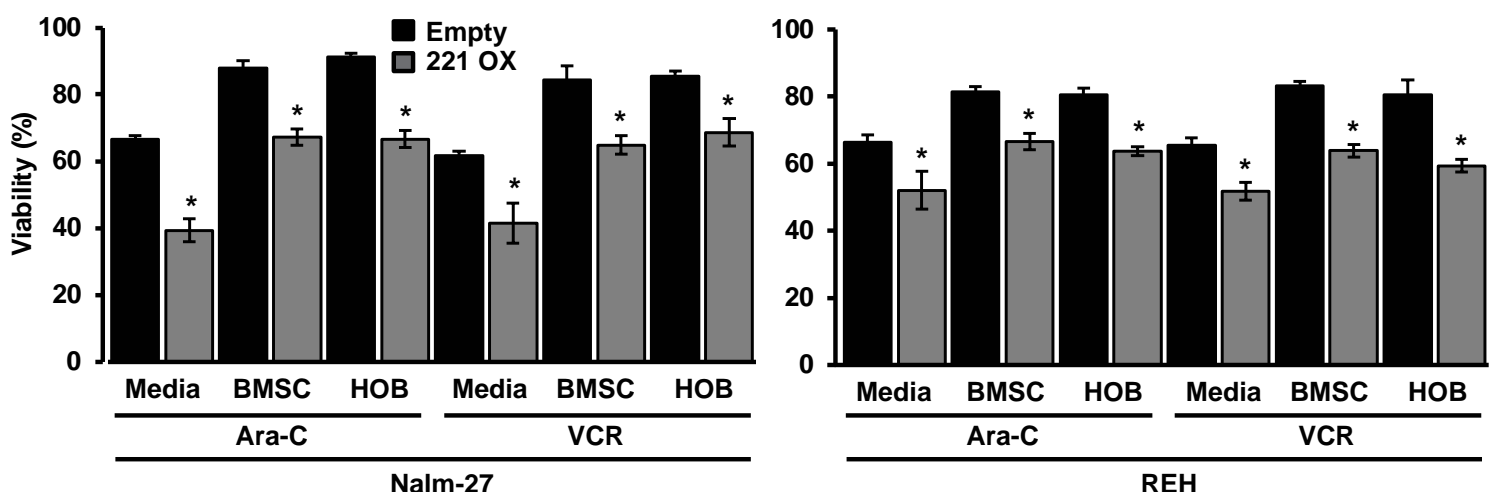

Figure 5: miR-221 overexpression can overcome BMM regulation of ALL proliferation and survival 


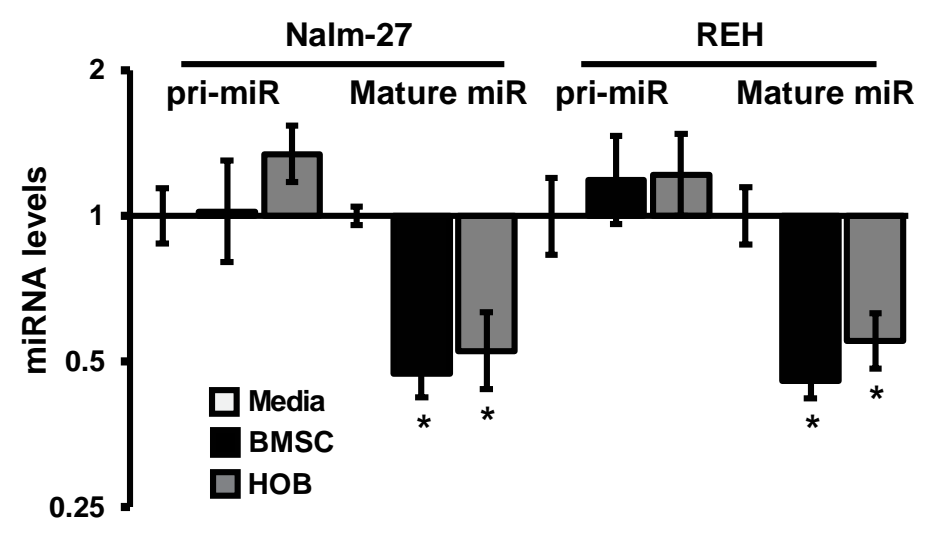

Figure 6: Primary transcript levels of miR-221/222 are unaltered in BMM influenced ALL 
Chapter V

General Discussion 
Significant advancements in leukemia treatment have been made since the first cytotoxic agent, arsenic, was administered in the mid-nineteenth century ${ }^{1}$. Drug selectivity has increased concurrent with the reduction in off-target toxicity. In the United States, the current percentage of patients with acute lymphoblastic leukemia (ALL) that achieve initial remission is greater than $95 \%$. Patients that are younger than fourteen tend to have a better prognosis than patients over the age of sixty ${ }^{2,3}$. This can be attributed, in part, to differences in treatment tolerance and the cytogenetics of patients that underpin specific cellular changes. Children can often tolerate more aggressive chemotherapy treatments than adults ${ }^{4}$. Children also have a lower likelihood of developing aggressive subtypes of leukemia which arise from cytogenetic abnormalities including translocations (i.e. Philadelphia chromosome) ${ }^{5}$. In all age groups the major concern lies with residual, treatment refractory, disease that is present after therapy has been completed. The number of remaining leukemia cells after treatment, termed minimal residual disease (MRD), has been shown to directly correlate with likelihood of disease relapse ${ }^{6}$. As mentioned previously, the bone marrow's protective nature plays a pivotal role in disease relapse through diverse protective cues that it provides to tumor cells. Not only is the bone marrow microenvironment the site of disease initiation, it is the most common site for relapse ${ }^{7}$. The ability of leukemia cells to commandeer the niche and arrogate normal HSPC signaling factors has been demonstrated to directly impact tumor cell resistance and survival ${ }^{8,9}$. The interruption of the cross-talk between the bone marrow niche and tumor cells has the potential to improve survival rates of ALL patients by rendering tumor cells more vulnerable to therapy induced death. Although modern treatments may eradicate the majority of leukemia cells from patients, a minority of surviving tumor cells ultimately dictate the length of a patient's disease-free survival. Modern conventional chemotherapy agents frequently target dividing cells. The misfortune with 
this strategy is two-fold; first, treatment effects the viability of non-cancerous dividing cells as bystanders, and second, tumor cells that are in a quiescent state are more likely to remain viable after treatment ${ }^{10-12}$. The inability to target non-dividing tumor cells is a clinical challenge in which novel strategies are being established. Although the development of inhibitors which disrupt tumor metabolism or adoptive cell transfer of T-cells with chimeric antigen receptors have been successful in the treatment of non-proliferative tumor cells, there are a minimal amount of cancer subtypes that will achieve therapeutic response ${ }^{13,14}$.

An initial step to combat refractory disease is to develop models which can specifically support examination of leukemia cells that are quiescent, and chemotherapy resistant, driven by bone marrow niche interactions. It is essential to investigate these interactions on a molecular scale in order to continue to bridge the gap between clinical application and bench-top results. Although in vivo models are beneficial because they more closely resemble human disease in a completely closed animal system, they can be very costly and time demanding. Developing in vitro models which conceivably are able to be modified for high-throughput experimentation, which are less expensive and more time efficient, could prove to be more effective. Advancing in vitro models would not replace the need for animal models, but it would potentially elevate in vivo experiment efficiency by better advising experimental design. With strong data in hand, for example, optimal use could be made of patient derived xenograph (PDX) models of hematopoietic disease. Our research team has designed an in vitro model that can assist in the investigation of refractory leukemic disease. Rainer Ordemann's laboratory observed CD34+ HSPC co-cultured with mesenchymal stem cells (MSCs) established different subpopulations ${ }^{15,16}$. The three HSPC subsets observed were either suspended in media (S), adhered to the MSCs monolayer which were phase bright (PB) under light contrast microscopy, 
or were buried beneath the MSC monolayer which were phase dim (PD). Not only were the HSCs in different spatial locations, phenotypic variations including cell cycle profile, oxygen tension, and preservation of stem-like characteristics were witnessed ${ }^{15}$. Since leukemia cells have many similarities to HSPCs, our laboratory applied their observations to our model. As described in Chapter $\mathrm{II}^{17}$, leukemia cells form similar distinct populations when in co-culture with BMSC or HOB that HSPCs formed with MSCs. One population in particular, the PD subset physically buried beneath adherent BMSC or $\mathrm{HOB}$, displayed a highly chemotherapy resistant phenotype. For reproducibility of results, a strict schedule of medium replacement and continued co-culture passage to newly confluent BMSC or $\mathrm{HOB}$ plates was maintained to ensure consistency with minimal culturing variability. In order to assess phenotypic changes within the different subsets of leukemia cells, previously developed G-10 sephadex particle column separation ${ }^{18}$ was utilized to separate the BMSC and HOB components from the tumor cells so that a pure population of leukemia cells could be isolated. Although our laboratory is aware of the fact that these specific leukemia cell populations may not be present in a patient in the same spatial context, the observation that a resistant, quiescent leukemic cell population exists which contributes to relapse of disease is apparent and has been previously shown to occur in patients ${ }^{12,19}$. As such, the resistant subset under the influence of BMSC or HOB provides a biologically relevant approach to address a significant clinical problem.

Further investigation was necessary to acquire a better understanding of the highly resistant PD leukemia cell population. A surprising observation demonstrated in Chapter III; Figure 2 indicated that the PD population was not a "fixed" population in terms of either physical location or phenotype ${ }^{20}$. Any of the three leukemia populations (S, PB or PD) could reconstitute the PD population demonstrating that spatial location relative to the bone marrow niche cells is 
the unique component dictating the altered phenotype of the cells and the relationship is dynamic. This observation further validates the influence the bone marrow microenvironment has on leukemia cells and why it is essential to disrupt these interactions. It also highlights the potential therapeutic advantage if approaches can be developed to drive tumor cells out of the protective niche since stable changes in tumor cells from the PD population were not noted. This approach is in contrast to the observation that sub-clones of leukemic cells have been described that have specific stable mutations and aggressive phenotype associated with it ${ }^{21,22}$. This model is focused uniquely on transient resistance that is conferred by interaction with BMSC and HOB that may provide a therapeutic target.

The protective nature that was observed from the bone marrow derived cells was shown to be highly specific to cells constituting that niche, and not simply "protection" of PD tumor cells buried beneath an adherent layer from any anatomical site. When ALL cells were co-cultured with non-bone marrow derived adherent cells (i.e. human embryonic kidney cells or mouse fibroblasts) and subsequently exposed to chemotherapy, protection was either entirely absent, or not as pronounced (Chapter III; Figure 3) ${ }^{20}$. Along with cell cycle distribution and chemosensitivity alterations, metabolite and histone gene expression profiles appear to have variations when comparing ALL cells grown in media alone to tumor cells co-cultured with BMSC or HOB (Chapter III; Figures 5,6$)^{20}$. These data support a much broader hypothesis that the tumor microenvironment alters not only survival and quiescent signals, but the cell's energy metabolism and epigenetic profile which has been supported by Cairns et al. ${ }^{23}$ and Taddei et al. ${ }^{24}$. Further experiments are underway in our laboratory to investigate the significance of niche regulated metabolism in pathogenesis of ALL. 
From these observations, a broadened appreciation for the multitude of signaling pathways that are potentially affected by the bone marrow regulation on ALL was gained. Recent reports have illustrated the involvement miRNAs have in normal hematopoiesis and the importance of temporal miRNA expression in differentiating progenitor cells ${ }^{25}$. Bone marrow microenvironment regulation of miRNAs in normal differentiation stages of hematopoiesis ${ }^{25-27}$ along with expanding observations that tumor cell miRNAs can be modulated by surrounding stroma ${ }^{28-31}$ contributed to our hypothesis that the bone marrow microenvironment regulates ALL cellular quiescence and survival through the modulation of miRNAs. We, and others, have documented many protein level changes in tumor cells that are influenced by niche signals, but miRNAs as a master regulator of tumor cell phenotype in this model had not been investigated ${ }^{32-}$ 37.

With a well-defined co-culture model, we sought to determine whether miRNAs were altered in ALL cells influenced by the bone marrow niche. miRNAs define one regulatory class of small non-coding RNAs that are ubiquitously expressed in plant and animal cells. Preliminary data showing that miRNA biogenesis proteins, Drosha and Dicer, were altered in ALL tumor cells co-cultured with BMSC or HOB (Chapter IV; Figure 1), further supported the rationale for investigating miRNA profiles in ALL cells. Consistent with the reduction in Drosha and Dicer levels, a miRNA microarray displayed a global decrease in miRNA levels in ALL cell cells cocultured with bone marrow niche cells. Focusing on modulated miRNAs that have previously been described to alter cell quiescence and survival ${ }^{38-43}$ and based on the results of the miRNA microarray, we assessed miR-221 and miR-222's (miR-221/222) role in ALL cell phenotype. As highlighted in chapter IV, miR-221/222 abundance is reduced in leukemia cells co-cultured with BMSC or HOB compared to their counterparts grown in media alone. It has been demonstrated 
by others that these miRNAs regulate the translation of the quiescence inducer p27 mRNA ${ }^{38,43-}$ 45. Reduced miR-221/222 was coincident with accumulation of tumor cells in a quiescent cell cycle phase along with chemotherapy resistance (shown in Chapter II and III) ${ }^{17,20}$. To investigate the biological significance of reduced miR-221/222 levels in ALL cells, we designed a miRNA "sponge" construct that would constitutively sequester miR-221/222 and therefore reduce its binding to endogenous target genes, such as p27. We observed that both proliferation rates and chemotherapy sensitivity were lowered in ALL cells with expression of the miRNA sponge cultured in media alone compared to cells expressing the empty vector control construct. We conclude from these observations that reducing miR-221/222 effectiveness at regulating its target genes partially mimics the microenvironment protection and cell cycle control of ALL cells we have consistently observed. We next investigated whether constitutively increased miR221/222 levels in ALL cells that were co-cultured with BMSC or HOB, would sensitize the tumor cells to chemotherapy exposure, theoretically by blocking the ability of BMSC or HOB to support the down regulation of these miRNAs. While we did not expect this single manipulation to completely blunt the supportive role of the BMSC or $\mathrm{HOB}$, the goal was to determine if downregulation of the miRNAs of interest was an essential part of the protective pathway. We examined this by constitutively expressing precursor miR-221 in ALL cells cultured in media alone or co-cultured with BMSC or $\mathrm{HOB}$ and measured their proliferation rates. As expected, ALL cells constitutively expressing miR-221 were more proliferative than empty vector control cells even when co-cultured with bone marrow niche cells. Important as a functional readout was the observation that when exposed to chemotherapy agents, even while in co-culture, ALL cells constitutively expressing miR-221 were less resistant than the empty vector controls. Together, these data indicate that ALL cells constitutively expressing miR-221 are partially able to 
overcome the bone marrow niche protective nature and become more susceptible to chemotherapy exposure. The manipulation of miR-221/222 in ALL could be an intriguing clinical target in conjunction with traditional chemotherapy to potentially eradicate resistant disease or to potentially decrease the levels of drugs required if sensitivity of tumor cells could be enhanced.

Although manipulating miRNA levels in vitro is a relatively standard technique, achieving this in humans remains challenging. miRNAs regulate over sixty percent of coding genes in humans ${ }^{46}$. Harnessing the potential to target tens to hundreds of genes which can redirect biological functions and pathways involved in tumor development and progression by manipulation of a single miRNA is an attractive concept. However, immediate concern is also raised regarding the global effect of such a strategy with the possibility that many critical functions in normal cells may also be disrupted with a negative outcome. This has been the longstanding issue with conventional therapy as well, and particularly challenging with leukemic cells that so closely resemble their healthy hematopoietic counterparts. As such, the issue in the forefront of miRNA or more broadly, RNA interference (RNAi) therapies is sustained stability and tissue selectiveness. To improve stability, investigators have developed various biological modifications including the addition of methyl groups and methylene bridges (locked nucleic acids) to ribose sugars which create RNA molecules which have a greater binding affinity to targets along with an increase resistance to RNase degradation ${ }^{47}$. A primary concern with RNAi therapy is target tissue specificity. The challenge begins with the RNA therapeutic exiting the circulatory system and transiting the cell membrane. Because the kidneys will filter and excrete molecules less than 50 kilodaltons (which include unconjugated RNA molecules), carrier constructs that encapsulate RNA molecules need to be utilized. PEGylated liposomes, lipidoids, and biodegradable polymers are a few of the methods employed as carriers to encapsulate RNA 
therapeutics ${ }^{48}$. These complexes employ successful transition between lipid membranes, but a lack of tissue specificity remains a drawback. Recently, a polypeptide derived from Archaea can form a stable transmembrane alpha helix under acidic conditions, which can fold and insert into lipid membranes ${ }^{49}$. Binding a neutral molecule to this $\mathrm{pH}$ low insertion peptide (pHLIP) theoretically will flip the peptide and attached molecule through the cell membrane and into the cytoplasm under low pH conditions. This has been shown by Frank Slack's laboratory to be an effective vehicle to selectively insert modified anti-sense miRNAs into low $\mathrm{pH}$ mouse tissues ${ }^{50}$. Since acidosis, which creates a low $\mathrm{pH}$ environment, is a hallmark of solid tumors ${ }^{51}$ and the leukemic bone marrow niche ${ }^{52}$, this molecule has potential to selectively target tumor cells including leukemia. Off-target selectivity is still a concern since many normal sites in the human body have lower than neutral pHs including the bone marrow, gastrointestinal tissue, and active muscle tissue ${ }^{51}$. Due to chemical and physical modifications along with the evolution of new technologies, miRNA therapy has strong therapeutic potential; but because of the tissue specificity quandary, clinical administration is still in its infancy. It remains important to continue the investigation of upstream regulators of miRNAs in order to discover the node of regulation that is clinically targetable until miRNA therapeutics become an applicable technology.

Collectively, the observations noted herein have illustrated the intricacy of not only the bone marrow microenvironment regulation of $A L L$, but the complexity of modeling these interactions. The intention of the described in vitro co-culture model is to better model resistant disease of the bone marrow niche in hopes of further advancement in the field of treating refractory ALL subsets to compliment strategies that effectively deal with bulk tumor. Since the bone marrow is one of the most common sites of tumor metastasis, the model can be modified to study the microenvironment regulation of other hematological malignancies along with solid 
malignancies further advancing its value. Utilizing this model we demonstrate for the first time that the bone marrow microenvironment represented by BMSC and HOB regulates ALL cell

survival and quiescence, in part, through modulation of miR-221/222. Reestablishment of miR221 expression partially sensitized bone marrow niche influenced ALL cells to chemotherapy while increasing their proliferation rate, which may represent a route of clinical intervention. Future experiments will need to be designed in order to dissect the significance of ALL Drosha and Dicer modulation by the bone marrow niche and the phenotypic alterations that occur once their protein levels are elevated. Our hope is that in the near future miR-221/222 replacement therapy can be employed along with additional agents to assist in the complete eradication of ALL saving thousands of patient lives per year.

\section{References}

1. Lissauer. Zwei Falle von Leukamie. Berl. Klin. Wochenschr. 2, 403-4 (1865).

2. Acute Lymphoblastic Leukemia Treatment Protocols: Treatment Protocols. (2015).

3. Adult Acute Lymphoblastic Leukemia Treatment. National Cancer Institute Available at: http://www.cancer.gov/types/leukemia/hp/adult-all-treatment-pdq. (Accessed: 14th March 2016)

4. Pui, C.-H. \& Jeha, S. New therapeutic strategies for the treatment of acute lymphoblastic leukaemia. Nat. Rev. Drug Discov. 6, 149-165 (2007).

5. Adult Acute Lymphoblastic Leukemia Treatment. National Cancer Institute Available at: http://www.cancer.gov/types/leukemia/hp/adult-all-treatment-pdq\#section/_1. (Accessed: 6th March 2016)

6. Basso, G. et al. Risk of Relapse of Childhood Acute Lymphoblastic Leukemia Is Predicted By Flow Cytometric Measurement of Residual Disease on Day 15 Bone Marrow. J. Clin. Oncol. 27, 5168-5174 (2009). 
7. Oriol, A. et al. Outcome after relapse of acute lymphoblastic leukemia in adult patients included in four consecutive risk-adapted trials by the PETHEMA Study Group. Haematologica 95, 589-596 (2010).

8. Ishikawa, F. et al. Chemotherapy-resistant human AML stem cells home to and engraft within the bone-marrow endosteal region. Nat. Biotechnol. 25, 1315-1321 (2007).

9. Iwamoto, S., Mihara, K., Downing, J. R., Pui, C.-H. \& Campana, D. Mesenchymal cells regulate the response of acute lymphoblastic leukemia cells to asparaginase. J. Clin. Invest. 117, 1049-1057 (2007).

10. Adomako, A. et al. Identification of markers that functionally define a quiescent multiple myeloma cell sub-population surviving bortezomib treatment. BMC Cancer 15, (2015).

11. Chen, Y. et al. Quiescence and attenuated DNA damage response promote survival of esophageal cancer stem cells. J. Cell. Biochem. 113, 3643-3652 (2012).

12. Lutz, C. et al. Quiescent leukaemic cells account for minimal residual disease in childhood lymphoblastic leukaemia. Leukemia 27, 1204-1207 (2013).

13. Zhang, X. et al. Induction of mitochondrial dysfunction as a strategy for targeting tumour cells in metabolically compromised microenvironments. Nat. Commun. 5, 3295 (2014).

14. Qin, $H$. et al. Eradication of B-ALL using chimeric antigen receptor-expressing $T$ cells targeting the TSLPR oncoprotein. Blood 126, 629-639 (2015).

15. Jing, D. et al. Hematopoietic stem cells in co-culture with mesenchymal stromal cells-modeling the niche compartments in vitro. Haematologica 95, 542-550 (2010).

16. Jing, D. et al. Oxygen tension plays a critical role in the hematopoietic microenvironment in vitro. Haematologica 97, 331-339 (2012).

17. Slone, W. L. et al. Modeling Chemotherapy Resistant Leukemia In Vitro. J. Vis. Exp. JoVE (2016). doi:10.3791/53645

18. Hathcock, K. S. Depletion of Accessory Cells by Adherence to Sephadex G-10. Current Protocols in Immunology. 55:I:3.6:3.6.1-3.6.5 (2001).

19. Zhang, B. et al. Microenvironmental protection of CML stem and progenitor cells from tyrosine kinase inhibitors through $\mathrm{N}$-cadherin and Wnt- $\beta$-catenin signaling. Blood 121, 1824 1838 (2013).

20. Moses, B. S. et al. Bone marrow microenvironment modulation of acute lymphoblastic leukemia phenotype. Exp. Hematol. 44, 50-59.e2 (2016).

21. Bochtler, T., Fröhling, S. \& Krämer, A. Role of chromosomal aberrations in clonal diversity and progression of acute myeloid leukemia. Leukemia 29, 1243-1252 (2015). 
22. Ma, X. et al. Rise and fall of subclones from diagnosis to relapse in pediatric B-acute lymphoblastic leukaemia. Nat. Commun. 6, 6604 (2015).

23. Cairns, R. A., Harris, I. S. \& Mak, T. W. Regulation of cancer cell metabolism. Nat. Rev. Cancer 11, 85-95 (2011).

24. Taddei, M. L., Giannoni, E., Comito, G. \& Chiarugi, P. Microenvironment and tumor cell plasticity: An easy way out. Cancer Lett. 341, 80-96 (2013).

25. Baltimore, D., Boldin, M. P., O'Connell, R. M., Rao, D. S. \& Taganov, K. D. MicroRNAs: new regulators of immune cell development and function. Nat. Immunol. 9, 839-845 (2008).

26. Shaham, L., Binder, V., Gefen, N., Borkhardt, A. \& Izraeli, S. MiR-125 in normal and malignant hematopoiesis. Leukemia 26, 2011-2018 (2012).

27. Rhyasen, G. W. \& Starczynowski, D. T. Deregulation of microRNAs in myelodysplastic syndrome. Leukemia 26, 13-22 (2012).

28. Lwin, T. et al. Follicular dendritic cell-dependent drug resistance of non-Hodgkin lymphoma involves cell adhesion-mediated Bim down-regulation through induction of microRNA-181a. Blood 116, 5228-5236 (2010).

29. Umezu, T., Ohyashiki, K., Kuroda, M. \& Ohyashiki, J. H. Leukemia cell to endothelial cell communication via exosomal miRNAs. Oncogene 32, 2747-2755 (2013).

30. Singh, R., Pochampally, R., Watabe, K., Lu, Z. \& Mo, Y.-Y. Exosome-mediated transfer of miR-10b promotes cell invasion in breast cancer. Mol. Cancer 13, 256 (2014).

31. Wu, H. et al. Tumor-microenvironment interactions studied by zonal transcriptional profiling of squamous cell lung carcinoma. Genes. Chromosomes Cancer 52, 250-264 (2013).

32. Fortney, J. E., Zhao, W., Wenger, S. L. \& Gibson, L. F. Bone marrow stromal cells regulate caspase 3 activity in leukemic cells during chemotherapy. Leuk. Res. 25, 901-907 (2001).

33. Hall, B. M. et al. Stromal cells expressing elevated VCAM-1 enhance survival of B lineage tumor cells. Cancer Lett. 207, 229-239 (2004).

34. Wang, L., O'Leary, H., Fortney, J. \& Gibson, L. F. Ph+/VE-cadherin+ identifies a stem cell like population of acute lymphoblastic leukemia sustained by bone marrow niche cells. Blood 110, 3334-3344 (2007).

35. Wang, L., Chen, L., Benincosa, J., Fortney, J. \& Gibson, L. F. VEGF-induced phosphorylation of Bcl-2 influences B lineage leukemic cell response to apoptotic stimuli. Leukemia 19, 344353 (2005).

36. Cooper, L. A. D. et al. The Tumor Microenvironment Strongly Impacts Master Transcriptional Regulators and Gene Expression Class of Glioblastoma. Am. J. Pathol. 180, 2108-2119 (2012). 
37. Patten, P. E. M. et al. CD38 expression in chronic lymphocytic leukemia is regulated by the tumor microenvironment. Blood 111, 5173-5181 (2008).

38. Kim, Y.-K. et al. Functional links between clustered microRNAs: suppression of cell-cycle inhibitors by microRNA clusters in gastric cancer. Nucleic Acids Res. 37, 1672-1681 (2009).

39. Chun-Zhi, Z. et al. MicroRNA-221 and microRNA-222 regulate gastric carcinoma cell proliferation and radioresistance by targeting PTEN. BMC Cancer 10, 367 (2010).

40. Pineau, P. et al. miR-221 overexpression contributes to liver tumorigenesis. Proc. Natl. Acad. Sci. U. S. A. 107, 264-269 (2010).

41. Zhang, J. et al. miR-221/222 promote malignant progression of glioma through activation of the Akt pathway. Int. J. Oncol. 36, 913-920 (2010).

42. Chen, L. et al. Downregulation of miR-221/222 sensitizes glioma cells to temozolomide by regulating apoptosis independently of p53 status. Oncol. Rep. 27, 854-860 (2012).

43. Sarkar, S. et al. Down-regulation of miR-221 inhibits proliferation of pancreatic cancer cells through up-regulation of PTEN, p27kip1, p57kip2, and PUMA. Am. J. Cancer Res. 3, 465477 (2013).

44. le Sage, C. et al. Regulation of the p27Kip1 tumor suppressor by miR-221 and miR-222 promotes cancer cell proliferation. EMBO J. 26, 3699-3708 (2007).

45. Felicetti, F. et al. The promyelocytic leukemia zinc finger-microRNA-221/-222 pathway controls melanoma progression through multiple oncogenic mechanisms. Cancer Res. 68, 2745-2754 (2008).

46. Friedman, R. C., Farh, K. K.-H., Burge, C. B. \& Bartel, D. P. Most mammalian mRNAs are conserved targets of microRNAs. Genome Res. 19, 92-105 (2009).

47. Lennox, K. A. \& Behlke, M. A. A direct comparison of anti-microRNA oligonucleotide potency. Pharm. Res. 27, 1788-1799 (2010).

48. Xue, H. Y., Guo, P., Wen, W.-C. \& Wong, H. L. Lipid-Based Nanocarriers for RNA Delivery. Curr. Pharm. Des. 21, 3140-3147 (2015).

49. Andreev, O. A., Engelman, D. M. \& Reshetnyak, Y. K. pH-sensitive membrane peptides (pHLIPs) as a novel class of delivery agents. Mol. Membr. Biol. 27, 341-352 (2010).

50. Cheng, C. J. et al. MicroRNA silencing for cancer therapy targeted to the tumour microenvironment. Nature 518, 107-110 (2015).

51. Vaupel, P., Kallinowski, F. \& Okunieff, P. Blood flow, oxygen and nutrient supply, and metabolic microenvironment of human tumors: a review. Cancer Res. 49, 6449-6465 (1989). 
52. Thing Mortensen, Bø. et al. Changing bone marrow micro-environment during development of acute myeloid leukaemia in rats. Br. J. Haematol. 102, 458-464 (1998). 